Portland State University

PDXScholar

1992

\title{
Preparation of electron donor and acceptor molecules for porphyrin derivatization
}

Christoph Hoefler

Portland State University

Follow this and additional works at: https://pdxscholar.library.pdx.edu/open_access_etds

Part of the Chemistry Commons

Let us know how access to this document benefits you.

Recommended Citation

Hoefler, Christoph, "Preparation of electron donor and acceptor molecules for porphyrin derivatization" (1992). Dissertations and Theses. Paper 4317.

https://doi.org/10.15760/etd.6201

This Thesis is brought to you for free and open access. It has been accepted for inclusion in Dissertations and Theses by an authorized administrator of PDXScholar. Please contact us if we can make this document more accessible: pdxscholar@pdx.edu. 
AN ABSTRACT OF THE THESIS OF Christoph Hoefler for the Master of Science in Chemistry presented in August 5, 1992.

Title: Preparation of Electron Donor and Acceptor Molecules for Porphyrin Derivatization

APPROVED BY THE MEMBERS OF THE THESIS COMMITTEE:
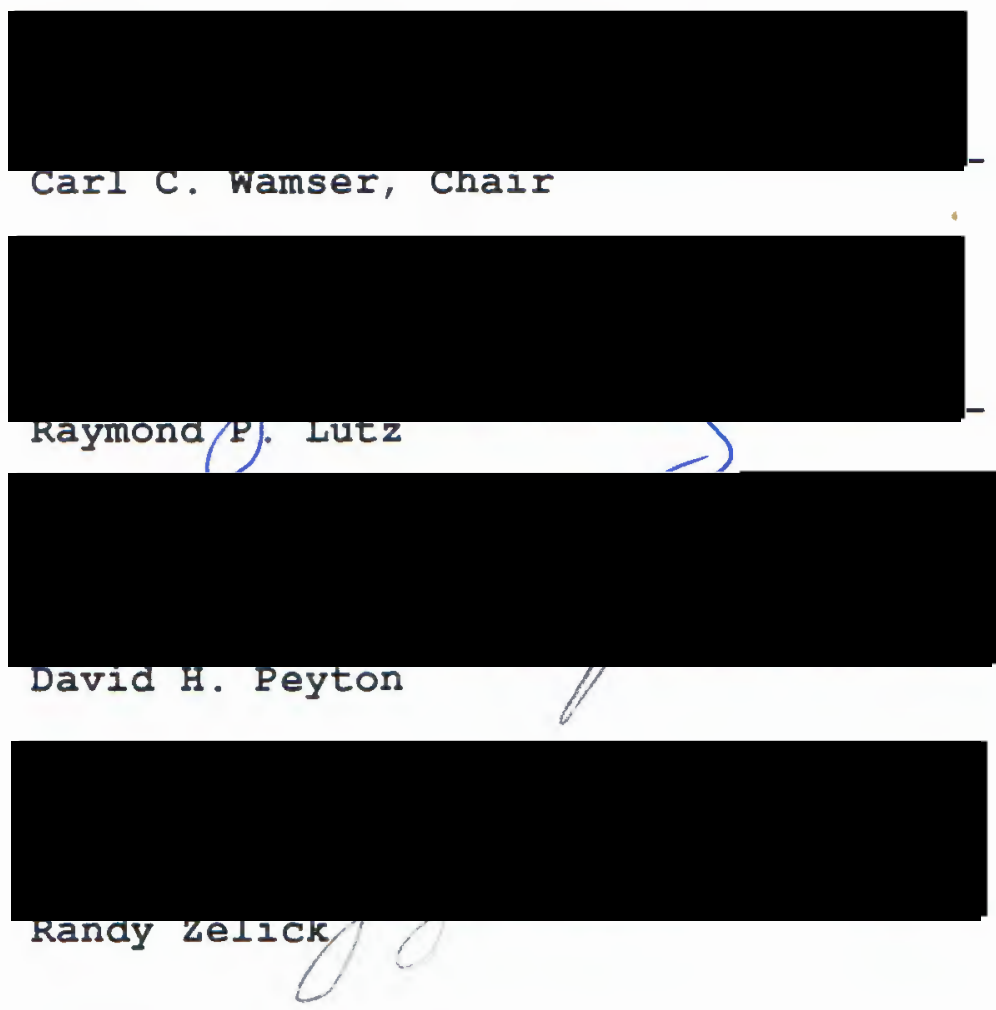

Porphyrins derivatized with electron donating and electron withdrawing groups can be used for artificial photosynthesis. Four new compounds, two electron donors and 
two electron acceptors, have been synthesized for prospective porphyrin linkages.

N-[4'-(N', N'-Dimethylamino) pheny 1]-4-bromobutanamide (BromoDonor) was synthesized in a substitution reaction of 4-bromobutyryl chloride with $\mathrm{N}, \mathrm{N}$-dimethyl-p-phenylene diamine. 4-Bromobutyryl chloride was obtained by refluxing the acid in thionyl chloride. The molecule was characterized by IR and $1_{\mathrm{H}-\mathrm{NMR}}$.

$$
\text { N-[4 '-(N' , N'-Dimethylamino) phenyl]-4-aminobutanamide }
$$

(AminoDonor) was prepared in a multi-step synthesis that involved the protection of an amino group. A tert-butoxy carbonyl group (BOC) was attached to 4-aminobutanoic acid as a first step. The amino-protected acid was coupled to N,N-dimethyl-p-phenylenediamine using a carbodiimide under mild reaction conditions. The protection group was cleaved with trifluoroacetic acid. The dihydrochloride was prepared for structural analysis. The compound was identified by elemental analysis, MS, IR and $1_{\mathrm{H}-\mathrm{NMR}}$.

1-(3-Bromopropy 1) -1'-phenylmethyl-4, 4 '-bipyridinium dibromide (Bromoviologen) was prepared in a two step synthesis. Benzyl bromide was attached in a nucleophilic substitution to 4,4'-dipyridyl in toluene to give 1-phenylmethyl-4-(4'-pyridyl) pyridinium bromide. 1,3-Dibromopropane was attached in the same reaction type to the monosubstituted salt in acetonitrile yielding the BromoDonor. Disubstitution to 258 of the 1,3-dibromo 
propane was observed, as confirmed by elemental analysis,

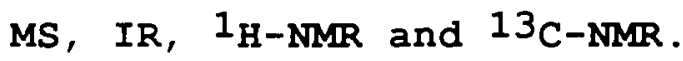

1-(3-Hydroxypropy 1) -1-phenylmethy 1-4, 4'-bipyridinium dibromide (HydroxyViologen) was prepared in the same manner by nucleophilic substitution of 1-phenylmethyl-4-(4'pyridyl)pyridinium bromide with 3-bromo-1-propanol in acetonitrile. The structure was confirmed by elemental

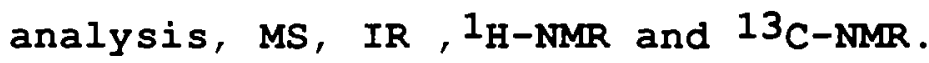

Several unsuccessful attempts have been done to link these donors and acceptors to different porphyrins. It was attempted to link the HydroxyViologen to TCCPP following typical ester formation procedures. Repeated attempts with DMAP as a catalyst and inert atmospheric conditions showed no improvements.

The coupling of AminoDonor to TCCPP was tried in a similar manner without success. No product formation was observed by using a carbodiimide as a coupling agent for AminoDonor and TCPP.

The attempt to link the Bromoviologen in a nucleophilic substitution to THPP in DMF with cesium carbonate as a base failed. Also without success was the attempt to attach the Bromoviologen to TCPP under similar reaction conditions. In all cases, porphyrin reaction products were isolated by chromatography, but none showed the appropriate spectral characteristics. 
PREPARATION OF ELECTRON DONOR AND ACCEPTOR MOLECULES FOR PORPHYRIN DERIVATIZATION

by

CHRISTOPH HOEFLER

A thesis submitted in partial fulfillment of the requirements for the degree of

\author{
MASTER OF SCIENCE \\ in \\ CHEMISTRY
}

Portland State University

1992 
TO THE OFFICE OF GRADUATE STUDIES:

The members of the Committee approve the thesis of Christoph Hoefler presented August 5, 1992.

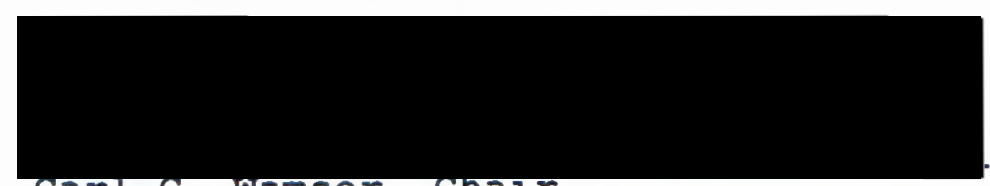

carl C. wamser, Chalr
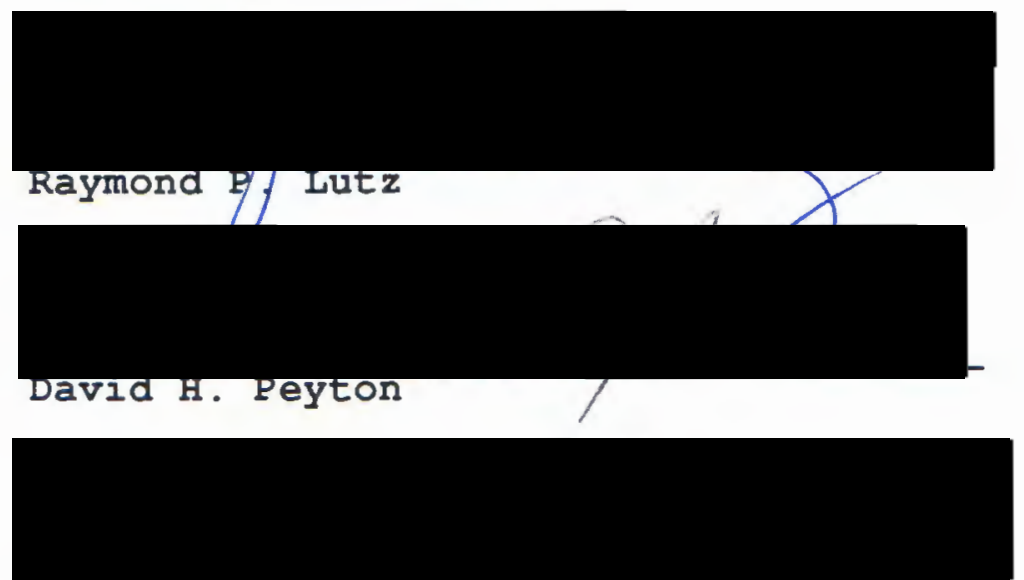

Randy zelick

APPROVED :

Bruce we Brown, chalr, Department of chemistry

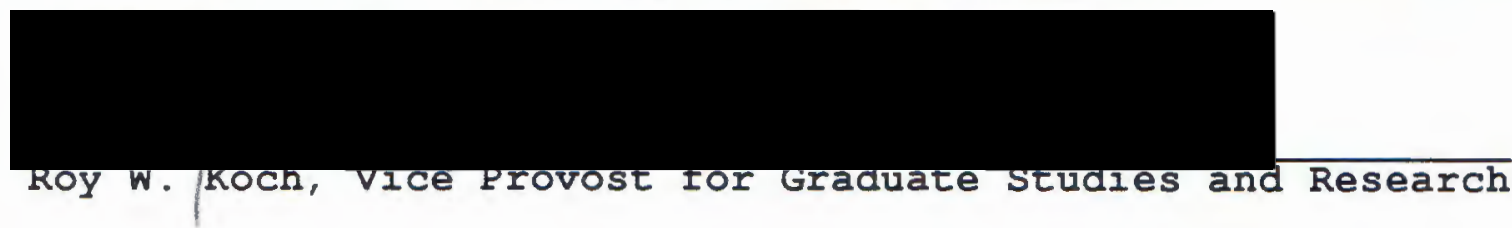




\section{ACKNOWLEDGMENTS}

I want to gratefully thank all the staff and faculty members who supported me in accomplishing this work. I especially would like to express my gratitude to Dr. Carl C. Wamser for his assistance, guidance and patience without which this thesis would not have been possible. 
TABLE OF CONTENTS

PAGE

ACKNOWLEDGMENTS

iii

LIST OF TABLES .

vii

LIST OF FIGURES

$\mathbf{x}$

\section{CHAPTER}

I

ARTIFICIAL PHOTOSYNTHESIS . . . . .

Introduction . . . . . . . . . . . . . 1

Electron Transfer . . . . . . . . 3

Porphyrin Films... . . . . . . . . . . 8

Electron Donors and Acceptors... . 11

Summary . . . . . . . . . . . . . 15

II

INSTRUMENTAL METHODS . . . . . . . . . 16

Experimental . . . . . . . . . 16

Physical Methods . . . . . . . . 16

Reagents . . . . . . . . . . 17

III SYNTHESIS OF PORPHYRINS . . . . . . . 22

Introduction . . . . . . . . . . 22

Experimental .......... . 23

IV SYNTHESIS OF BROMOVIOLOGEN . . . . . . 27 
1-Phenylmethyl-4-(4'-pyridyl) pyridinium chloride... . . . . . 30 Structural Analysis. . . . . . . . 30 1-Phenylmethyl-4-(4'-pyridyl) pyridinium bromide (Previologen). 32 Structural Analysis... . . . . . 33 Bromoviologen . . . . . . . . . . . 35 Structural Analysis . . . . . . . 35

Introduction . . . . . . . . . . . . . 44

Hydroxyviologen . . . . . . . . . . 44

Structural Analysis. . . . . . . . 45

VI SYNTHESIS OF AMINODONOR . . . . . .

Introduction . . . . . . . . . . . 51

$\mathrm{N}$-(Tert-butoxycarbonyl) -4-amino butanoic acid.......... . 53 Structural Analysis. . . . . . . . 54 Boc-protected AminoDonor . . . . . 56 Structural Analysis . . . . . . . 56 AminoDonor . . . . . . . . . . . 61 Structural Analysis....... . 62

VII SYNTHESIS OF BROMODONOR . . . . . . Introduction . . . . . . . . . . . 66

4-Bromobutyryl Chloride . . . . . . 67 Structural Analysis . . . . . . . . 68 BromoDonor 68 Structural Analysis... . . . . . 69

VIII COUPLING ATTEMPTS OF ACCEPTORS AND DONORS TO THE PORPHYRINS . . . . . . . 72 Introduction . . . . . . . . . . . . 72 TCCPP and HydroxyViologen (a1). . . 74 
TCCPP and HydroxyViologen (a2). . . 75 TCCPP and HydroxyViologen (a3). . . 76 TCCPP and AminoDonor $\left(b_{1}\right) . . . .976$ TCCPP and AminoDonor $\left(\mathrm{b}_{2}\right)$. . . . . 77 TCPP and AminoDonor (b3). . . . . . 77 THPP and BromoViologen (c). . . . . 77 TCPP and Bromoviologen (d). . . . . 78

Conclusion . . . . . . . . . . . . 79

REFERENCES CITED . . . . . . . . . . . . . . . 81

APPENDIX . . . . . . . . . . . . . . . . 85 


\section{IIST OF TABLES}

TABLE

PAGE

I

I I

I I I

IV

V

VI

VII

VIII

IX

$\mathrm{x}$

XI

XII

XIII

$1_{H-N M R}$ Chemical Shifts for THPP . . . . . .

Infrared Absorption Bands for TCCPP . . .

26

Infrared Absorption Bands for 1-Phenyl

methyl-4-(4'-pyridyl)pyridinium Chloride . .

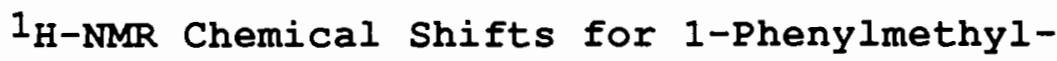

4-(4'-pyridyl) pyridinium Chloride . . . . .

Infrared Absorption Bands for Previologen.

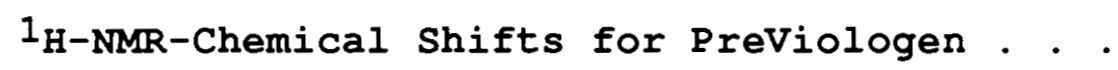

Infrared Absorption Bands for Bromoviologen

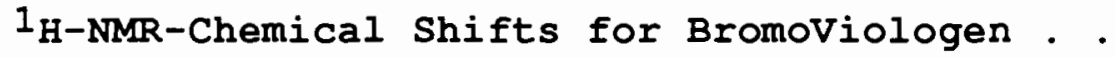

Viologen

13C-NMR Chemical shifts for Bromoviologen.

FAB-MS Data for Bromoviologen . . . . . .

Disubstituted Viologen Mixture Infrared Absorption Bands for HydroxyViologen . . . . . . . . . . . .

$I_{H-N M R}$ Chemical Shifts for Hydroxyviologen. 
XVI FAB-MS Data for HydroxyViologen . . . . . .

XVII Elemental Analysis for Hydroxyviologen . . .

XVIII Infrared Absorption Bands for $\mathrm{N}$-(Tertbutoxycarbonyl)-4-aminobutanoic acid

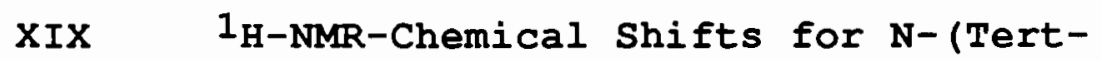

butoxycarbonyl)-4-aminobutanoic acid . . . .

$\mathrm{XX}$ Infrared Absorption Bands for BOC-protected Aminodonor . . . . . . . . . . . . . . .

XXI $\quad 1_{H-N M R}$ Chemical Shifts for BOC-protected AminoDonor . . . . . . . . . . . . . 58

XXII FAB-MS Data for BOC-AminoDonor . . . . . .

XXIII Elemental Analysis of BOC-protected

AminoDonor

XXIV Infrared Absorption Bands for $N^{-}\left[4^{\prime}-\left(N^{\prime}, N^{\prime}-\right.\right.$ Dimethylaminophenyl) ]-4-aminobutanamide . .

XXV Infrared Absorption Bands for $N^{-}\left[4^{\prime}-\left(N^{\prime}, N^{\prime}-\right.\right.$ Dimethylaminophenyl) ]-4-aminobutanamide Dihydrochloride .

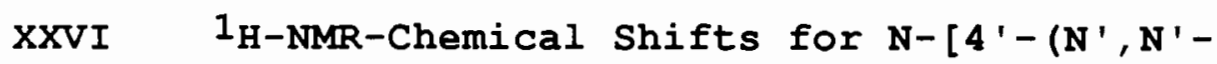
Dimethylaminophenyl) ]-4-aminobutanamide . .

XXVII Infrared Absorption Bands for 4-Bromobutyryl Chloride. 


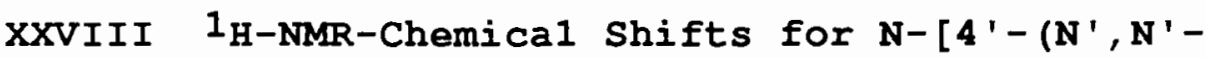

Dimethylaminopheny 1) ]-4-bromobutanamide . .

XXIX Infrared Absorptions Bands for $N^{-}\left[4^{\prime}-\left(N^{\prime}, N^{\prime}-\right.\right.$

Dimethylaminophenyl) ]-4-bromobutanamide . . 
IIST OF FIGURES

FIGURE

PAGE

1. Energy Level Diagram . . . . . . . . . . . . 4

2. Picture of the Tetrad Molecule

3. Picture of Porphyrins used for Interfacial Polymerization . . . . . . . . . . . . .

4. Picture of an Idealized Film Structure after Hydrolysis of the Acid Chlorides . . . . .

5. Model of the Redox Potential Gradient across an Artificial Membrane . . . . . . . . . 10

6. Structures of Acceptor Target Molecules . . 13

7. Structures of Donor Target Molecules . . .

8. Overview of Possible Linkages between

Porphyrins, Donors and Acceptors . . . . .

9. Synthesis of THPP . . . . . . . . . . . . 23

10. Synthesis of TCCPP . . . . . . . . 23

11. Syntheses of Bromoviologen and HydroxyViologen . . . . . . . . . . . . 28

12. Structure of Bromoviologen . . . . . . . . . 40

13. Structure of HydroxyViologen . . . . . . . . 48

14. Synthesis of AminoDonor . . . . . . . . . . 52

15. Synthesis of BromoDonor . . . . . . . . . . 67 


\section{CHAPTER I}

\section{ARTIFICIAL PHOTOSYNTHESIS}

\section{INTRODUCTION}

In nature the photosynthesis process is used to convert light into a storable chemical form. This unique system is fairly complex so that many reactions involved in this process are still not completely understood. A great advance, for which the Nobel Prize was awarded in 1988, was the elucidation of the reaction center in purple bacteria, 1, 2 which resembles chlorophyll in its mode of action.

The essence in photosynthesis is that $\mathrm{CO}_{2}$ and water are used for the buildup of larger molecular compounds using sunlight as the energy supply. Natural photosynthesis has an overall gross efficiency of 9.28 .3 This value is however lowered to $2 \%$ if dark reactions and photorespiration are considered.

Different approaches have been made to mimic photosynthesis. 4-6 The research in solar energy conversion developed to a fast growing area in the last 15 years. Most photochemistry which has been done so far has focused on sensitizers or light absorbing compounds whose absorption 
maxima were in the UV region. Such systems would actually absorb only up to 58 of the sunlight which reaches the earth's surface. A main reason for this low performance is that most of the UV light is filtered out by the ozone layer.

For this reason new sensitizers with absorption maxima in the visible region had to be found and examined. The most obvious step was to use light absorbers that are abundant in nature.

The light absorbing unit in photosynthesis is chlorophyll whose basic structure is derived from a porphyrin molecule. Such porphyrin structures have absorption maxima that range between 400 and $700 \mathrm{~nm}$. The spectral distribution of sunlight reaching the earth surface shows this absorption region to contain almost 508 of the available energy. 7

In general the sunlight is used as an energy supply for water cleavage, executed by the photosynthesis process. The outcome of the water cleavage reaction is molecular oxygen that reenters the respiration cycle and hydrogen stored in the form of a reducing agent (e.g. NADPH or NADH). Water cleavage requires a minimum energy of $1.23 \mathrm{~V}$ which corresponds a wavelength of $509 \mathrm{~nm}$. Since only about 708 of the photon energy contributes to the desired cleavage reaction 5 the limiting wavelength is further lowered to about $400 \mathrm{~nm}$. Nature avoids using an inefficient photosystem 
at $400 \mathrm{~nm}$ and adapts to the sun's performance by using two connected photosystems (P680 and P700) to achieve the required potential difference.

An artificial photosystem has the benefit that it can be made much more durable than a natural one. In addition, an artificial photosystem could be optimized for a specific energy conversion problem like fuel generation, water splitting or electricity production. This might lead finally to higher solar efficiencies in comparison to a natural system.

\section{Electron Transfer}

The photochemical reaction in the reaction center of photosynthesis is an electron transfer step which leads to charge separation induced by irradiation. The quantum yield for this simple photochemical reaction is almost unity, which means that every absorbed photon gives rise to an electron transfer.

In a simplified model the chlorophyll containing protein can be seen as an electron donating group attached to a ubiquinone unit that acts as an electron acceptor. Irradiation moves electrons to excited states in the chlorophyll molecule from where they can move to an electron acceptor. In fact many complex mechanisms mediate this electron transfer that leads to an effective charge separation. 
A model compound consisting of a porphyrin and a covalently linked electron acceptor (or donor) would be very useful to scrutinize the nature of the electron transfer in such linked systems. Reference (9) gives a survey of the most important achievements in this field so far. An energy level diagram (see Figure 1) displays the competing processes that can occur in a D-A (donor-acceptor) linked system. 9

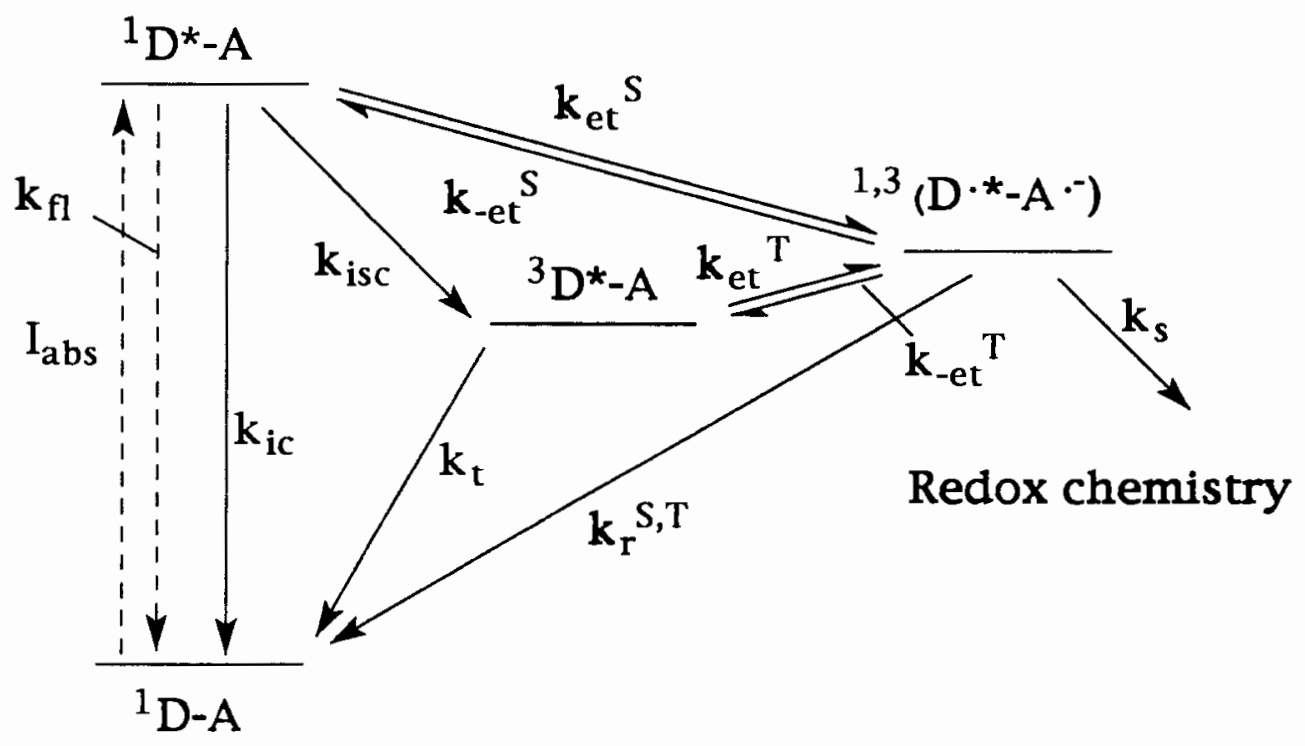

Eigure 1. Energy level diagram.

The acceptor group is able to oxidatively quench the excited state of the donor group. This leads to formation of a radical ion pair $\left(\cdot{ }^{+} \mathrm{D}-\mathrm{A}^{-} \cdot\right)$, which can react in a subsequent redox reaction, e.g. water splitting.

The quenching can occur either from an excited singlet or triplet state of the donor. The transitions are indicated 
by the rate constants $k_{e t} \mathbf{S}$ and $k_{e} t^{T}$. Competing processes are fluorescence $\left(k_{f l}\right)$, internal conversion $\left(k_{i c}\right)$ and intersystem crossing ( $k_{i s c}$ ) from the excited singlet state as well as phosphorescence $\left(k_{p}\right)$ and nonradiative decay $\left(k_{n r}\right)$ from the triplet state. Effective charge separation requires that :

$I-1$

$I-2$

$$
\begin{aligned}
& k_{e t} S \gg\left(k_{f l}+k_{i c}+k_{i s c}\right) \\
& k s \quad \gg\left(k_{r} S+k_{-e t} S+k_{-e t^{T}}\right)
\end{aligned}
$$

A model compound has a well defined structure and environment, which consequently simplifies studies on intramolecular electron transfer. The general photoinduced electron transfer reaction is then

$$
\mathrm{D}+\mathrm{A} \stackrel{\mathrm{hv}}{\longrightarrow} \mathrm{D}^{++}+\mathrm{A}^{-\cdot}
$$

The electron transfer step can occur in two different ways. Either the acceptor is reductively quenched from its excited state by the donor or the donor is oxidatively quenched from its excited state by the acceptor. In most covalently linked porphyrin acceptor systems the latter is the case and the following reaction scheme can be applied: Effective charge separation is limited by the competing back reaction that leads to recombination of the positive and negative charge. 
$\mathrm{I}-4 \quad \mathrm{D}-\mathrm{A} \stackrel{\mathrm{hv}}{\longrightarrow} \mathrm{D}^{*-\mathrm{A}} \longrightarrow \mathrm{D}^{+}-\mathrm{A}^{-}$

$\mathrm{I}-5 \quad \mathrm{D}^{+}-\mathrm{A}^{-} \longrightarrow \mathrm{D}-\mathrm{A}$

It is therefore desirable to find systems that have reverse electron transfer rates. Studies on covalent linked systems where the donor is a porphyrin and the acceptor is a viologen (disubstituted dipyridinium compound) have been done extensively.10-19 In most cases a mesotetraphenylporphyrin was used as donor, but porphyrins with one pyridine ring have also been used. The studies focused on how geometry affects the electron transfer kinetics. This was done by varying the spacer groups between porphyrin and viologen and/or by changing the attachment position lortho, meta and para) of the spacer to the tetraphenylporphyrin.

Charge separation can further be improved by covalently linking another donor molecule to the D-A linked system. Since 1985, studies ${ }^{20-28}$ have been made on so-called triad and related molecules (tri for three subunits).

In these systems electron transfer proceeds in sequential steps. The porphyrin in the excited state is oxidatively quenched by the acceptor followed by an electron transfer from the donor molecule to the porphyrin. The process is depicted in Equations I-6 and I-7. 
$\mathrm{I}-6 \quad \mathrm{D}-\mathrm{P}-\mathrm{A} \stackrel{\mathrm{hv}}{\longrightarrow} \mathrm{D}-\mathrm{P}^{*}-\mathrm{A} \longrightarrow \mathrm{D}-\mathrm{P}^{+}-\mathrm{A}^{-}$ $I-7$<smiles>[2H][PH+][CH][CH][CH][PH2+][3H]</smiles>

Such systems can be extended by addition of further electron donor and acceptor groups (tetrad, pentad etc.). Advantageous in multi-linked systems is that a sequential electron transfer process occurs, similar to nature, which prevents charge recombination. The most prominent example is the tetrad molecule $29-31$ (see Figure 2) that consists of a porphyrin with a covalently linked carotenoid polyene as a donor and a diquinone species as acceptor attached in trans configuration. Quantum yields of up to 0.83 and lifetimes up to $340 \mu$ s could be achieved with such systems depending on the solvent.

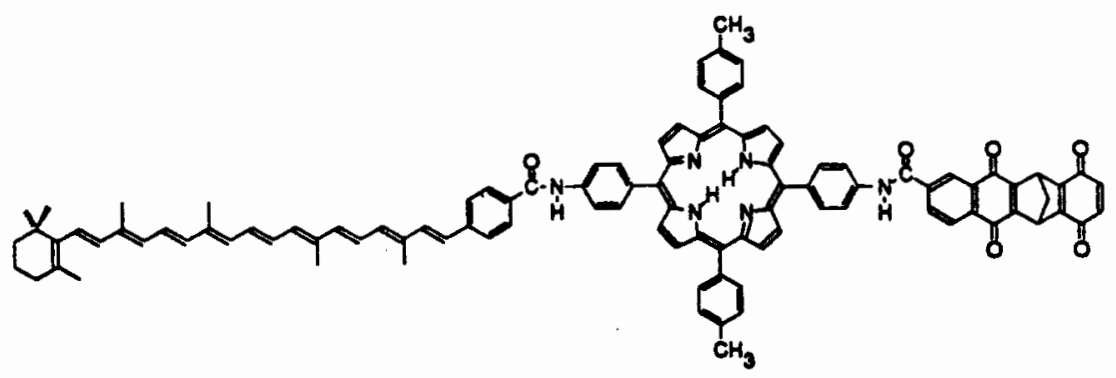

Figure 2. Picture of the Tetrad Molecule. 


\section{Porphyrin Films}

Thin films of photoactive material like porphyrins can be used to convert solar energy into electrical or chemical energy. Such films have been prepared by interfacial polymerization. 32-34 Hereby two reactive monomers dissolved in two immiscible solutions are constrained to react only at the interface of these solutions.

Thin polymeric porphyrin films have been prepared using tetra ( $P$-hydroxyphenyl) porphyrin (THPP) in aqueous base with tetra ( $p$-chlorocarbonylphenyl) porphyrin (TCCPP) in chloroform or dichloromethane and tetra(p-aminophenyl) porphyrin (TAPP) in DMSO with TCCPP in ethyl acetate. $32 \mathrm{~A}$ picture of these porphyrins is given in Figure 3.

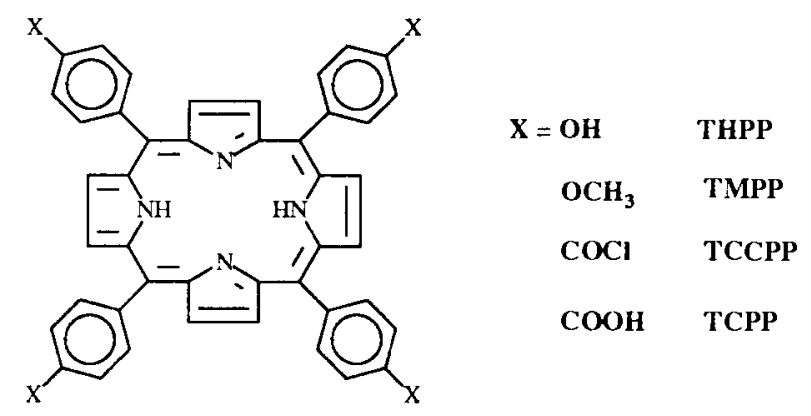

Eigure 3, Picture of Porphyrins used for Interfacial Polymerization.

The diffusion of the porphyrins through the membrane is hindered by their size so that the polymerization process stops at an early stage to yield films that are extremely fragile and thin $(\sim 0.01 \mu \mathrm{m})$. Rinsing the film pieces in 
various solvents and water removes traces of monomers and low oligomers, and hydrolyzes unreacted acid chloride. This leads to two distinct sides of each polymer film, one that is abundant in carboxylic acid groups ( $C$ side) and the other containing hydroxy (H side) or amino (N side) groups. A picture of the film is given in Figure 4.

\section{H-SIDE}

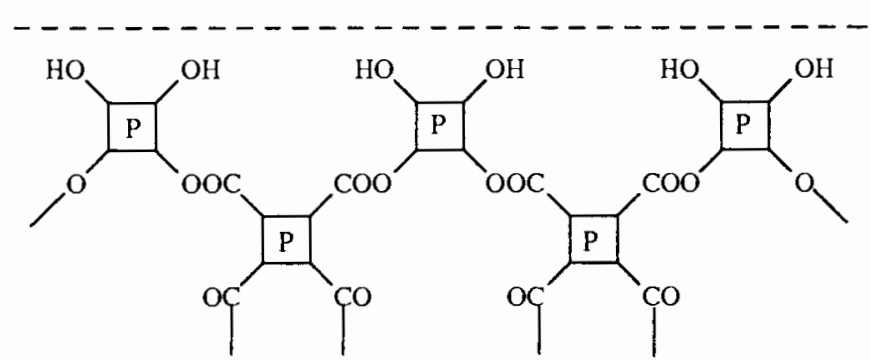

$$
\mathrm{P}=\underset{\text { THPP }}{\text { linked }}
$$

branched network of porphyrin polyester

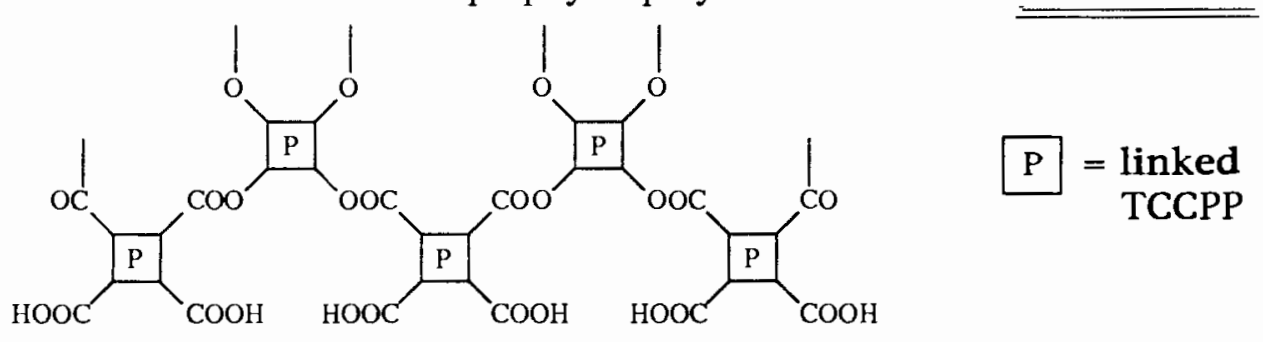

C-SIDE

Eigure 4. Picture of an idealized film structure after hydrolysis of the acid chlorides.

It is assumed that the actual surface is much more irregular than represented in the idealized figure. The film displays a structural asymmetry in functional groups across the membrane due to this limited degree of order. Presumably this structural asymmetry is responsible for a redox 
asymmetry that leads to charge separation upon irradiation. According to this model the smallest degree of linkages is found in close proximity to the surface, whereas inside the membrane the linkage of up to four functional groups may occur. Consequently eight different substitution patterns are conceivable along the membrane $\left[C_{1}\right.$ through $C_{4}$ and $H_{1}$ through $\mathrm{H}_{4}$; where $\mathrm{x}_{\mathrm{n}}(n=1-4)$ is a TCCPP or THPP monomer with linkage to $n$ other porphyrins].33

C surface

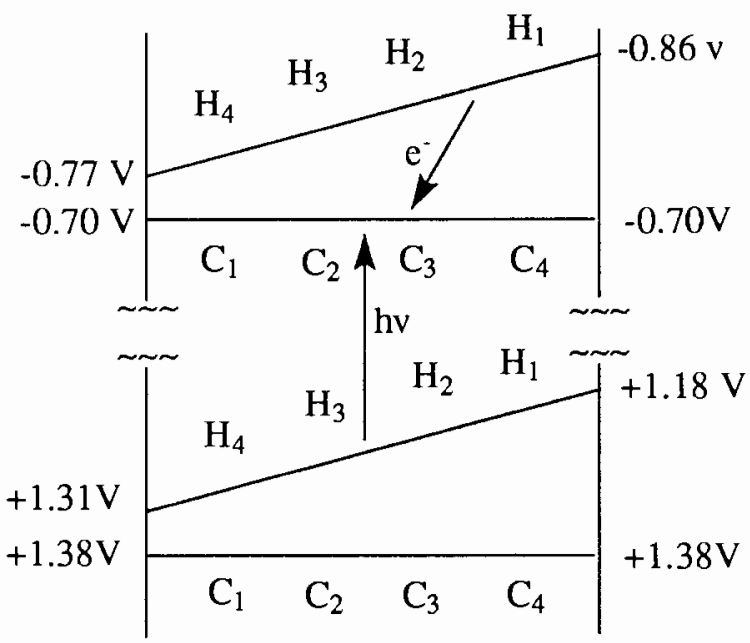

Figure 5, Model of the Redox Potential Gradient across an Artificial Membrane.

Electron transport within the film occurs from the $\mathrm{H}-$ side towards the $C$ side leading to an accumulation of electrons on the $C$ side and holes on the $H$ side. The electrons are transported along a redox gradient through the membrane. Figure 5 shows a model for this redox 
gradient. 33,34 The redox potentials were calculated by earlier studies. 34,35 This can be compared with the natural photosynthesis process where electrons are also moved along a redox gradient.

\section{Electron Donors And Acceptors}

Electron donating and electron accepting groups might be attached in different combinations on the film surfaces. Since electrons are moved to the c-side of the film upon irradiation, linking an electron acceptor on the c-side and an electron donor group on the H-side should lead to longer charge separation times. Such an arrangement would correspond a multiad (derived from the previously mentioned triad molecule). The opposite combination, with a donor at the electron rich $\mathrm{C}-$ side and an acceptor at the $\mathrm{H}-\mathrm{side}$ should shorten charge separation times.

Since the films are so fragile and sensitive to mechanical force, mild reaction conditions are required for these final couplings to the film. To study the effects of the substituted groups, linkages on the monomer compounds should be done first.

Electron donating groups include alkylated amines, carotenoids, aromatics (substituted), polyaromatics and porphyrins. $36 \mathrm{~N}, \mathrm{~N}$-Dimethyl-p-phenylenediamine has been chosen as an electron donating group. The diamine was 
covalently linked to a propyl group that contained the corresponding functional group in the terminal position.

Electron accepting groups include quinones, geminal unsaturated dicyano compounds, aromatics substituted with electron withdrawing groups, ammonium compounds and viologens. 37 The most widespread examples that appear in nature are quinones. Viologens have found industrial application as herbicides. The synthesis of an asymmetric viologen has been chosen as electron acceptor. Again the acceptor moiety is separated by a propyl group spacer.

The attachment of the electron acceptor as well as the electron donor on both sides is desired to study its effects. Therefore functional groups at the other end of the spacer had to be chosen so that all different combinations are possible. The donor has been synthesized with an amino or a bromo group at its end. The viologen has been synthesized with a hydroxy and bromo group as functional group. An overview of all four target molecules is given in Figures 6 and 7. All four target molecules are new compounds. This was verified by an online literature research at Chemical Abstracts on 23 June 1992. The research was done by formula index and nomenclature of the compounds. 


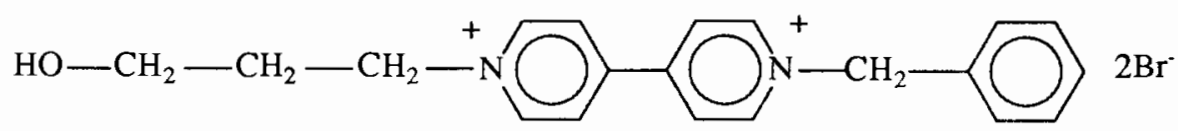

HydroxyViologen

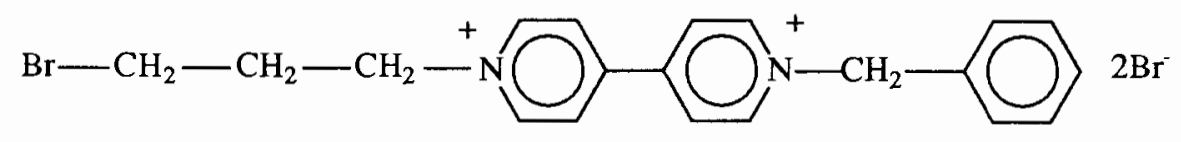

BromoViologen

Eigure 6. Structures of Acceptor Target Molecules.<smiles>CN(C)c1ccc(NC(=O)CCCN)cc1</smiles>

AminoDonor<smiles>CN(C)c1ccc(NC(=O)CCCBr)cc1</smiles>

BromoDonor

Eigure 7. Structures of Donor Target Molecules.

The C-side offers either an acid chloride or a carboxylic acid (after hydrolysis) as functional group. The Hydroxyviologen can react in an substitution reaction with the acid chloride to form an ester. The AminoDonor can react in the same reaction type to form an amide bond. The 
AminoDonor could also be attached to a carboxylic acid under milder reaction conditions using a carbodiimide as a coupling agent. Also conceivable is a nucleophilic substitution of a Bromoviologen or BromoDonor with a carboxylic acid.

The H-side has an phenol as functional group. The Bromoviologen as well as the BromoDonor should react in a nucleophilic substitution with the hydroxy group. An overview of all different combinations is illustrated in Figure 8 .

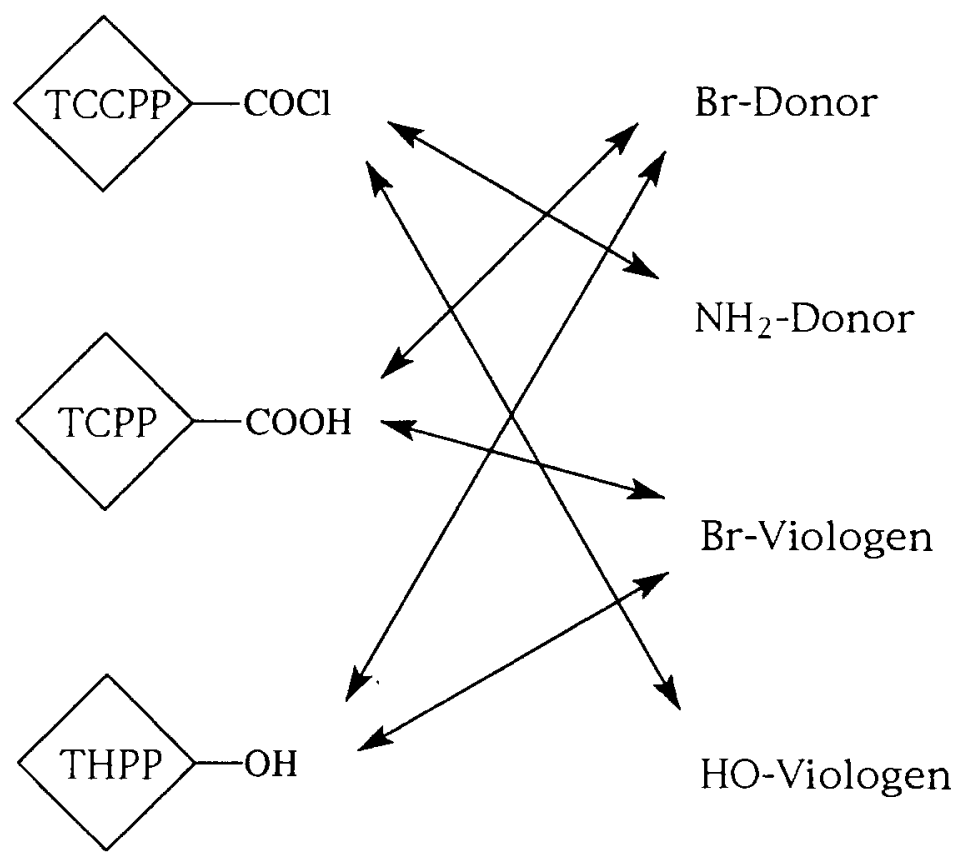

Figure 8 , Overview of possible Linkages between Porphyrins, Donors and Acceptors. 


\section{Summary}

Porphyrin films can be used for solar energy conversion. Upon irradiation they separate charge for a limited time. The attachment of donor and acceptor molecules on opposite sides of the film might improve charge separation times. The intent of the work was to synthesize new donor and acceptor molecules and to attach them to the same porphyrins that are used for the film synthesis. Preferentially mild reaction conditions were chosen for the final couplings due to the sensitivity of the films to mechanical force and hydrolysis. 
CHAPTER II

INSTRUMENTAL METHODS

EXPERIMENTAL

\section{Physical Methods}

Eractional Distillation. Purification of liquid products was achieved by distillation using a fractionation column. For vacuum distillations the apparatus was connected to a cooling trap of acetone/dry ice to protect the pump.

Elemental Analysis. Elemental analysis was performed by Galbraith Laboratories Inc., Knoxville, Tennessee.

Melting Roints. Melting points of solid phase compounds were determined using sealed capillary tubes in a Mel-Temp apparatus. Melting points could be determined to a limit of $300^{\circ} \mathrm{C}$.

Infrared spectra. The infrared spectra were recorded on a FTIR Perkin-Elmer spectrophotometer having a range of 4000-500 $\mathrm{cm}^{-1}$. Spectra of solids were obtained from $\mathrm{KBr}$ pellets. Spectra of liquids were obtained between $\mathrm{NaCl}$ plates. All spectra were calibrated using a polystyrene film. The following abbreviations were used for the description of the spectra: $s h=$ sharp, br $=$ broad, $\mathbf{s}=$ 
strong, $\mathrm{m}=$ middle, $\mathbf{w}=$ weak, as = asymmetric, $\mathrm{sm}=$ symmetric.

Nuclear Magnetic Resonance spectra. $\quad 90 \mathrm{MHz}$ proton NMR spectra were recorded on a Varian Model EM-390 spectrometer. $400 \mathrm{MHz}$ proton and $100 \mathrm{MHz}$ carbon-13 spectra were recorded on a Bruker AMX-400 spectrometer. Chemical shifts were reported relative to TMS or DSS for proton and carbon-13 spectra and are given in units of ppm.

Mass spectra. Mass spectra were performed at oregon Graduate Institute on a fast atom bombardment (FAB) mass spectrometer. The peak units are given by the $\mathrm{m} / \mathrm{z}$ (mass/charge) ratio.

\section{Reagents}

Acetonitrile. Analytical reagent grade $\mathrm{CH}_{3} \mathrm{CN}$ was purchased from Aldrich and further purified. $\mathrm{CH}_{3} \mathrm{CN}$ was refluxed over phosphorous pentoxide for several hours then distilled. The distillate was redistilled again from potassium carbonate (anhydrous) using a fractionating column.

Benzyl bromide. Analytical reagent grade $\mathrm{C}_{6} \mathrm{H}_{5} \mathrm{CH}_{2} \mathrm{Br}$ was purchased from American Tokyo Kasei, Inc. (TCI) and used without further purification.

Benzyl chleride. $\mathrm{C}_{6} \mathrm{H}_{5} \mathrm{CH}_{2} \mathrm{Cl}$ was purchased from Aldrich and distilled before using. 
3-Bromo-1-propanol. Analytical reagent grade Br$\left(\mathrm{CH}_{2}\right) 3^{-\mathrm{OH}}$ was purchased from TCI and used without further purification.

4-Bromobutanoic acid. 4-Bromobutanoic acid was purchased from Aldrich and used without further purification.

4-Bromobutyryl chloride. Analytical grade $\mathrm{Br}\left(\mathrm{CH}_{2}\right)_{3} \mathrm{COCl}$ was purchased from Aldrich and used without further purification.

Cesium carbonate. Analytical reagent grade $\mathrm{Cs}_{2} \mathrm{CO}_{3}$ was purchased from Aldrich and used without further purification.

Chloroform. Analytical reagent grade $\mathrm{CHCl}_{3}$ was purchased from Aldrich and further purified. $\mathrm{CHCl}_{3}$ was dried over calcium chloride (anhydrous) and distilled using a fractionating column. The distillate was stored over molecular sieve $4 \AA$.

Cyclohexane. Analytical reagent grade cyclohexane was purchased from Aldrich and used without further purification.

1,8-Diazabicyclo[5,4,0] undec-7-ene (DBU). Analytical reagent grade DBU was purchased from Aldrich and used without further purification.

1.3-Dibromopropane. Analytical reagent grade $\mathrm{Br}-$ $\left(\mathrm{CH}_{2}\right) 3^{-\mathrm{Br}}$ was purchased from TCI and used without further purification. 
Dichloromethane. HPLC grade $\mathrm{CH}_{2} \mathrm{Cl}_{2}$ was purchased from J.T. Baker and dried over molecular sieve $4 \AA$. 1-(3-Dimethylaminopropyl)-3-ethylcarbodiimide hydrochloride. Analytical reagent grade was purchased from Aldrich and used without further purification.

Dimethylformamide. Analytical grade $\left(\mathrm{CH}_{3}\right) 2_{2} \mathrm{NCHO}$ was purchased from Aldrich and used without further purification.

Dimethylsulfoxide. Analytical reagent grade DMSO was purchased from Mallinckrodt and used without further purification.

Dioxane. Analytical grade $p$-dioxane was purchased from Aldrich and used without further purification.

4, 4'-Dipyridyl. Analytical reagent grade 4,4'dipyridyl was purchased from TCI and used without further purification.

Ethyl acetate. HPLC grade ethyl acetate was purchased from J.T. Baker and used without further purification.

Hydrochloric acid. Analytical grade $\mathrm{HCl}$ was purchased from J.T. Baker and used without further purification.

Iodotrimethylsilane. ( $\left(\mathrm{CH}_{3}\right)_{3} \mathrm{SiI}$ was purchased from Aldrich and used without further purification.

Magnesium sulfate. Analytical grade $\mathrm{MgSO}_{4}$ was purchased from Mallinckrodt and used without further purification. 
$\mathrm{N}, \mathrm{N}-$ Dimethyl-p-phenylenediamine. Analytical grade $\mathrm{NH}_{2}-$ $\mathrm{C}_{6} \mathrm{H}_{4}-\mathrm{N}\left(\mathrm{CH}_{3}\right)_{2}$ was purchased from $\mathrm{TCI}$ and distilled in vacuum before using.

Phosphomolybdic acid. A $20 \%$ solution in ethanol of phosphomolybdic acid was purchased from Aldrich and used without further purification.

Ryridine. Analytical reagent grade $\mathrm{C}_{5} \mathrm{H}_{5} \mathrm{~N}$ was purchased from Aldrich and further purified. Pyridine was kept over potassium hydroxide overnight and distilled using a fractionating column. The distillate was stored over molecular sieve $4 \AA$.

Pyridinium chloride. $\mathrm{C}_{5} \mathrm{H}_{5} \mathrm{~N} \cdot \mathrm{HCl}$ was purchased from Aldrich and used without further purification.

Silica gel. Silica gel grade $60,60 \AA 230-400$ mesh was purchased from Aldrich and used without further purification.

Sodium bicarbonate. Analytical grade $\mathrm{NaHCO}_{3}$ was purchased from Mallinckrodt and used without further purification.

Sodium bisulfite. Analytical grade $\mathrm{NaHSO}_{3}$ was purchased from Aldrich and used without further purification.

Sodium hydroxide. Analytical grade $\mathrm{NaOH}$ was purchased from Matheson, Coleman \& Bell and used without further purification. 
Sodium sulfate. Analytical grade $\mathrm{Na}_{2} \mathrm{SO}_{4}$ was purchased from Matheson, Coleman \& Bell and used without further purification.

Sodium dithionite. Analytical grade $\mathrm{Na}_{2} \mathrm{~S}_{2} \mathrm{O}_{4}$ was purchased from Aldrich and used without further purification.

2-(Tert-butoxycarbonyloxyimino)-2-phenylacetonitrile. Boc-on was purchased from Aldrich and used without further purification.

5,10,15,20-Tetrakis (4-methoxyphenyl)-21H, 23H-porphine. TMPP was purchased from Aldrich and used without further purification.

5,10,15,20-Tetrakis-(4-carboxyphenyl)-porphine, TCPP was purchased from Porphyrin Products Inc. and used without further purification

Thionyl chloride. $\mathrm{SOCl}_{2}$ was purchased from Aldrich and distilled before using.

Triethylamine. Analytical reagent grade $E t_{3} \mathrm{~N}$ was purchased from Aldrich and further purified through distillation.

Trifluoroacetic acid. $\mathrm{CF}_{3} \mathrm{COOH}$ was purchased from Aldrich and used without further purification. 
CHAPTER III

SYNTHESIS OF PORPHYRINS

\section{INTRODUCTION}

Tetrakis-(4-hydroxyphenyl)porphyrin (THPP) and tetrakis-(4-chlorocarbonylphenyl)porphyrin (TCCPP) were prepared by modifying functional groups of the commercially available tetrakis-(4-methoxyphenyl) porphyrin (TMPP) and tetrakis-(4-carboxyphenyl) porphyrin (TCPP), respectively. THPP was prepared by an ether cleavage of TMPP according to reference (38) with slight modifications. The TMPP as delivered from Aldrich showed significant impurities. Concluding from a ${ }^{1}$ H-NMR that was taken of this material the impurities could be mainly ethylbenzene and one or more further compounds in minute concentration. A chromatographic purification of TMPP before the ether cleavage was not done, because it was assumed from previous references 38 that the ether cleavage would not be complete and lead to hydroxy- methoxyporphyrin mixtures. Such a mixture would have required a subsequent chromatography to obtain pure materials.

To simplify the usual procedure for preparation of THPP from TMPP with pyridinium chloride, and to promote 
cleavage of all four ether groups an alternative method11 was attempted using iodotrimethylsilane as cleaving agent. However, no cleavage was observed for TMPP.

The synthesis of TCCPP was done following a typical preparation method for acid chlorides from acids. 39 A structural overview for THPP and TCCPP synthesis are given in Figure 9 and Figure 10.

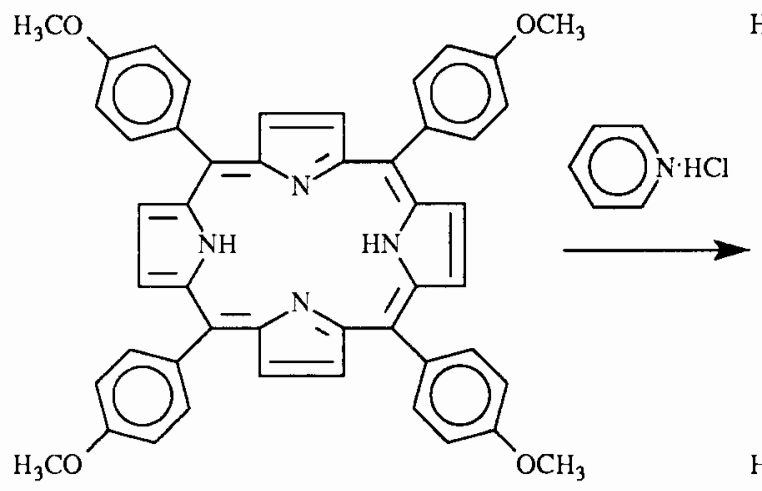

TMPP

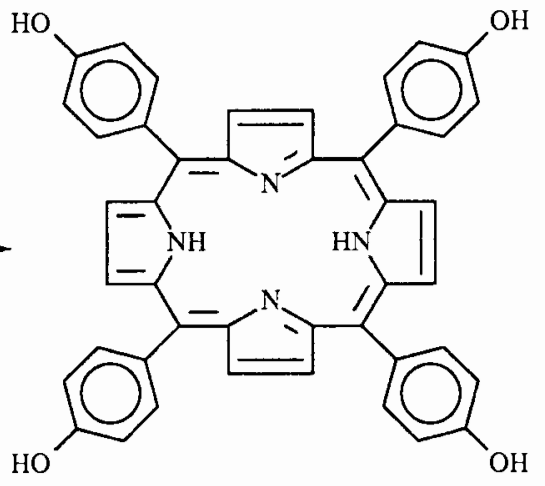

THPP

Eigure 9, Synthesis of THPP.

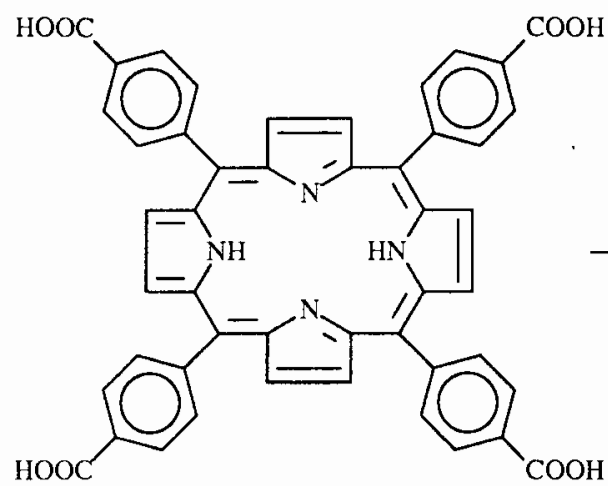

TCPP

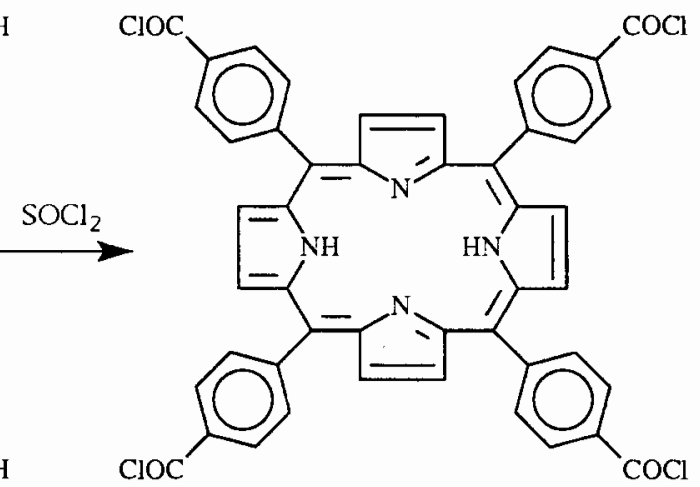

TCCPP

Eigure 10, Synthesis of TCCPP. 


\section{Experimental}

\section{$5,10,15,20$-Tetrakis- (4-hydroxypheny 1$)-21 \mathrm{H}, 23 \mathrm{H}-$}

porphine (THPP). Tetrakis-(4-methoxyphenyl)porphine (TMPP) $(5.0 \mathrm{~g}, 6.8 \mathrm{mmol})$ and pyridinium chloride $(100.0 \mathrm{~g}$, $864 \mathrm{mmol}$ ) were refluxed in a $250 \mathrm{ml}$ 3-neck round-bottom flask with reflux condenser, drying tube and thermometer. The solution was heated to $210^{\circ} \mathrm{C}$ and magnetically stirred. After 6 hours, an additional $25 \mathrm{~g}(216 \mathrm{mmol})$ of pyridinium chloride were added and the solution refluxed for 2 more hours.

The hot, green fluid was poured into 1.51 ice-cold water. Ethyl acetate $(500 \mathrm{ml})$ was poured into this solution and the $\mathrm{pH}$ adjusted to 13 by addition of $6 \mathrm{M}$ NaOH. The color changed from green to purple. The layers were separated and the water phase extracted three more times with $200 \mathrm{ml}$ of ethyl acetate. The combined organic layers were dried over $\mathrm{Na}_{2} \mathrm{SO}_{4}$, filtered and evaporated off to dryness on a rotovap. The purple crude material obtained was further dried on the oil pump [crude yield: $5.3 \mathrm{~g}(78 \mathrm{mmol})=1148]$.

A portion of this crude product $(1.52 \mathrm{~g})$ was purified by column chromatography over silica gel with $\mathrm{MeOH}$ as the solvent ( $30 \mathrm{~cm}$ height, $4.5 \mathrm{~cm}$ diameter column). This resulted in $1.1 \mathrm{~g}$ recovery. The yield was $3.86 \mathrm{~g}(5.7$ mmol) $=848$ (calculated for whole charge). 
Nuclear Magnetic Resonance Spectroscopy. The spectrum was taken on a $400 \mathrm{MHz}$ NMR. The chemical shifts are listed in Table I. The THPP was dissolved in methanold4 using TMS as a standard. The spectrum consists of a singlet for the pyrrole protons and an $A A^{\prime} B B^{\prime}$ pattern for the p-substituted phenol. The phenol proton is exchanged with the solvent and doesn't show up. No peak for the methoxy protons is observed in the 3-4 ppm region which indicates that the cleavage was successful on all four ether bonds. The integration corresponds with the ratio of protons.

TABLE I

$1_{\text {H-NMR CHEMICAL SHIFTS FOR THPP }}$

\begin{tabular}{cccc}
\hline ppm & Rel. Int. & Splitting & Assignment \\
\hline 8.90 & 3.9 & broad & pyrrole- $\underline{\underline{H}}$ \\
8.03 & 4.0 & doublet & aromat- $\underline{\underline{H}}$ \\
7.24 & 4.0 & doublet & aromat $-\underline{\underline{H}}$ \\
\hline
\end{tabular}

$5,10,15,20-$ Tetrakis-[4-(chlorocarbonyl) pheny 1$]-21 \mathrm{H}$. 23H-perphine (TCCPP). Tetrakis-(4-carboxyphenyl) porphine (TCPP) (500 $\mathrm{mg}, 0.63 \mathrm{mmol})$ was refluxed with $10 \mathrm{ml}$ (137 mmol) of freshly distilled thionyl chloride in a $100 \mathrm{ml}$ round-bottom flask with reflux condenser and drying tube for 6 hours. Excess thionyl chloride was distilled off, finally in vacuum. The blue residue was 
further dried on the oil pump. The yield was $528 \mathrm{mg}$ $(0.61-\mathrm{mmol})=978$.

Infrared spectroscopy. The infrared absorptions are tabulated in Table II and the spectrum is shown in the Appendix. The spectrum was taken from an earlier TCCPP preparation, which was stored for 7 months in a dessicator. The acid chloride got partly hydrolyzed during that time, but still shows a strongly shifted carbonyl stretch vibration at $1778 \mathrm{~cm}^{-1}$. This indicates that the acid chloride is quite stable to hydrolysis and can be temporarily stored under dessication. The carboxyl group gives rise to broad $\mathrm{H}-0$ stretching at $3448 \mathrm{~cm}^{-1}$ and a second carbonyl stretching at $1731 \mathrm{~cm}^{-1}$.

\section{TABLE II}

INFRARED ABSORPTION BANDS FOR TCCPP

3448 (br)

2966 (m)

1778 (vs)

1601 (m)

1537 (w)

1401 (m)

1240 (w)
3036 (m)

2872 (m)

1731 (s)

1560 (w)

1490 (m)

1307 (w)

1202 (s) 
CHAPTER IV

\section{SYNTHESIS OF BROMOVIOLOGEN}

\section{INTRODUCTION}

Asymmetric 4,4'-bipyridinium salts have already been prepared in various combinations. 40 The crucial step is to prevent disubstitution after the monosubstition, which would lead to a viologen. A structural overview is illustrated in Figure 11. The principle is to use a very nonpolar solvent like toluene or cyclohexane. The monosubstitution leads to formation of a salt, which immediately precipitates out due to its low solubility in the nonpolar solvent. The 1-phenylmethyl-4-(4'-pyridyl) pyridinium bromide as well as the chloride has been prepared. It was found that the bromide salt formation occurs much faster and in higher yield.

The presence of viologen can be detected by a simple test. Sodium dithionite can reduce the viologen to a radical ion. This radical ion is a chromophore, since charge delocalization is possible over the whole ring system. The formation can easily be detected as a strong blue color. 
a)
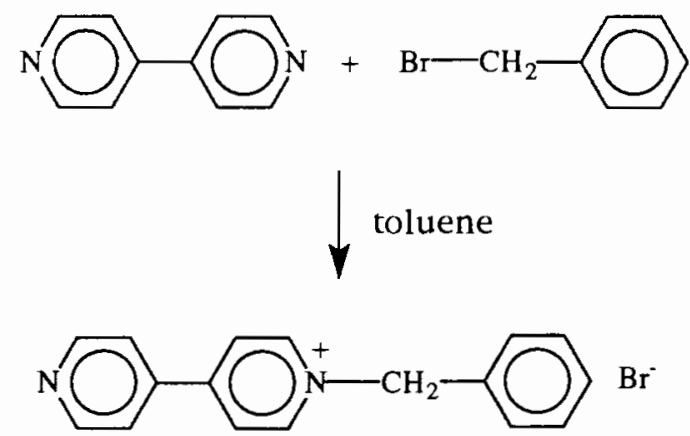

b) $\mathrm{Br}-\left(\mathrm{CH}_{2}\right)_{3}-\mathrm{Br}+$
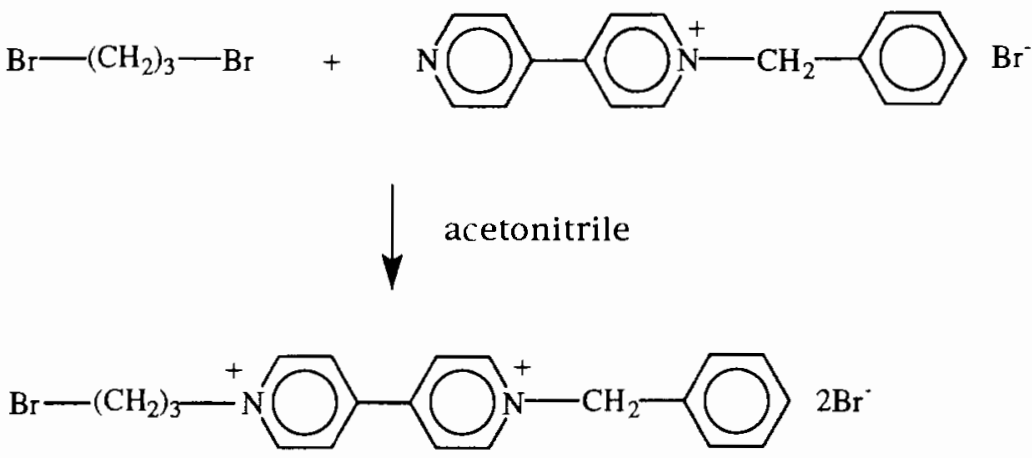

BromoViologen

c) $\mathrm{HO}-\left(\mathrm{CH}_{2}\right)_{3}-\mathrm{Br}+$<smiles>c1ccc(C[n+]2ccc(-c3ccncc3)cc2)cc1</smiles>
$\mathrm{Br}^{-}$

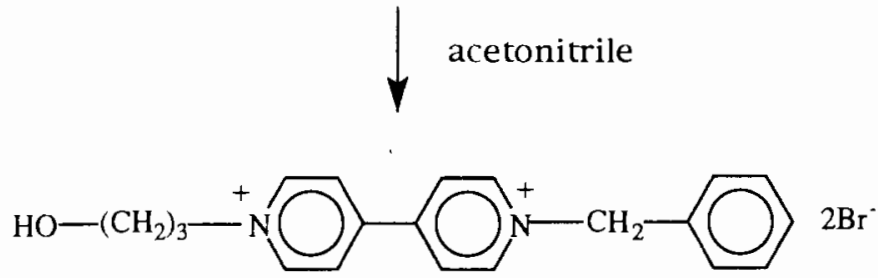

HydroxyViologen

Figure 11. Syntheses of Bromoviologen and Hydroxyviologen. 
The viologens were only synthesized from the bromide to increase the solubility of the viologen for subsequent reactions. A problem in the synthesis of the Bromoviologen is that both bromides in 1,3-dibromopropane can be replaced by the monosubstituted bipyridiniun salt. To prevent this a solvent must be used that dissolves the monosubstituted dipyridyl but not the formed viologen. The doubly positive-charged viologen should precipitate out of solution and is thereby protected from a subsequent substitution. Polar aprotic solvents that can be used for this reaction are acetonitrile, dimethylformamide and dimethylsulfoxide. Solubility tests indicated that acetonitrile is most suitable in this sequence, since it has the lowest dielectric constant and is still able to dissolve the monosubstituted bromide. DMF and DMSO are too polar and dissolve viologen readily. The viologen product has a limited solubility in acetonitrile so that the formation of disubstituted product was observed only to 48. In the second substitution the undesired disubstituted viologen is formed that immediately precipitates out of solution. That way the equilibrium is shifted favorably for a new disubstitution. The long reaction time enhances this byproduct. Formation of this product was prevented by increasing the amount of 1,3-dibromopropane for monosubstitution. 
1-Phenylmethyl-4-(4'-pyridyl)pyridinium chloride

The reaction was done following similar procedures of a previous reference.13 4,4'-Dipyridyl $(20.0 \mathrm{~g}, 128 \mathrm{mmol})$ was dissolved in $300 \mathrm{ml}$ toluene by slightly heating in a $1000 \mathrm{ml} 3$-neck round-bottom flask equipped with reflux condenser and addition funnel. Freshly distilled benzyl chloride $(13.2 \mathrm{ml}, 115 \mathrm{mmol})$ was added dropwise within 20 minutes. The first precipitate was formed after two hours. The solution was allowed to cool to room temperature after 28 hours. The white precipitate was filtered off, washed with diethyl ether and dried in oil pump vacuum. The dithionite test applied on the crude product was negative, indicating absence of viologen. The yield was $2.74 \mathrm{~g}$ ( 9 mol) $=8 \%$. The melting point was determined to be $235-236^{\circ} \mathrm{C}$.

\section{Structural Analysis}

Infrared spectroscopy. The infrared absorptions are tabulated in Table III and the spectrum is shown in the Appendix. The characteristic feature of the spectrum is a very strong absorption at $1637 \mathrm{~cm}^{-1}$ due to $\mathrm{C}=\mathrm{N}$ stretching. The ring "breathing" modes can clearly be distinguished at $1595 \mathrm{~cm}^{-1}$ and $1495 \mathrm{~cm}^{-1}$ with the lower range frequency typically stronger than the first. The out-of-plane vibrations of the monosubstituted phenyl ring appear in the expected region at $690 \mathrm{~cm}^{-1}$ and $720 \mathrm{~cm}^{-1}$. 


\begin{tabular}{|c|c|}
\hline $3424(b r, m)$ & $3107 \quad(w)$ \\
\hline 3025 (s) & 2978 (m) \\
\hline 2931 (m) & $2884(w)$ \\
\hline 1637 (vs) & 1595 (m) \\
\hline 1548 (m) & 1531 (m) \\
\hline 1495 (m) & 1454 (m) \\
\hline $1413(\mathrm{~m})$ & 1360 (w) \\
\hline $1343(w)$ & $1290(w)$ \\
\hline 1225 (m) & 1202 (w) \\
\hline 1178 (m) & 1161 (m) \\
\hline 1078 (พ) & 720 (m) \\
\hline 690 (w) & $620(w)$ \\
\hline
\end{tabular}

Nuclear Magnetic Resonance Spectroscopy. The spectrum was recorded on the $90 \mathrm{MHz}$ spectrometer. The material was dissolved in $\mathrm{D}_{2} \mathrm{O}$ with DSS as a standard. The molecule has a symmetry plane, which leads to chemically equivalent protons on either side. The monosubstitution splits the pyridyl resonances in two $A A^{\prime} B B^{\prime}$ pattern.41 The $A A^{\prime} B B^{\prime}$ pattern at lower field can be assigned to the substituted pyridyl ring due to deshielding of the positive charge. The benzyl protons appear in the expected 
region. All peak integral ratios are as expected. The chemical shifts are presented in Table IV.

\author{
TABLE IV
}

1 $\mathrm{H}$-NMR CHEMICAL SHIFTS FOR

1-PHENYLMETHYL-4-(4'-PYRIDYL) PYRIDINIUM CHLORIDE

\begin{tabular}{cccc} 
Chem. Shift & Rel. Int. & Splitting & Assignment \\
5.80 & 2 & singlet & -CH2-ph \\
7.50 & 5 & singlet & -CH2-aromat-H \\
7.83 & 2 & doublet & pyridyl-H \\
8.36 & 2 & doublet & pyridyl-H \\
8.73 & 2 & doublet & pyridinium-H \\
9.03 & 2 & doublet & pyridinium-H \\
\hline
\end{tabular}

1-Phenylmethyl-4-(4'-pyridyl) pyridinium bromide (Previologen)

The reaction was done following procedures of previously described viologen syntheses. 42 4,4'-Dipyridyl $(10.0 \mathrm{~g}, 64 \mathrm{mmol})$ was dissolved in $300 \mathrm{ml}$ toluene in a $1000 \mathrm{ml}$ 3-neck round-bottom flask equipped with reflux condenser and addition funnel. The solution was heated to $100^{\circ} \mathrm{C}$. Benzyl bromide $(8.7 \mathrm{ml}, 73 \mathrm{mmol})$ was added within 60 minutes. The first product precipitated out after 1-2 minutes.

After 2 hours an additional $50 \mathrm{mmol}$ of benzyl bromide was added, because TLC showed the presence of unreacted 4,4'-dipyridyl. The heating was removed after a total of 
3.5 hours and the solution allowed to cool overnight. The yellowish precipitate was isolated by filtration, washed with diethyl ether and dried in oil pump vacuum.

The dithionite test applied on this obtained salt gave no blue color, indicating no viologen formation. The yield was $6.7 \mathrm{~g}(20 \mathrm{mmol})=32 \%$. The melting point was determined to be $228-230^{\circ} \mathrm{C}$.

\section{Structural Analysis}

Infrared spectroscopy. The frequencies are tabulated in Table $\mathrm{V}$ and the spectrum is displayed in the Appendix.

\section{TABLE V}

INERARED ABSORPTION BANDS FOR PREVIOLOGEN

\begin{tabular}{|c|c|c|}
\hline $3424(b r, m)$ & 3095 & (w) \\
\hline 3025 (m) & 2978 & (m) \\
\hline 2919 (w) & 1631 & (s) \\
\hline 1590 (s) & 1531 & (m) \\
\hline 1490 (m) & 1454 & (m) \\
\hline 1219 (m) & 1155 & (m) \\
\hline $802(s)$ & 608 & (s) \\
\hline
\end{tabular}

The main feature is the strong absorption at $1631 \mathrm{~cm}^{-1}$ due to $\mathrm{C}=\mathrm{N}$ vibration mode. The phenyl ring "breathing" 
modes are at $1590 \mathrm{~cm}^{-1}$ and $1490 \mathrm{~cm}^{-1}$. A weak $\mathrm{C}-\mathrm{H}$ stretching of the phenyl ring can be seen at $3095 \mathrm{~cm}^{-1}$.

Nuclear Magnetic Resonance Spectroscopy. The spectrum was recorded on the $90 \mathrm{MHz}$ spectrometer. The material was dissolved in $D_{2} O$ with DSS as a standard. All peaks appear as expected in the aromatic region except for the benzyl protons. The pyridyl portion of the spectrum consists of two shifted AA'BB' patterns.43 The lower field pattern can be assigned to substituted pyridyl ring due to the deshielding effect of the positive charge. Integration ratios were in agreement with the expected proton distribution. The chemical shifts are reported in Table VI .

TABLE VI

$1_{\text {H-NMR CHEMICAL SHIFTS FOR PREVIOLOGEN }}$

\begin{tabular}{cccc}
\hline Ppm & Rel. Int & Splitting & Assignment \\
\hline 5.83 & 2 & singlet & CH2-ph \\
7.50 & 5 & singlet & CH2-ph-H \\
7.86 & 2 & doublet & aromat $-\mathrm{H}$ \\
8.38 & 2 & doublet & aromat $-\mathrm{H}$ \\
8.73 & 2 & doublet & aromat $-\mathrm{H}$ \\
9.06 & 2 & doublet & aromat $-\mathrm{H}$ \\
\hline
\end{tabular}


Bromoviologen

1-Phenylmethyl-4-(4'-pyridyl)pyridinium $(2.6 \mathrm{~g}$, $7.9 \mathrm{mmol}$ ) was dissolved in $300 \mathrm{ml}$ acetonitrile by heating to $80^{\circ} \mathrm{C}$ in a $1000 \mathrm{ml} 3$-neck round-bottom flask with reflux condenser. 1,3-Dibromopropane $(8.1 \mathrm{ml}, 79 \mathrm{mmol})$ was added at once after all of the monosubstituted bipyridinium salt had dissolved. The solution was refluxed for 9 days. The first yellow precipitate was observed after 1.5 days. The solution was allowed to cool to room temperature overnight. The yellow precipitate was filtered off and dried in oil pump vacuum $(2.36 \mathrm{~g})$.

The acetonitrile phase was dried by rotary evaporation to give a yellow substance, which was further dried in oil pump vacuum. It remained a yellow substance. The dithionite test on both fractions were positive. $1_{\mathrm{H}-\mathrm{NMR}}$ and TLC showed that only the first obtained precipitate was the desired product. The yield was $2.36 \mathrm{~g}$ $(4.4 \mathrm{mmol})=56 \%$. The substance decomposes by heating above $300^{\circ} \mathrm{C}$.

\section{Structural Analysis}

Infrared spectroscopy. The infrared absorptions are tabulated in Table VII and the spectrum is shown in the Appendix. The most striking feature in the spectrum is the strong, sharp absorption at $1631 \mathrm{~cm}^{-1}$ due to $\mathrm{C}=\mathrm{N}$ stretching vibrations. One of two double bond stretches 
for indicating the phenyl ring can't be seen on the spectrum, but the second is present at $1495 \mathrm{~cm}^{-1}$. As an explanation the first vibration is either low and hidden under the strong $\mathrm{C}=\mathrm{N}$ double bond vibration or the adjacent positive charge shifts the two bands to lower frequencies. The "breathing" modes can then be assigned to the absorptions at $1554 \mathrm{~cm}^{-1}$ and $1448 \mathrm{~cm}^{-1}$ which are in the anticipated range. This set of assignments corresponds well with the anticipated intensities of the absorption. The aromatic $\mathrm{C}-\mathrm{H}$ stretching can be seen at $3095 \mathrm{~cm}^{-1}$. No specific C-Br vibration between 680 and $500 \mathrm{~cm}^{-1}$ can be assigned, because the vibrations in this region are poorly resolved.

TABLE VII

INFRARED ABSORPTION BANDS FOR BROMOVIOLOGEN

\begin{tabular}{|c|c|c|}
\hline 3436 & (s) & 3095 (w) \\
\hline 3025 & (m) & 2989 (m) \\
\hline 2860 & $(w)$ & 1631 (s) \\
\hline 1554 & $(w)$ & 1507 (w) \\
\hline 1495 & $(w)$ & $1448(\mathrm{~m})$ \\
\hline 1360 & (w) & 1270 (w) \\
\hline 1208 & $(w)$ & 1172 (w) \\
\hline 826 & (m) & 737 (w) \\
\hline
\end{tabular}


Nuclear Magnetic Resonance Spectroscopy. The $1_{\mathrm{H}-\mathrm{NMR}}$ spectrum was recorded on the $400 \mathrm{MHz}$ spectrometer and is shown in the Appendix. The viologen was dissolved in methanol-d4, and TMS was the standard. The assignment in table form can be seen in Table VIII.

\section{TABLE VIII}

$1_{\text {H-NMR CHEMICAL SHIFTS FOR BROMOVIOLOGEN }}$

\begin{tabular}{cccc} 
Chem. Shifts & Rel. Int. & Splitting & Assignment \\
\hline 2.70 & 1.18 & quint & Br-CH2-CH2- \\
3.61 & 1.21 & triplet & Br-CH2-CH2- \\
4.98 & 1.21 & triplet & CH2-bipyridyl \\
6.06 & 1.00 & singlet & CH2-ph \\
7.47 & 1.50 & multiplet & CH2-aromat-H \\
7.65 & 1.00 & multiplet & CH2-aromat-H \\
8.74 & 2.36 & multiplet & bipyridyl-H \\
9.39 & 2.38 & multiplet & bipyridyl-H \\
\hline
\end{tabular}

The spectrum shows that both the monosubstituted viologen and the disubstituted viologen were formed in the reaction. The ratio could be calculated by peak integration to be about 27:1(mono/di). The Bromoviologen contains a propyl group that has a triplet, quintet, and triplet pattern. The methylene protons adjacent to bromide experience a less deshielding influence than the ones in 
the neighborhood of the positively charged bipyridinium.

Therefore the triplet at lowest field can be assigned to the methylene protons adjacent to the pyridinium ring. The heteroaromatic p-substituted dipyridyl displays the typical $A A^{\prime} B B^{\prime}$ pattern at very low field due to the positive charge. The benzyl protons show as a singlet, and the phenyl protons give rise to a multiplet in the aromatic region.

\section{TABLE IX}

1 H-NMR CHEMICAL SHIFTS FOR DISUBSTITUTED VIOLOGEN

\begin{tabular}{|c|c|c|c|}
\hline ppm & Rel. Int. & splitting & Assignment \\
\hline 3.01 & 0.04 & quintet & $\mathrm{CH}_{2}-\mathrm{CH}_{2}-\mathrm{CH}_{2}$ \\
\hline 5.09 & 0.10 & triplet & $\mathrm{CH}_{2}-\mathrm{CH}_{2}-\mathrm{CH}_{2}$ \\
\hline 6.06 & $1.00^{\star}$ & singlet & $\mathrm{CH}_{2}-\mathrm{ph}$ \\
\hline 7.47 & $1.50^{\star}$ & multiplet & $\mathrm{CH}_{2}$-aromat-H \\
\hline 7.65 & $1.00^{\star}$ & multiplet & $\mathrm{CH}_{2}$-aromat-H \\
\hline 8.74 & $2.36^{\star}$ & multiplet & 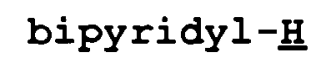 \\
\hline 9.39 & $2.38^{\star}$ & multiplet & bipyridyl-프 \\
\hline
\end{tabular}

${ }^{*}$ peaks in common with Bromoviologen (Table VIII)

The disubstituted viologen possesses a vertical symmetry plane in contrast to the Bromoviologen. As a consequence the two outside methylene groups are chemically equivalent and have the same chemical shifts. The propyl group with its symmetry plane through the 
middle positioned carbon gives rise to a quintet and a triplet pattern. The chemical shifts for the benzyl and the aromatic protons are not affected by the disubstitution and are the same as those of the Bromoviologen. For this reason no specific integration could be done for the aromatic protons for the disubstituted viologen. The chemical shifts and the proton assignments are given in Table IX. The spectrum is shown in the Appendix.

${ }^{13} \mathrm{C}$-MMR Spectroscopy, A decoupled carbon-13 NMR spectrum reveals the number of nonequivalent carbons in a compound. The material was dissolved in methanol-d4 using TMS as a standard. Peak assignments were done by calculations using reference values available in the literature. 44 No equivalent could be found for the disubstituted dipyridyl unit so that values for a -NR3 ${ }^{+}$ group were taken instead, assuming that the alkylated ammonium group has similar effects as the positively charged bipyridinium group. The Bromoviologen has a horizontal symmetry plane. This symmetry property has the consequence that the aromatic ortho and meta positions are chemically equivalent. Considering these points the spectrum of the Bromoviologen should consist of 10 peaks in the aromatic region (above $110 \mathrm{ppm}$ ) and 4 peaks in the alkyl region (80-0 ppm), which are both in agreement with the experimental results. The chemical shifts as well as 
the assignments are given in Figure 12 and Table $\mathrm{x}$. The spectrum is shown in the Appendix.

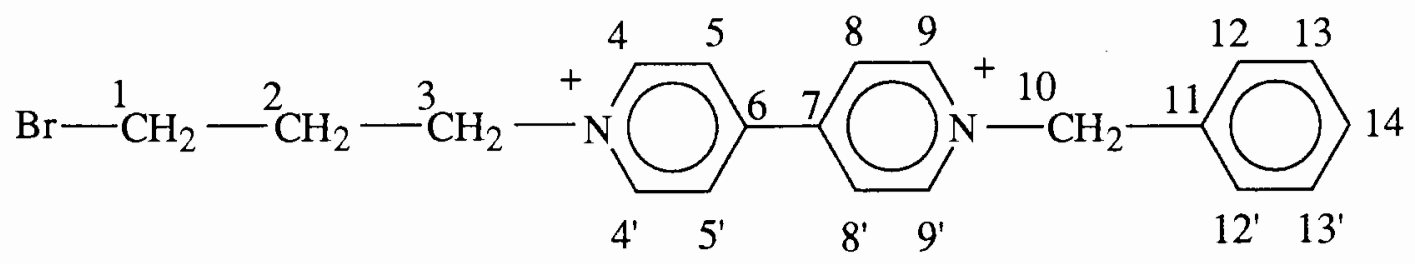

Figure 12. Structure of Bromoviologen.

TABLE X

${ }^{13}$ C-NMR CHEMICAL SHIFTS FOR BROMOVIOLOGEN

\begin{tabular}{|c|c|c|c|}
\hline ppm & assignment & ppm & assignment \\
\hline 29.5 & $\mathrm{C} 2$ & 130.7 & $\mathrm{C} 8, \mathrm{C} 8^{\prime}$ \\
\hline 34.7 & C1 & 131.1 & $\mathrm{C} 14$ \\
\hline 61.6 & C3 & 134.3 & $\mathrm{C} 11$ \\
\hline 65.7 & $\mathrm{C} 10$ & 147.0 & c6 \\
\hline 128.5 & $\mathrm{C} 13, \mathrm{C} 13^{\prime}$ & 147.3 & $C 7$ \\
\hline 128.6 & $\mathrm{C} 12, \mathrm{C} 12^{\prime}$ & 151.3 & $\mathrm{C} 4, \mathrm{C} 4^{\prime}$ \\
\hline 130.5 & $\mathrm{C} 5, \mathrm{C} 5^{\prime}$ & 151.4 & $\mathrm{C9} . \mathrm{Cg}{ }^{\prime}$ \\
\hline
\end{tabular}

FAB Mass spectrometry. The results for FAB-MS spectrometry are listed in Table XI. The spectrum is shown in the Appendix. The first striking feature of the spectrum is that the molecular ion peak is missing. This may be due to the fact that the substance is dissolved in 
a matrix (in this case glycerol) and the bromide ions are able to dissociate from the molecule. Fragments that leave the matrix upon irradiation are not accompanied by bromide ions for this reason. The backbone structure however can be seen at 370 units. Another assumption that must be made is that the viologen was reduced during the irradiation process. Peak positions are given by the value $\mathrm{m} / \mathrm{z}$ (mass to charge ratio). Considering that the viologen carries a double positive charge, the peak for the backbone should appear at 185 units. Since this is not the case the viologen must be only a +1 ion. This statement is supported by the fact that viologens are easily reducible and the solvents used for the matrix (glycerol and $n$-butyl alcohol) are good electron donors. The fragmentation pattern follows expected cleavages. The loss of the phenyl group leads to the monosubstituted dipyridyl. The presence of a bromine in this fragment can be seen in two neighboring lines that represent the ${ }^{79} \mathrm{Br}$ and $81_{\mathrm{Br}}$ isotopes, respectively. Loss of the bromine gives rise to a peak at 197 units. Finally the propyl group is cleaved off to yield dipyridyl which results in a peak at 157 units. The peak at 247 results if the bromopropyl group is cleaved off first from the backbone structure. Additional adduct formations can be observed. Glycerol adds to the monosubstituted dipyridyl (peak 247) to give a peak at 338 units. The disubstitution impurity can be 
assigned to a peak at 617 units. This dimer carries one bromide with it, supported by the fact that the isotopic pair of lines is observed. The loss of this bromine gives rise to a small peak at 536 units.

TABLE XI

FAB-MS DATA FOR BROMOVIOLOGEN

$\begin{array}{cccc}\mathrm{m} / \mathrm{z} & \text { intensity } & \text { fragment assignment } \\ 617 & 17 & 2.0 & \\ 536 & 57 & \\ 370 & 94 & \\ 279 & 67 & \\ 197 & 100 & \\ 157 & 33 & \end{array}$

Elemental analysis. The results of the elemental analysis are shown in Table XII. They are in poor agreement with the calculated results. The experimentally obtained values don't add up to $100 \%$. One reason for this could be that the sample still contained water, which is favored by the hygroscopic nature of the Bromoviologen. A 
calculation for Bromoviologen dihydrate was done and showed much better agreement with the experimental results.

\section{TABLE XII}

ELEMENTAL ANALYSIS OF BROMOVIOLOGEN AND DISUBSTITUTED VIOLOGEN MIXTURE

\begin{tabular}{ccccc}
\hline & \& $\mathrm{C}$ & \& $\mathrm{H}$ & \& $\mathrm{N}$ & \% \\
\hline calc. & 45.35 & 4.09 & 5.29 & 45.26 \\
calc. & 42.51 & 4.09 & 5.29 & 42.42 \\
dihydrate & & & & \\
exp. & 43.64 & 4.08 & 5.24 & 42.26 \\
\hline
\end{tabular}


CHAPTER V

\section{SYNTHESIS OF HYDROXYVIOLOGEN}

\section{INTRODUCTION}

Viologens are electron acceptors. The presence of an alcohol group during the HydroxyViologen synthesis presents the risk that the viologen might get reduced during preparation. To prevent this the 3-bromo-1-propanol concentration should be kept low and reaction times kept short. The described synthesis displayed no reduction of the viologen, as indicated by $1_{H-N M R}$ and the absence of a blue color.

\section{HydroxyViologen}

The synthesis was done similar to previous viologen preparations described in the literature. 45 1-Phenylmethyl4-(4'-pyridyl)pyridinium bromide (2.0 $9,6 \mathrm{mmol})$ was dissolved in $200 \mathrm{ml}$ anhydrous acetonitrile in a $1000 \mathrm{ml}$ 3-neck round-bottom flask equipped with reflux condenser. 3-Bromo-1-propanol (1.1 $\mathrm{ml}, 12 \mathrm{mmol})$ was added at once and the solution refluxed. An additional $1.1 \mathrm{ml}$ (12 mmol) 3-bromo-1-propanol was added after 9 hours. The first precipitate was yellow and observed after 24 hours reaction 
time. The solution was allowed to cool after 41 hours. The precipitate was filtered off and dried in oil pump vacuum $(1.33 \mathrm{~g})$. A dithionite-test applied on the yellow crude turned out positive. The yield was $1.33 \mathrm{~g}(2.8 \mathrm{mmol})=$ 478 . The melting point was determined to be $236-238^{\circ} \mathrm{C}$.

\section{Structural Analysis}

Infrared spectroscopy. All absorption frequencies are tabulated in Table XIII and the spectrum is included in the Appendix. The $0-H$ stretch vibration can be observed at $3330 \mathrm{~cm}^{-1}$ as a broad band due to intermolecular hydrogen bonding. The $C-O$ stretching is difficult to assign in the fingerprint region. Saturated primary alcohols absorb in the region between 1085 and $1030 \mathrm{~cm}^{-1}$ so that the absorption band at $1072 \mathrm{~cm}^{-1}$ could be the C-O stretching. The in-plane $\mathrm{O}-\mathrm{H}$ deformation vibration can be assigned to the absorption at $1366 \mathrm{~cm}^{-1}$. The strongest band in the spectrum is the $\mathrm{C}=\mathrm{N}$ stretching vibration at $1637 \mathrm{~cm}^{-1}$. The shorter wavelength $\mathrm{C}=\mathrm{C}$ stretching vibration for the phenyl ring is not observed, maybe for the same reasons as mentioned for the Bromoviologen. However, the weak $\mathrm{C}-\mathrm{H}$ stretching vibration at $3107 \mathrm{~cm}^{-1}$ and the moderately strong absorptions at $732 \mathrm{~cm}^{-1}$ and $690 \mathrm{~cm}^{-1}$ clearly indicate the phenyl ring presence. This is also supported by the observation of characteristic weak overtone bands in the region $1660-2000 \mathrm{~cm}^{-1}$. 
TABLE XIII

INERARED ABSORPTION BANDS FOR HYDROXYVIOLOGEN

\begin{tabular}{|c|c|}
\hline 3330 (br) & $3107(w)$ \\
\hline 3025 (s) & 2989 (s) \\
\hline $2872(\mathrm{~m})$ & 1637 (vs) \\
\hline 1554 (m) & 1507 (m) \\
\hline 1495 (m) & 1448 (s) \\
\hline 1366 (m) & 1325 (w) \\
\hline 1172 (m) & 1072 (m) \\
\hline $873(\mathrm{~m})$ & 732 (m) \\
\hline 690 (w) & 614 \\
\hline
\end{tabular}

Nuclear Magnetic Resonance Spectroscopy. The proton chemical shifts for the HydroxyViologen, acquired at 400 MHz, are listed in Table XIV. The spectrum is shown in the Appendix. The material was dissolved in methanol-d4 using TMS as a standard. The propyl chain gives rise to a triplet, quintet and triplet pattern. The methylene protons adjacent to the hydroxy group are deshielded and show up at lower field than the quintet pattern. The triplet pattern of the methylene protons adjacent to the dipyridyl unit appear at lowest field in the propyl pattern, since they are strongly deshielded by the positive charge. The disubstituted dipyridyl displays the expected AA'BB' patterns of a 1,4-disubstituted aromatic compound. Due to 
the deshielding of the positive charges the pattern is shifted downfield to $9.03 \mathrm{ppm}$. The benzyl protons appear as a singlet, and the phenyl protons appear as a multiplet in the aromatic region. All integrated peaks are in accordance with the expected proton ratio.

TABLE XIV

$1_{\text {H-NMR CHEMICAI SHIFTS FOR HYDROXYVIOLOGEN }}$

\begin{tabular}{|c|c|c|c|}
\hline $\mathrm{ppm}$ & Rel. Int. & Splitting & Assignment \\
\hline 2.30 & 1.00 & quintet & $\mathrm{HO}-\mathrm{CH}_{2}-\mathrm{CH}_{2}$ \\
\hline 3.68 & 1.00 & triplet & $\mathrm{HO}-\mathrm{CH}_{2}-\mathrm{CH}_{2}-$ \\
\hline 4.90 & 1.00 & triplet & CH2-bipyridyl \\
\hline 6.03 & 1.00 & singlet & $\mathrm{CH}_{2}-\mathrm{ph}$ \\
\hline 7.47 & 1.51 & multiplet & $\mathrm{ph}-\underline{\mathrm{H}} \quad(m+p)$ \\
\hline 7.63 & 1.00 & multiplet & $\mathrm{ph}-\underline{\underline{H}}(0)$ \\
\hline 8.72 & 1.98 & multiplet & 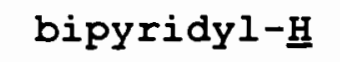 \\
\hline 9.34 & 1.99 & multiplet & bipyridyl-프 \\
\hline
\end{tabular}

${ }^{13} \mathrm{C}$-NMR Spectroscopy: The pure material was dissolved in methanol-d4 using TMS as a standard. The spectrum is shown in the Appendix. Peak assignments were done using a $-\mathrm{NR}_{3}{ }^{+}$group for the calculations as substitute for the bipyridinium assuming similar effects. 46 The Hydroxyviologen has a horizontal symmetry plane. For this reason the ortho positions and meta positions give rise to only one peak each. The total number of nonequivalent 
aromatic carbons is 10 and the number of nonequivalent alkyl carbons is 4 , which are both in agreement with the experimental results. The specific assignments of the peaks is given in Table $\mathrm{XV}$ and Figure 13.

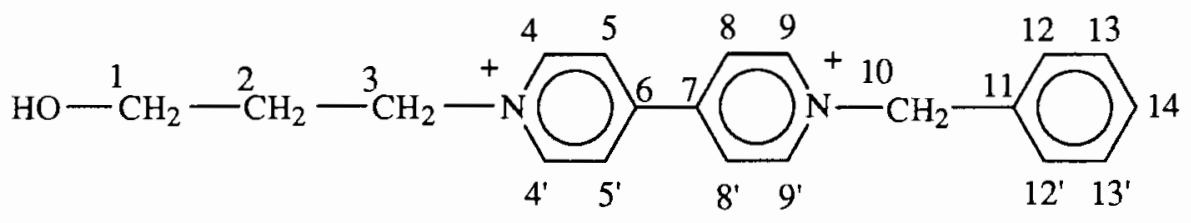

Eigure 13, Structure of Hydroxyviologen.

TABLE XV

${ }^{13}$ C-NMR CHEMICAL SHIFTS FOR HYDROXYVIOLOGEN

\begin{tabular}{cccc}
\hline ppm & assignment & ppm & assignment \\
\hline 34.5 & $\mathrm{C} 2$ & 130.8 & $\mathrm{C} 8, \mathrm{C} 8^{\prime}$ \\
59.0 & $\mathrm{C} 3$ & 131.2 & $\mathrm{C} 14$ \\
60.9 & $\mathrm{C} 1$ & 134.3 & $\mathrm{C} 11$ \\
65.8 & $\mathrm{C} 10$ & 147.0 & $\mathrm{C} 6$ \\
128.3 & $\mathrm{C} 13, \mathrm{C} 13^{\prime}$ & 147.4 & $\mathrm{C} 7$ \\
128.6 & $\mathrm{C} 12, \mathrm{C} 2^{\prime}{ }^{\prime}$ & 151.1 & $\mathrm{C4}, \mathrm{C} 4^{\prime}$ \\
130.5 & $\mathrm{C} 5, \mathrm{C}^{\prime}$ & 151.7 & $\mathrm{C} 9, \mathrm{C} 9^{\prime}$ \\
\hline
\end{tabular}

FAB Mass spectrometry. The results for FAB mass spectrometry are listed in Table XVI. The spectrum is shown in the Appendix. As in the Bromoviologen spectrum it can be observed that the molecular ion peak is missing. 
TABLE XVI

FAB-MS DATA FOR HYDROXYVIOLOGEN

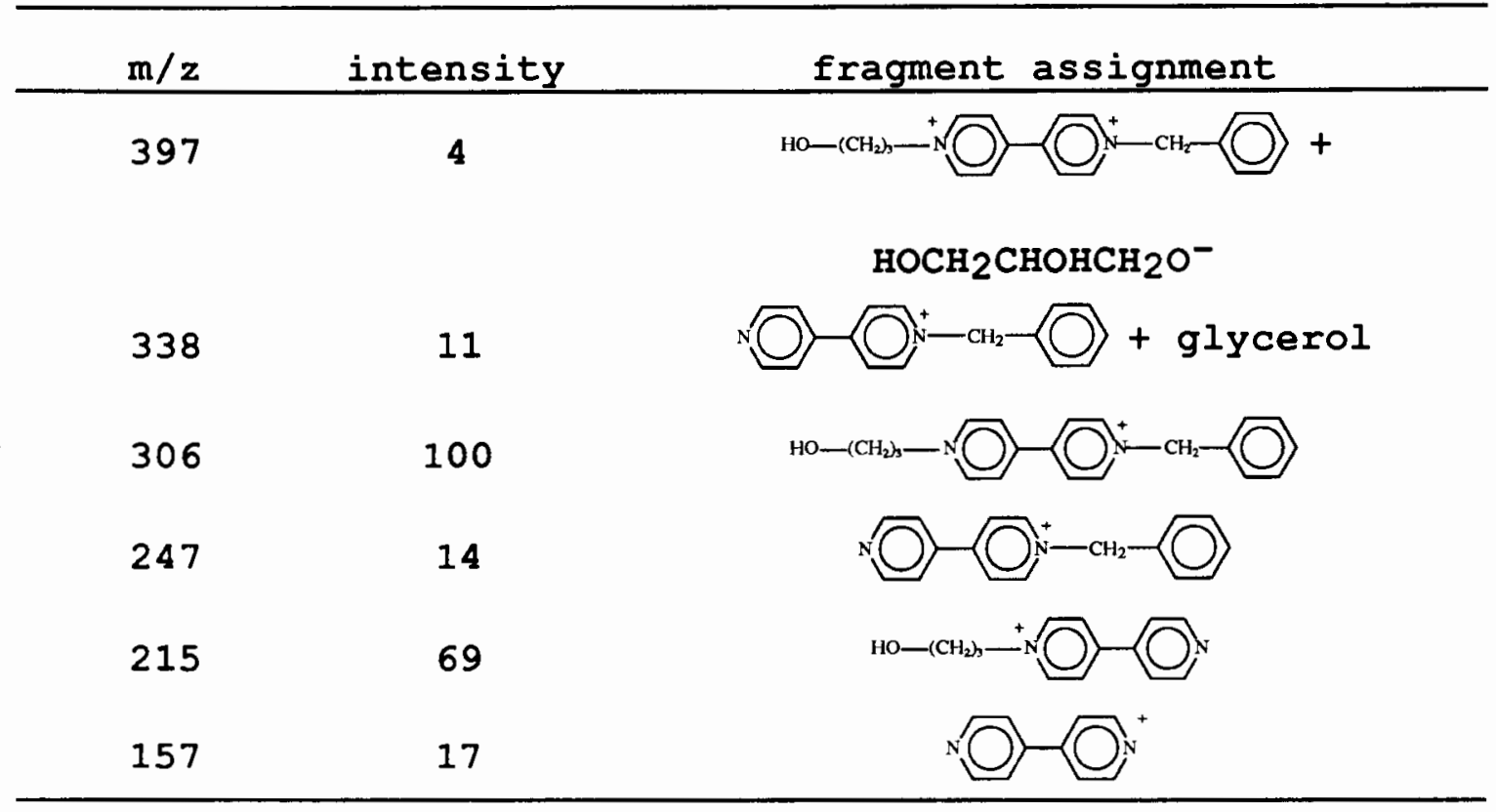

The backbone structure can be seen at 306 units. Again it must be assumed that the viologen was reduced in the ionization process. The splitting off of the propyl group is responsible for the peak at 247 units. Preferred is however the loss of the benzyl group, which can be concluded from the higher peak intensity at 215 units. The further loss of the propyl group leads to 4,4'-dipyridyl, which can be seen as the peak at 157 units. The observed peak at 185 units is due to the solvent glycerol, which was confirmed by a blank sample. In addition to the fragments, some adduct formations are observable. The first one is a combination of glycerol and benzylbipyridyl at peak 247. 
The second at 397 is due to adduct formation of the Hydroxyviologen and a glycerol alkoxide.

Elemental Analysis. The data for elemental analysis are listed in Table XVI. The calculated values are in agreement with the experimentally obtained results. The maximum deviation is 0.258 .

\section{TABLE XVII}

ELEMENTAL ANALYSIS OF HYDROXYVIOLOGEN

\begin{tabular}{lllll}
\hline & $8 \mathrm{C}$ & $8 \mathrm{H}$ & $8 \mathrm{~N}$ & $8 \mathrm{Br}$ \\
\hline calc. & 51.53 & 4.76 & 6.01 & 34.28 \\
exp. & 51.28 & 4.84 & 5.89 & 34.36 \\
\hline
\end{tabular}


CHAPTER VI

SYNTHESIS OF AMINODONOR

\section{INTRODUCTION}

The synthesis of the AminoDonor involves the coupling of an amino group with a carboxylic acid. The formation of an amide bond can usually be done by reaction of the corresponding acid chloride with an amine. In this case the starting material (4-aminobutanoic acid) contained both an amine group as well as a carboxylic acid group, so that the acid chloride would lead to polymer formation.

The approach for the synthesis was derived from peptide synthesis. 47 Hereby the amino group of the bifunctional starting material was protected by a tertbutoxycarbonyl group (Boc). The amino protected acid was then coupled with the donor amine using a carbodiimide as a coupling agent. The last step was the removal of the Boc protecting group with a strong acid.

The free amine is very sensitive towards oxidation. Exposure of the free amine to air leads to darkening within hours. Therefore for each use small amounts were prepared right away to keep exposure to air as low as possible. The 
amine dihydrochloride was prepared for structural analysis. A structural overview is illustrated in Figure 14 .

a)<smiles>CCCCCCCCCCCCC(=O)OC(=O)ON=C(C#N)c1ccccc1</smiles>

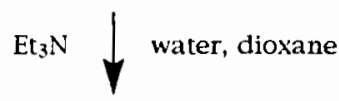<smiles>O=C(O)CCCCCC(=O)NC(=O)c1ccccc1</smiles>

b)

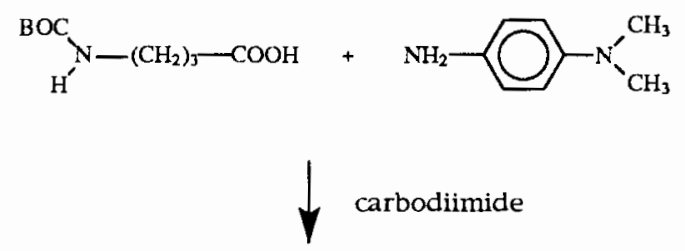<smiles>CN(C)c1ccc(NC(=O)CCCCCC(=O)OCc2ccccc2)cc1</smiles>

BOC-protected AminoDonor

c)<smiles>CN(C)c1ccc(NC(=O)CCCCC(=O)OC(C)(C)C)cc1</smiles><smiles>CCCC(C)(C)C(=O)O</smiles>

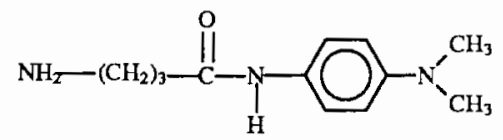
AlnimoDonor 
N-(Tert-butoxycarbonyI)-4-aminobutanoic acid

The synthesis was done according to the literature.48 4-Aminobutanoic acid $(8.0 \mathrm{~g}, 77 \mathrm{mmol})$ and $16.2 \mathrm{ml}$

(116 mmol) of triethylamine were dissolved in a mixture of $70 \mathrm{ml}$ water and $50 \mathrm{ml}$ dioxane. 2-(Tert-

butoxycarbonyloxyimino) -2-phenylacetonitrile (Boc-on)

$(21.0 \mathrm{~g}, 85.3 \mathrm{mmol})$ was added to this solution, whereby a slight yellow colorization was observed. This mixture was stirred for 24 hours. Water $(50-\mathrm{ml})$ and $100 \mathrm{ml}$ of ethyl acetate were added and the layers separated. The water phase was acidified to $\mathrm{pH} 3$ and extracted three times with $100 \mathrm{ml}$ of ethyl acetate. The combined organic phases were evaporated off on a rotovap to give a yellowish high viscosity oil. Yellow-white crystals were obtained from this oil after storage in the refrigerator for one night.

For further purification the crystals were dissolved in ether and extracted two times with $0.5 \mathrm{~N} \mathrm{NaHCO}_{3}$ solution. The combined aqueous layers were acidified with $5 \%$ citric acid and extracted three times with $100 \mathrm{ml}$ of ether. The combined organic layers were dried over $\mathrm{MgSO}_{4}$, filtered and evaporated off on the rotovap. It remained a slightly colored oil. Cooling of this oil in the refrigerator led to formation of white crystals.

The yield was $12.22 \mathrm{~g}(64 \mathrm{mmol})=83 \%$. The melting point was found to be $54-55^{\circ} \mathrm{C}$. 
Structural Analysis

Infrared spectroscopy. The infrared absorptions are tabulated in Table XVIII and the spectrum is shown in the Appendix. Characteristic functional groups in the molecule are a carboxylic acid and an amide. In the solid state, a hydrogen bonded hydroxy group exhibits a typical broad absorption at $3365-3324 \mathrm{~cm}^{-1}$. The carboxyl $\mathrm{C}=0$ stretching vibration is observed at $1725 \mathrm{~cm}^{-1}$. Assignments of $\mathrm{C}-\mathrm{O}$ stretching and $\mathrm{O}-\mathrm{H}$ deformation vibrations can't be made, since many other absorptions are observed in this region like - $\mathrm{CH}_{2} \mathrm{CO}$ - deformation vibration and $\mathrm{C}-\mathrm{N}$ stretching vibration. The $\mathrm{N}-\mathrm{H}$ stretching vibration of the amide overlaps with the broad band of the hydroxy group.

\section{TABLE XVIII}

INFRARED ABSORPTION BANDS FOR N-(TERT-BUTOXYCARBONYI) -4-AMINOBUTANOIC ACID

3365 (br)

2978 (s)

2860 (m)

1725 (s)

1542 (s)

1366 (m)

1166 (m)

$861($ w)
3224 (br)

2931 (m)

2813 (พ)

1678 (s)

1454 (m)

1278 (m)

1014 (m)

661 (m) 
Nuclear Magnetic Resonance Spectroscopy. The spectrum was recorded on the $90 \mathrm{MHz}$ instrument. The material was dissolved in $\mathrm{CDCl}_{3}$ using TMS as a standard. The chemical shifts and the assignments are tabulated in Table $x I x$. The three methyl groups of the Boc protecting group can freely rotate and appear therefore as a singlet. The propyl group of the aliphatic acid gives rise to the expected triplet, quintet, triplet pattern. The methylene protons adjacent to the nitrogen experience the biggest shift to low field followed by the triplet from the methylene protons next to the carboxylic group. The proton attached to the nitrogen shows up as a broad peak at 4.85 Ppm due to the quadrupole moment of the nitrogen. 49 The integration of the peaks is in agreement with the expected hydrogen ratio.

\section{TABLE XIX}

1 H-NMR CHEMICAL SHIFTS FOR N' (TERTBUTOXYCARBONYL) '4-AMINOBUTANOIC ACID

\begin{tabular}{cccc}
\hline Ppm & Rel. Int & Splitting & Assignment \\
\hline 1.43 & 9 & singlet & (CH3) $3-\mathrm{O}$ \\
1.83 & 2 & quintet & $\mathrm{CH}_{2}-\mathrm{CH}_{2}-\mathrm{CH}_{2}-$ \\
2.35 & 2 & triplet & $\mathrm{CH}_{2}-\mathrm{CH}_{2}-\mathrm{COOH}$ \\
3.18 & 2 & triplet & $-\mathrm{HN}-\mathrm{CH}_{2}-\mathrm{CH}_{2}-$ \\
4.85 & 1 & singlet & NH-CH2 \\
\hline
\end{tabular}


Boc-protected AminoDonor

The coupling of the amine with an acid was done according to reference. 48 The $\mathrm{N}, \mathrm{N}$-dimethyl-p-phenylene diamine was distilled in vacuum before using. $\mathrm{N}$-(Tertbutoxycarbony l)-4-aminobutanoic acid (6.05 $\mathrm{g}, 32 \mathrm{mmol}$ ) and $4.4 \mathrm{ml}$ ( $31.7 \mathrm{mmol}$ ) of triethylamine were dissolved in $50 \mathrm{ml}$ dichloromethane in a $250 \mathrm{ml}$ round-bottom flask. $\mathrm{N}, \mathrm{N}$-dimethyl-p-phenylenediamine $(4.3 \mathrm{~g}, 31.7 \mathrm{mmol})$ and $6.1 \mathrm{~g}$ (32 mmol) of 1-(3-dimethylaminopropyl)3-ethylcarbodiimide hydrochloride were added to this solution. The solution turned slightly brown. This mixture was stirred at room temperature for 16 hours. The solution was washed with $80 \mathrm{ml}$ water, $80 \mathrm{ml} 508$ citric acid, $80 \mathrm{ml}$ water, $80 \mathrm{ml}$ saturated $\mathrm{NaHCO}_{3}$ solution and $80 \mathrm{ml}$ water again. The organic phase was dried over $\mathrm{MgSO}_{4}$, filtered and evaporated off on a rotovap. A white-brown solid was obtained, then recrystallized from cyclohexane/dioxane $(v: v, 16: 3)$. This gave white crystals, which were then dried on the oil pump. The yield was $7.25 \mathrm{~g}(22.9 \mathrm{mmol})=$ 748. The melting point was found to be $117^{\circ} \mathrm{C}$.

\section{Structural Analysis}

Infrared spectroscopy. The infrared absorptions are tabulated in Table $\mathrm{xx}$ and the spectrum is shown in the Appendix. The important functional groups are two secondary amide bonds and a para substituted phenyl ring. Two sharp 
$\mathrm{N}-\mathrm{H}$ stretching vibrations are observed at $3342 \mathrm{~cm}^{-1}$ and $3307 \mathrm{~cm}^{-1}$. The bands are slightly shifted to lower frequencies due to the solid state. The amide I band as a consequence of the $C=0$ stretching vibration can be seen at $1684 \mathrm{~cm}^{-1}$. The amide II band indicates $\mathrm{N}-\mathrm{H}$ deformation and $\mathrm{C}-\mathrm{N}$ stretching vibrations. They appear as strong absorptions at $1648 \mathrm{~cm}^{-1}(\mathrm{C}-\mathrm{N})$ and $1531 \mathrm{~cm}^{-1}(\mathrm{~N}-\mathrm{H})$. The two medium strong bands at $1272 \mathrm{~cm}^{-1}$ and $1166 \mathrm{~cm}-1$ can be assigned to a asymmetric and symmetric C-O-C stretching vibration, respectively. The para substituted phenyl ring gives rise to characteristic medium absorption at $808 \mathrm{~cm}^{-1}$. The "breathing" modes are present at $1595 \mathrm{~cm}^{-1}$ and $1443 \mathrm{~cm}^{-1}$.

\section{TABLE $X X$}

INFRARED ABSORPTION BANDS FOR BOC-PROTECTED AMINODONOR

3342 (sh, s)

3177 (w)

2931 (m)

2790 (m)

1648 (s)

1595 (m)

1443 (m)

1166 (m)
3307 (sh, s)

2978 (m)

2872 (m)

1684 (s)

1607 (m)

1531 (s)

1272 (m)

808 (m) 
Nuclear Magnetic Resonance Spectroscopy. The spectrum was recorded on the $90 \mathrm{MHz}$ NMR spectrometer and it is shown in the Appendix. The material was dissolved in $\mathrm{CDCl}_{3}$ using TMS as a standard. The chemical shifts are tabulated in Table XXI.

\section{TABLE XXI}

$1_{\text {H-NMR CHEMICAL SHIFTS FOR BOC-PROTECTED AMINODONOR }}$

\begin{tabular}{cccc}
\hline ppm & Rel. Int. & Splitting & Assignment \\
1.50 & 9 & singlet & ( $\left.\mathrm{CH}_{3}\right)_{3}-\mathrm{O}$ \\
1.90 & 2 & quintet & $\mathrm{NH}-\mathrm{CH}_{2}-\mathrm{CH}_{2}-$ \\
2.40 & 2 & triplet & $\mathrm{CH}_{2}-\mathrm{CO}$ \\
2.93 & 6 & singlet & $\mathrm{N}\left(\mathrm{CH}_{3}\right)_{2}$ \\
3.25 & 2 & triplet & $\mathrm{NH}-\mathrm{CH}_{2}-\mathrm{CH}_{2}-$ \\
4.91 & 1 & singlet & $\mathrm{NH}-\mathrm{CH}_{2}-\mathrm{CH}_{2}-$ \\
6.81 & 2 & doublet & aromat- \\
7.56 & 2 & doublet & aromat-H \\
8.28 & 1 & singlet & NH-aromat \\
\hline
\end{tabular}

The methyl hydrogens of the Boc protection group are chemically equivalent and appear as a singlet. The propyl group gives rise to the expected triplet, quintet, triplet splitting. The methylene protons adjacent to the nitrogen experience the strongest deshielding effect and show up at lowest field. The hydrogens from the amide bond appear as 
singlets. The one in proximity to the phenyl ring is deshielded and is shifted to lower field for this reason. Both peaks are broadened due to the quadrupole moment of the nitrogen. 58 The para-substituted phenyl ring exhibits the classical $A A^{\prime} B B^{\prime}$ splitting pattern. Integration is in agreement with the expected hydrogen ratio.

FAB Mass spectrometry. The results for FAB mass spectrometry are listed in Table XXII. The spectrum is shown in the Appendix. The molecular ion peak, which indicates the molecular weight of the compound, is observable with the highest intensity at 321 units. One property of the FAB method is that a proton is added to each fragment or the original compound. So in fact the molecular ion peak was expected at 322 units. As an explanation it could be conceived that the AminoDonor preferentially gets oxidized to form a radical cation instead of accepting a proton. The dimer of BOC-AminoDonor is protonated in contrast to the monomer and the corresponding peak at 643 units can be clearly observed in weaker intensity. The remaining peaks are in agreement with the expected fragmentation pattern. The tertiary-butyl group is cleaved off first to yield a fragment that gives rise to a peak at 266 units. The further loss of $\mathrm{CO}_{2}$ is responsible for a peak at 222 units. Theoretically it also could be possible that a $\mathrm{N}\left(\mathrm{CH}_{3}\right)$ radical is cleaved off, which is unlikely in comparison to the competitive $\mathrm{CO}_{2}$ 
loss, and furthermore not in agreement with the subsequent cleavage pattern. The loss of NH3 leads to a peak at 205 units. The peak at 185 is due to the solvent glycerol. The remaining $\mathrm{N}, \mathrm{N}$-dimethyl-p-phenylene causes a peak at 137 units. The final peak assignment at 121 can be assigned to a $\mathrm{N}, \mathrm{N}^{\prime}$-dimethylphenyleneamine radical.

\section{TABLE XXII}

FAB-MS DATA FOR BOC-AMINODONOR

321

100

fragment assignment

643 intensity

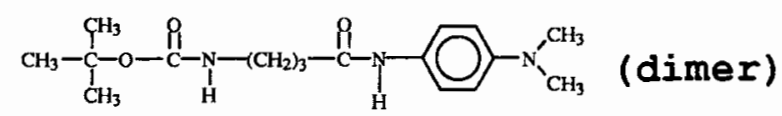

266

49

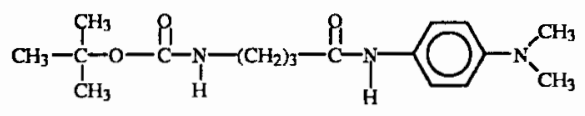

222

47

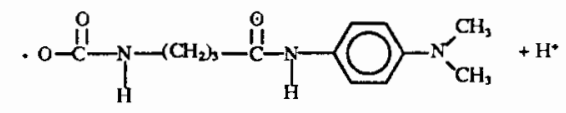

205 46

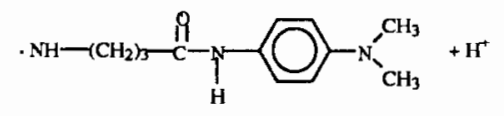

137

87

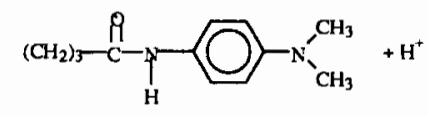

121

21
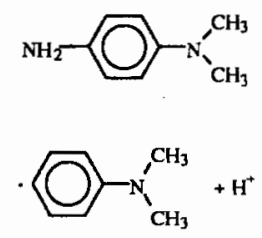
Elemental analysis. The results for elemental analysis are shown in Table XXIII. The calculated values are in agreement with the experimentally obtained results.

\section{TABLE XXIII}

ELEMENTAL ANALYSIS OF BOC-PROTECTED AMINODONOR

\begin{tabular}{llll}
\hline & $8 \mathrm{C}$ & $8 \mathrm{H}$ & $\& \mathrm{~N}$ \\
\hline calc. & 63.53 & 8.47 & 13.09 \\
exp. & 63.47 & 8.44 & 12.99 \\
\hline
\end{tabular}

\section{AminoDonor}

The removal of the BOC amino protecting group was done according to reference. 50 Boc-protected AminoDonor $1250 \mathrm{mg}$, $0.81 \mathrm{mmol}$ ) was stirred at room temperature with $1.5 \mathrm{ml}$ $(19.4 \mathrm{mmol})$ of trifluoroacetic acid in a $25 \mathrm{ml}$ round-bottom flask for 15 minutes. Immediate gas evolution and a very slight color change to purple were observed. The solution was cooled down in an ice bath and adjusted to $\mathrm{pH} 13$ by addition of $6 \mathrm{M} \mathrm{NaOH}$. The purple color disappeared at basic $\mathrm{pH}$. The aqueous solution was extracted three times with $25 \mathrm{ml}$ dichloromethane. The combined organic layers were dried over $\mathrm{Na}_{2} \mathrm{SO}_{4}$, filtered and evaporated off on the rotovap. The crude was further dried on the oil pump. The yield was $177 \mathrm{mg}(0.8 \mathrm{mmol})=998$. The amine dihydrochloride was prepared for structural analysis, since the free amine is sensitive to oxidation. Thus $3 \mathrm{M} \mathrm{HCl}$ 
$(0.25 \mathrm{ml})$ was added to $50 \mathrm{mg}$ of the free amine. The excess water and hydrochloric acid were evaporated off in vacuum.

\section{Structural Analysis}

Infrared spectroscopy. The infrared absorptions of the free amine are tabulated in Table XxIV, and the infrared absorptions of the dihydrochloride are tabulated in Table XXV. The spectra are shown in the Appendix.

AminoDoner. Characteristic groups are primary and tertiary amines as well as a secondary amide. The $\mathrm{N}-\mathrm{H}$ stretching vibration of the primary amine appears as a broad band of medium intensity. Two absorption bands at $3424 \mathrm{~cm}^{-1}$ and $3295 \mathrm{~cm}^{-1}$ are sticking out of this broad band indicating the asymmetric and symmetric vibrations. The $\mathrm{N}-\mathrm{H}$ deformation vibration can be observed at $1631 \mathrm{~cm}^{-1}$. It is not possible to identify unambiguously the $C-N$ stretching vibration in the fingerprint region due to its common weak absorption. The amide I band ( $C=0$ stretching vibration) appears as a strong absorption at $1654 \mathrm{~cm}^{-1}$. The amide II band is observed as a strong absorption at $1519 \mathrm{~cm}^{-1}$. The para-substituted phenyl ring gives rise to two characteristic $\mathrm{C}=\mathrm{C}$ stretching modes. The higher wavenumber one is observed at $1601 \mathrm{~cm}^{-1}$, the lower wavenumber one is hidden by the amide II band. The benzene para substitution pattern can clearly be determined by a single medium absorption at $814 \mathrm{~cm}^{-1}$. 
TABLE XXIV

INERARED ABSORPTION BANDS FOR

$\mathrm{N}-\left[4^{\prime}-\left(\mathrm{N}^{\prime}, \mathrm{N}^{\prime}\right.\right.$-DIMETHYIAMINOPHENYI) ]-4-AMINOBUTANAMIDE

\begin{tabular}{llll}
3424 & $(\mathrm{br})$ & 3295 (s) \\
3107 & $(\mathrm{~m})$ & 2954 (m) \\
2884 & $(\mathrm{~m})$ & 2790 (m) \\
1654 & $(\mathrm{~s})$ & 1631 (m) \\
1601 & $(\mathrm{~s})$ & 1519 (vs) \\
1478 (m) & 1443 (m) \\
1319 (m) & 1161 (w) \\
814 (m) & 520 (w) \\
\hline
\end{tabular}

AminoDonor Dihydrochloride. The spectrum displays all important absorption bands like amide I and II. A detailed description is redundant, since it was done for the free amine, so that just the hydrohalide absorptions are described. The $\mathrm{N}_{-} \mathrm{H}^{+}$stretching vibrations of the $\mathrm{NH}_{3}{ }^{+}$ group can be viewed as a number of broad bands 51 with medium intensity from $3436 \mathrm{~cm}^{-1}$ to $3048 \mathrm{~cm}^{-1}$. The $\mathrm{N}-\mathrm{H}^{+}$ stretching vibrations from the $\mathrm{R}_{3} \mathrm{NH}^{+}$group are shifted in correct manner to lower frequencies and appear as a bundle of peaks with medium intensity from $2684 \mathrm{~cm}^{-1}$ to $2496 \mathrm{~cm}^{-1}$. 
INFRARED ABSORPTION BANDS FOR

$$
\begin{gathered}
\mathrm{N}-\left[4^{\prime}-\left(\mathrm{N}^{\prime}, \mathrm{N}^{\prime}-\mathrm{DIMETHYIAMINOPHENYL}\right)\right]-4-A M I N O B U T A N A M I D E \\
\text { DIHYDROCHLORIDE }
\end{gathered}
$$

$\begin{array}{lll}3436 & (\mathrm{br}) & 3283(\mathrm{~m}) \\ 3236 & (\mathrm{~m}) & 3189(\mathrm{~m}) \\ 3048 \text { (s) } & 2966(\mathrm{~s}) \\ 2884 \text { (m) } & 2684(\mathrm{~m}) \\ 2637 \text { (m) } & 2578(\mathrm{~m}) \\ 2496 \text { (m) } & 2449(\mathrm{~m}) \\ 1684 \text { (vs) } & 1601(\mathrm{~m}) \\ 1548 \text { (s) } & 1519(\mathrm{~s}) \\ 1478 \text { (m) } & 1313(\mathrm{~m}) \\ 1137 \text { (m) } & 849(\mathrm{~m})\end{array}$

Nuclear Magnetic Resonance Spectroscopy. The spectrum was recorded on the $90 \mathrm{MHz}$ instrument. The spectrum of the is shown in the Appendix. The dihydrochloride (to avoid oxidation) was dissolved in $\mathrm{D}_{2} \mathrm{O}$ using DSS as a standard. The chemical shifts are tabulated in Table XXVI. The amine protons as well as the amide proton are exchanged with the solvent and don't appear in the spectrum. The propyl group gives rise to a triplet, quintet, triplet pattern with the triplet adjacent to the nitrogen at lowest field. The two methyl groups attached to the diamine are chemically equivalent and give rise to a 
singlet. The aromatic protons don't appear in an expected $A A^{\prime} B B^{\prime}$ pattern but as a multiplet in the aromatic region. Since the spectrum was taken in acidic medium it could be assumed that both nitrogens on the benzene ring can get protonated creating a similar environment on both sides. In this case the AA'BB' splitting pattern can't be observed.

\section{TABLE XXVI}

1 H-NMR CHEMICAL SHIFTS FOR

N- [4 '-(N', N'-DIMETHYIAMINOPHENYL) ]-4-AMINOBUTANAMIDE

\begin{tabular}{cccc}
\hline ppm & Rel. Int & Splitting & Assignment \\
2.08 & 2 & quintet & ${ }_{\mathrm{H}_{3} \mathrm{~N}-\mathrm{CH}_{2}-\mathrm{CH}_{2}-}$ \\
2.66 & 2 & triplet & $\mathrm{CH}_{2}-\mathrm{CO}$ \\
3.16 & 2 & triplet & ${ }_{\mathrm{H}_{3} \mathrm{~N}-\mathrm{CH}_{2}-\mathrm{CH}_{2}-}$ \\
3.33 & 6 & singlet & $\mathrm{N}\left(\mathrm{CH}_{3}\right)_{2}$ \\
7.78 & 4 & multiplet & aromat $-\mathrm{H}$ \\
\hline
\end{tabular}


CHAPTER VII

\section{SYNTHESIS OF BROMODONOR}

\section{INTRODUCTION}

The BromoDonor synthesis involves an amide bond formation in its final step. The procedure was to form the 4-bromobutyryl chloride first, which is then allowed to react with $\mathbf{N}, \mathbf{N}$ dimethyl-p-phenylenediamine. Although straightforward looking, this synthesis was troublesome. The formation of side products in large scale was observed each time the coupling was attempted. Changing the base from pyridine to triethylamine and varying the reaction time increased the yield only little.

The attempt to synthesize the BromoDonor under milder reaction conditions using the carboxylic acid and the amine as starting materials and a carbodimide as coupling agent failed. Product formation of less than 18 was observed by this method.

Furthermore it turned out that the BromoDonor is sensitive to light exposure and heat. A structural overview of the synthesis is given in Figure 15. 
a)

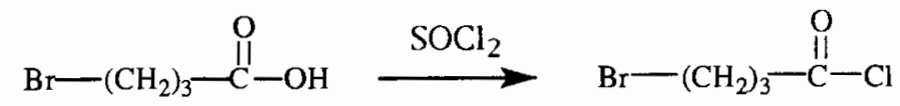

b)

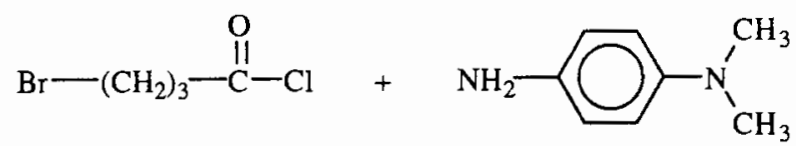

$\mathrm{CHCl}_{3} \downarrow \mathrm{Et}_{3} \mathrm{~N}$

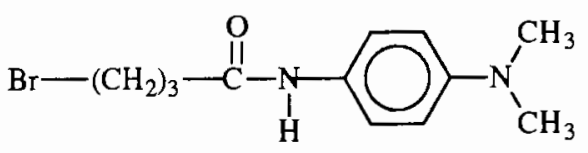

BromoDonor

Eigure 15, Synthesis of BromoDonor.

\section{4-Bromobutyryl chloride}

The acid chloride is prepared by the common known procedure of refluxing the acid in thionyl chloride. 4-Bromobutyric acid (11.98 $\mathrm{g}, 71 \mathrm{mmol})$ and $10 \mathrm{ml}$ (137 mmol) thionyl chloride were refluxed in a $25 \mathrm{ml}$ round-bottom flask equipped with reflux condenser and drying tube for 2 hours. The thionyl chloride was distilled before using. Excessive thionyl chloride was subsequently distilled off. The acid chloride was distilled in vacuum (bp $106^{\circ} \mathrm{C}$ at 4.3 Torr). A colorless oil was obtained. The yield was $12.58 \mathrm{~g}$ $(68 \mathrm{mmol})=95 \%$. 


\section{Structural Analysis}

Infrared spectroscopy. The infrared absorption bands are listed in Table XXVII and the spectrum is shown in the Appendix. The $\mathrm{C}=0$ stretching vibration of the acid chloride is shifted in typical manner to higher frequency and appears at $1789 \mathrm{~cm}^{-1}$. The very weak absorption band at $3565 \mathrm{~cm}^{-1}$ suggests that the acid chloride was hydrolyzed only to a small degree during the sample preparation.

\section{TABLE XXVII}

INFRARED ABSORPTION BANDS FOR 4-BROMOBUTYRYL CHLORIDE

\begin{tabular}{llll}
3565 & $(\mathrm{w})$ & $2966(\mathrm{~m})$ \\
2907 & $(\mathrm{~m})$ & $1789(\mathrm{~s})$ \\
1437 & $(\mathrm{~m})$ & $973(\mathrm{~m})$ \\
\hline
\end{tabular}

\section{BromoDonor}

The coupling of the amine with the acid chloride is carried out in a typical preparation method using triethylamine as a base. 4-Bromobutyryl chloride $15.93 \mathrm{~g}$, $32 \mathrm{mmol}$ ) was dissolved in $25 \mathrm{ml} \mathrm{DMF}$ and stirred in a $500 \mathrm{ml}$ Erlenmeyer flask. Pyridine $(3.3 \mathrm{ml}, 41.6 \mathrm{mmol})$ and $4.22 \mathrm{~g}$ (31 mmol) N,N-dimethyl-p-phenylenediamine were added. The solution was stirred at room temperature overnight. To this solution $40 \mathrm{ml}$ of $1 \mathrm{M} \mathrm{NaOH}$ were added and the $\mathrm{pH}$ verified as basic. The brown solution was extracted with $100 \mathrm{ml}$ of ether, twice with $50 \mathrm{ml}$ of $1 \mathrm{M} \mathrm{HCl}$ and once with $60 \mathrm{ml}$ of 
water. Since all product seemed to be in the water phase, the solution was neutralized with $\mathrm{NaHCO}_{3}$ and extracted two times with $100 \mathrm{ml}$ of ether. The combined organic layers were dried for 2 hours over $\mathrm{Na}_{2} \mathrm{SO}_{4}$ and the ether evaporated off on the rotovap. The residue was very impure. Therefore it was dissolved in ether again and the product precipitated out by addition of cyclohexane. The precipitate was filtered, recrystallized from cyclohexane and dried in vacuum. The yield was $0.42 \mathrm{~g}(1.4 \mathrm{mmol})=58$. The melting point was determined to be $114-116^{\circ} \mathrm{C}$.

\section{Structural Analysis}

Infrared spectroscopy. The infrared absorption bands are listed in Table XXIX and the spectrum in shown is the Appendix. The main characteristic group is a secondary amide. The $\mathrm{N}-\mathrm{H}$ stretching vibration can be seen at 3260 $\mathrm{cm}^{-1}$, indicating trans configuration. The amide $I$ band $(C=0$ stretching vibration) is observed at $1648 \mathrm{~cm}^{-1}$. The amide II band ( $\mathrm{N}-\mathrm{H}$ deformation and $\mathrm{C}-\mathrm{N}$ stretching vibration) shows up as a strong absorption band at $1525 \mathrm{~cm}^{-1}$. The breathing modes of the benzene ring can be seen at 1590 $\mathrm{cm}^{-1}$ and $1495 \mathrm{~cm}^{-1}$. A single strong absorption at $814 \mathrm{~cm}^{-1}$ clearly indicates the para-substitution of the benzene ring.

Nuclear Magnetic Resonance Spectroscopy. The spectrum was recorded on the $90 \mathrm{MHz}$ spectrometer and is 
shown in the Appendix. The chemical shifts are tabulated in Table XXVIII. The material was dissolved in $\mathrm{CDCl}_{3}$ using TMS as a standard. The propyl group gives rise to a triplet, quintet, triplet splitting pattern. The methylene protons adjacent to the bromide can be assigned to the triplet at lowest field due the deshielding effect of the bromide. The para-substituted benzene ring displays the expected AA'BB' splitting pattern. The amide proton is hidden under the doublet of the aromatic pattern at $7.41 \mathrm{ppm}$. The deshielding effect of the nitrogen and the benzene ring move the chemical shift to such low field but within range of the literature values. The two methyl groups can freely rotate and appear as a singlet.

\section{TABLE XXVIII}

$1_{\text {H-NMR CHEMICAL SHIFTS FOR }}$ N- $[4$ ' - (N' , N' -DIMETHYLAMINOP HENYL ) ] -4-BROMOBUTANAMIDE

\begin{tabular}{cccc}
\hline ppm & Rel. Int. & Splitting & Assignment \\
2.26 & 2 & quintet & $\mathrm{CH}_{2}-\mathrm{CH}_{2}-\mathrm{CH}_{2}$ \\
2.56 & 2 & triplet & $\mathrm{CO}-\mathrm{CH}_{2}$ \\
3.03 & 6 & singlet & $\mathrm{N}(\mathrm{CH} 3)_{2}$ \\
3.73 & 2 & triplet & $\mathrm{CH} 2-\mathrm{Br}$ \\
6.81 & 2 & doublet & aromat-H \\
7.41 & 2 & doublet & aromat-H \\
\hline
\end{tabular}


TABLE XXIX

INERARED ABSORPTION BANDS FOR

$N-\left[4^{\prime}-\left(N^{\prime}, N^{\prime}-D\right.\right.$ IMETHYLAMINOPHENYL) ] -4-BROMOBUTANAMIDE

3260 (s)

3107 (m)

2907 (m)

1648 (s)

1590 (m)

1437 (m)

1260 (m)

814 (s) $3166(\mathrm{~m})$

3048 (m)

$2801(\mathrm{~m})$

$1613(\mathrm{~m})$

1525 (vs)

1260 (m)

1161 (m)

520 (w) 
CHAPTER VIII

COUPLING ATTEMPTS OF ACCEPTORS AND DONORS TO THE PORPHYRINS

\section{INTRODUCTION}

It was first attempted to couple the Hydroxyviologen in a substitution reaction with TCCPP. The first experiment was done following typical procedures 52 using triethylamine as a base. Since the coupling was unsuccessful the experiment was repeated using $\mathbf{N}, \mathbf{N}$-dimethylaminopyridine (DMAP) 53 as a catalyst. The catalytic activity of DMAP has been found to increase the yield tremendously in this type of reaction. 54 Even with this catalyst a coupling couldn't be achieved. An assumption was that traces of water would hydrolyze the acid chloride before the linkage could occur. To exclude this possibility the experiment was repeated with both triethylamine as base and DMAP as catalyst under inert atmosphere. All solvents had been dried again before using. The experiment did not result in the desired linkage. It can be concluded that moisture was not the reason for the failure of the coupling. These three experiments are described under sections a1 to a3 below.

In the same type of reaction it was attempted to link the AminoDonor to TCCPP. The AminoDonor was prepared 
separately before the experiment, dried in vacuum for one or two days and used right away so that contact with air was minimized. The experiment was done twice. One attempt was made following typical procedures using triethylamine as base, and the other with DMAP as an additional catalyst. In both cases no linkage could be observed by $1_{\mathrm{H}}$ NMR. These experiments are described under sections $b_{1}$ and $b_{2}$.

A further possibility to couple an amine and a carboxylic acid is using a coupling agent like a carbodiimide. The attempt to link TCPP and AminoDonor in the same manner as done before for the AminoDonor synthesis was not successful. The experimental description is described in section $b_{3}$.

A further attempt was to attach the Bromoviologen to THPP. The reaction is a nucleophilic substitution following the $\mathrm{S}_{\mathrm{N}} 2$ mechanism. Polar aprotic solvents are suitable for this reaction type since they solvate only the cations leading to 'naked anions' with much higher nucleophility. Such solvents are DMF, DMSO or HMPA. HMPA shows significantly higher reaction rates in comparison to other aprotic solvents. It was attempted to couple TCPP as nucleophile with Bromoviologen in HMPA according to previously described esterifications.55,56 surprisingly the solubility of the porphyrin in FMPA is very low. The limited solubility made the coupling reaction impossible. The reaction of the phenol group with Bromoviologen was 
carried out using DMF as solvent and cesium carbonate as base. 57 Methyl iodide was added to the solution at its final stage to methylate the unreacted phenol groups. This was done to decrease the polarity of the molecule so that a subsequent chromatography could be carried out easier. The linkage was unsuccessful even under refluxing and 24 hours reaction time, although the methylation was found to be complete within 30 minutes to yield TMPP. The experiment is described in section $c$.

A further attempt was to couple the Bromoviologen in a nucleophilic substitution to TCPP. The synthesis was done according to reference (58) using cesium carbonate as a base. Also in this case no product formation could be detected by NMR. The experiment is described in section $d$.

\section{TCCPP and HydroxyViologen (a)}

TCCPP (446 mg, $0.51 \mathrm{mmol}$ ) was dissolved in $20 \mathrm{ml}$ anhydrous DMF and cooled in an ice bath. Hydroxyviologen $(240 \mathrm{mg}, 0.51 \mathrm{mmol})$ and $0.86 \mathrm{ml}$ (6.1 mmol) triethylamine were dissolved in $50 \mathrm{ml}$ anhydrous $\mathrm{DMF}$ and added to this solution. Heat evolution and brown colorization was observed at this step. The solution was stirred for 10 minutes at $0^{\circ} \mathrm{C}$ and for 20 more minutes at room temperature. Water $(10 \mathrm{ml})$ was added to stop the reaction whereby heat evolution was also observed. The DMF/water phase was evaporated off to dryness in vacuum. The brown-purple crude 
was dissolved in methanol with a little $3 \mathrm{M} \mathrm{HCl}$ addition and chromatographed on a silica gel column $(100 \mathrm{~g}$ silica gel, height $15 \mathrm{~cm}$, diameter $4.5 \mathrm{~cm}$, eluent MeOH/3 M $\mathrm{HCl}$ $\mathrm{v}: \mathrm{v} ; 9: 1$ ). No product formation could be observed by $1_{\mathrm{H}-}$ NMR .

\section{TCCPP and HydroxyViologen (a2L}

Hydroxyviologen $(73 \mathrm{mg}, 0.16 \mathrm{mmol})$ and $0.88 \mathrm{ml}(6.3$ mmol) triethylamine were dissolved in $200 \mathrm{ml}$ DMF (anhydrous). 4-Dimethylaminopyridine (DMAP) (7 mg) was added whereby the color changed slightly from yellow to green-yellow. TCCPP (137 mg, $0.16 \mathrm{mmol}$ ) was dissolved in $100 \mathrm{ml} \mathrm{DMF} \mathrm{(anhydrous)} \mathrm{and} \mathrm{added} \mathrm{at} \mathrm{once.} \mathrm{The} \mathrm{solution}$ turned brown in color. Weak heat evolution was observed. The organic phase was distilled off in vacuum after 18 hours reaction time. The remaining crude was dissolved in a little DMF and chromatographed on a column (150 g silica gel, eluent first DMF then MeOH). The top of the column was sliced off and extracted with $\mathrm{MeOH}$ (acidified), since it contained porphyrin. However, $1_{H-N M R}$ analysis of each fraction displayed no product formation.

\section{TCCPP and HydroxyVielogen (a3.L}

HydroxyViologen (593 $\mathrm{mg}, 1.27 \mathrm{mmol}$ ) and $621 \mathrm{mg}$ (5.08 mmol) DMAP were dissolved in $100 \mathrm{ml}$ DMF (anhydrous) in a $250 \mathrm{ml} 3$-neck flask with addition funnel and two gas 
tube adapters. The setup was flushed with $N_{2}$ for 10 minutes. Triethylamine $(7.09 \mathrm{ml}, 5.08 \mathrm{mmol})$ was added to this solution. The color changed from yellow to greenyellow. TCCPP (1.1 $\mathrm{mg}, 0.13 \mathrm{mmol}$ ) was dissolved in $50 \mathrm{ml}$ DMF (anhydrous) and added immediately via an addition funnel. The color changed from brown to purple with time. The solution was stirred under N2 atmosphere for 24 hours. Water $(3 \mathrm{ml})$ was added and the solution stirred for 30 more minutes. The DMF phase was distilled off in vacuum and the crude material rinsed thoroughly with water and $\mathrm{CH}_{2} \mathrm{Cl}_{2}$ to remove unreacted viologen and DMAP. 1 $1_{H-N M R}$ of this crude showed that there could be no coupling product in there.

\section{TCCPP and AminoDonor (b1)}

AminoDonor $(177 \mathrm{mg}, 0.8 \mathrm{mmol})$ was dissolved in $30 \mathrm{ml}$ anhydrous dichloromethane. The solution was cooled down in an ice bath. TCCPP (171 $\mathrm{mg}, 0.2 \mathrm{mmol}$ ) dissolved in $20 \mathrm{ml}$ anhydrous dichloromethane was added at once to this solution. Brown colorization was observed. Triethylamine $(0.33 \mathrm{ml}, 2.39 \mathrm{mmol})$ was added after 3 minutes and the solution stirred at room temperature. The reaction was stopped after 45 minutes by addition of $2 \mathrm{ml}$ water and vigorous stirring. The organic phase was evaporated off on the rotovap. The crude mixture was dissolved in methanol with a small amount of $3 \mathrm{M} \mathrm{HCl}$ and chromatographed on a column $(100 \mathrm{~g}$ silica gel, height $35 \mathrm{~cm}$, diameter $2 \mathrm{~cm}$, 
eluent $\mathrm{MeOH} / 3 \mathrm{M} \mathrm{HCl} \mathrm{v}: \mathrm{v} ; 25: 1)$. No product formation could be detected by $1_{\mathrm{H}-\mathrm{NMR}}$.

ICCPP and AminoDonor (b2)

AminoDonor (61 mg, $0.27 \mathrm{mmol}), 8 \mathrm{mg}$ (0.065 mmol) DMAP and $1.53 \mathrm{ml}(11.0 \mathrm{mmol})$ triethylamine were dissolved in 40 $\mathrm{ml}$ anhydrous dichloromethane. TCCPP (238 $\mathrm{mg}, 0.27 \mathrm{mmol}$ ) was dissolved in $25 \mathrm{ml}$ anhydrous dichloromethane and added at once via an addition funnel. Heat evolution and brown colorization was observed. The organic phase was evaporated off after 18 hours to dryness. The remaining crude material was dissolved in $5 \mathrm{ml} \mathrm{DMF}$ and chromatographed on a column (100 g silica gel, eluent acetone). The upper part of the column was sliced off and extracted with MeOH (acidified). $1_{\text {H-NMR }}$ analysis of each fraction showed no product formation.

TCPP and AminoDonor (b3)

TCPP (100 mg, $0.13 \mathrm{mmol})$ and $138 \mathrm{mg}(0.47 \mathrm{mmol})$ of AminoDonor dihydrochloride were dissolved in $20 \mathrm{ml}$ dichloromethane. Triethylamine $(0.44 \mathrm{ml}, 0.6 \mathrm{mmol})$ and $98 \mathrm{mg}$ (5.11 mmol) of 1-(3-dimethylaminopropyl)-3-ethyl carbodiimide hydrochloride were added and the solution stirred at room temperature for 24 hours. The organic phase was extracted with $5 \%$ citric acid, washed with water, dried over $\mathrm{Na}_{2} \mathrm{SO}_{4}$, filtered and further dried on the oil pump. NMR analysis of the crude indicated no product formation. 
THPP and Bromoviologen (c)

Cesium carbonate $(1.43 \mathrm{~g}, 0.44 \mathrm{mmol})$ and Bromoviologen (116 $\mathrm{mg}, 0.22 \mathrm{mmol}$ ) were dissolved in $150 \mathrm{ml} \mathrm{DMF}$ and stirred. The solution turned black. THPP (150 mg, 0.22 mmol) was added and the solution stirred at room temperature for 20 hours. The color changed to green. Methyl iodide $(0.2 \mathrm{ml}, 3.3 \mathrm{mmol})$ was added and the solution stirred until the methylation was found to be complete after 30 minutes. The organic phase was distilled off to dryness and the purple remaining crude material chromatographed on a silica gel column (150 g silica gel, height $30 \mathrm{~cm}$, diameter $4.5 \mathrm{~cm}$, eluent first chloroform then methanol). Different fractions were obtained, whereby the main product was TMPP. The desired coupling product could not be detected by $1_{H-N M R}$ analysis.

TCPP and BromoViologen (d)

TCPP (200 mg, $0.25 \mathrm{mmol}$ ) was partly dissolved in deionized water. The $\mathrm{pH}$ of this solution was 4.75. A $20 \%$ $\mathrm{Cs}_{2} \mathrm{CO}_{3}$ solution was added to the TCPP solution until the $\mathrm{pH}$ reached 9. The aqueous solution was evaporated off to dryness and the crude product dissolved in $35 \mathrm{ml}$ DMSO, giving it a purple color. Bromoviologen (134 mg, $0.25 \mathrm{mmol}$ ) was added and the solution refluxed for 16 hours. An additional $325 \mathrm{mg}(1.0 \mathrm{mmol}) \mathrm{Cs}_{2} \mathrm{CO}_{3}$ was added, since a 
control TLC showed no product formation (no additional spot and no quenching of the red porphyrin fluorescence was observed in comparison with the starting material).

Although the solution was refluxed for 30 more hours, no product formation could be seen by TLC. Therefore $74 \mathrm{mg}$ (0.48 mmol) of DBU were added as another base. The DMSO was distilled off to dryness after 80 hours reaction time and the crude dissolved in $6 \mathrm{ml} \mathrm{MeOH}$. The crude was chromatographed on a silica gel column $(30 \mathrm{~g}$ silica gel, height $22 \mathrm{~cm}$, diameter $2 \mathrm{~cm}$, eluent $\mathrm{MeOH}$ ). None of the fractions contained the desired product, as tested by $1_{\mathrm{H}}$ NMR spectroscopy.

\section{CONCLUSION}

Four new molecules have been synthesized, two electron donors and two electron acceptors. Each compound has a specific functional group attached, so that covalent linkages to other molecules are possible. The molecules can be used for artificial photosynthesis due to their electron donating or electron accepting properties.

The attempt to couple these compounds to porphyrins was unsuccessful. The reaction conditions for the couplings were chosen to be mild in the first instance, e.g., room temperature without acidic or basic conditions. This approach was taken for prospective linkages to the porphyrin film, because mild reaction conditions would have 
been necessary to avoid destroying the sensitive film. The typical reaction conditions were scrutinized for the various linkages and were found not to be applicable for these specific porphyrins, electron donors and acceoptors. Further research could be done to make these linkages possible. One possibility might be to synthesize donors and acceptors with better leaving groups. Studies could be done on an Iodoviologen, a TosylateViologen or an IodoDonor for nucleophilic substitutions with THPP or TCPP. 
REFERENCES CITED

1. J. Deisenhofer, H. Michel, Angew. Chem. 101, 872 (1989)

2. R. Huber Angew. Chem. 101, 849 (1989)

3. R R. Hautala, R. B. King, C. Kutal Selar Fnergy: Chemical Conversion and Storage; The Humana Press: Clifton, NJ, 1979; p 39

4. D. Woerle Praxis Magazin 4/40, 10 (1991)

5. E. Schuhmacher Chimia $32(6), 193$ (1978)

6. G. Calzaferri, L. Forss, W. Spahni Chiuz $21(5), 161$ (1987)

7. H. D. Scharf, J. Fleischhauer, H. Leismann, I. Ressler, $W$. Schleker, R. Weitz Angew. Chem. Int. Ed. Engl. 18, 652 (1979)

8. D. Creed, R. A. Caldwell Rhotochem. Photobiol, 6, 715 (1985)

9. M. A. Fox, M. Chanon, Rhotoinduced Electron Transfer Part D; Elsevier: New York, 1988; p306

10. N. M. Guindy, F. M. Elzawawy, D. Y. Sabry collect. Czech. Chem. Commun. 57, 26 (1992)

11. H. Kaogawa, K. Koga Bull. Chem. Soc. Jen. 65, 301 (1992)

12. M. E. Jung, M. A. Lyster J. Org. Chem. $42(23), 3761$ (1977)

13. I. Okura, H. Hosono I. Phys. Chem, 96, 4466 (1992)

14. Y. Yamamoto, S. Noda, N. Nanai, I. Okura, Y. Inoue Bul1. Chem. Soc. Jpn. 64, 1392 (1991)

15. V. Y. Shafirovich, E. Amouyal, J. Delaire chem. Phys. Lett. 178 (1), 24 (1991) 
16. S. Noda, H. Hideyuki, I. OIkura, Y. Yamamoto, Y. Inoue J. Chem. Soc. Faraday Trans. 86 (5), 811 (1990)

17. Y. Yamamoto, S. Noda, N. Nanai, I. Okura, Y. Inoue Bull. Chem. Soc. Jpn. 62, 2152 (1989)

18. I. Okura, Y. Kiniumi Bull. Chem. Soc. Jpn. 63(10), 2922 (1990)

19. R. J. McMahon, R. K. Force, H. H. Patterson, M. S. Wrighton I.Am. Chem. Soc, $110(8), 2670$ (1988)

20. N. Mataga, A. Karen, T. Okada, S. Nishitani, N. Kurata, Y. Sakata, S. Misumi J. Phys.Chem. 88, 5138 (1989)

21. J. R. Bolton, T. F. Ho, S. Liauw, A. Scemiarczuk, C. S. K. Wan, A. C. Weedon, I. Chem. Soc. Chem. Commun , 559 (1985)

22. S. Nishitani, N. Kurata, Y. Sakata, S. Misumi, A. Karen, T. Okada, N. Mataja, I. Am. Chem. Soc. 105, 7771 (1983)

23. D. Gust, P. Mathis, A. L. Moore, P. A. Liddell, G. A. Nemeth, W. R. Lehman, T. A. Moore, R. V. Bensasson, E. J. Land, C. Chachaty Rhotochem. Photobiol, 37S, 46 (1983)

24. D. Gust, T. A. Moore I. Photochem, 29, 173 (1985)

25. D. Gust, T. A. Moore, L. R. Makings, P. A. Liddell, G. A. Nemeth, A. L. Moore I. Am. Chem. Sec, 108, 8028 (1986)

26. P. Seta, E. Bienvenue, A. I. Moore, P. Mathis, R. V. Bensasson, P. Liddell, P. J. Pessiki, A. Joy, T. A. Moore, D. Gust Nature 316,653 (1985)

27. P. A. Liddell, D. Barrett, L. K. Makings, P. J. Pessiki, D. Gust, T. A. Moore, I.Am. Chem.Soc. 108, 5350 (1986)

28. M. R. Wasielewski, M. P. Niemczyk, W. A. Svec, E. B. Pewitt I.Am. Chem. Soc. 107, 5562 (1985)

29. D. Gust, T. A. Moore, A. L. Moore, P. Mathis, J. C. Mialocq, W. R. Lehman, R. V. Bensasson, E. J. Land, D. Doizi, P. A. Liddell, G. A. Nemeth Nature 307, 630 (1984) 
30. D. Gust, T. A. Moore, A. I. Moore, G. Seely, P. A. Liddell, D. Barrett, L. O. Harding, X. C. Ma, S. Lee, T. Gao Tetrahedron 45, 4867 (1989)

31. C. Vaughan New Scientist 26 (May), 34 (1990)

32. C. C. Wamser Mol, Cryst. Iig. Cryst, 194, 65 (1991)

33. C. C. Wamser, V. Senthilathipan, W. Ii SPIE Proce. 1436,114 (1991)

34. C. C. Wamser, R. R. Bard, V. Senthilathipan, V. C. Anderson, J. A. yates, H. K. Lonsdale, G. W. Rayfield, D. F. Friesen, D. A. Lorenz, G. C. Stangle, P. van Eikeren, D. R. Baer, R. A. Ransdell, J. H. Golbeck, W. C. Babcock, J. J. Sandberg, S. E. Clarke J.Am. Chem. Soc, 111, 8485 (1989)

35. R. A. Ransdell, Ph.D Thesis, Portland State University

36. M. A. Fox, M. Chanon, Photoinduced Electron Transfer Part D; Elsevier: New York, 1988; p372

37. M. A. Fox, M. Chanon, Photoinduced Electron Transfer Part D: Elsevier: 1988; p377

38. M. Momenteau, J. Mispelter, B. Loock, E. Bisagni I. Chem, Soc. Trans I, 189 (1983)

39. C. A. Buehler, D. E. Pearson Survey of Organic Syntheses: Wiley-Interscience \& Sons: New York, 1970; p860

40. B. Reichman, F. R. Fan, A. J. Bard I. Flectrochem Soc, 127,333 (1980)

41. A. J. Gordon, R. A. Ford, The Chemist's Compaion: A Handbook fo Practical Data Techniques and References: John Wiley \& Sons: New York, 1972

42. M. P. Pileni, A. M Braun, M. Graetzel Photochem. Photobiol. 31, 423 (1980)

43. A. Ault, G. O. Dudek, An Introduction to Proton Nuclear Maqnetic Resonance Spectroscopy; Holden-Day : San Fransisco, 1976

44. E. Breitmaier, G. Bauer, 13c-NMR Spectroscopy; Harwood Academic: London, 1984

45. R. H. Baker, D. H. Thompson, Y. Lei, M. J. Hope, J. K. Hurst Langmuir, 2592 (1991) 
46. W. Kemp, Organic Spectroscopy; 3rd ed W. H. Freeman: NewYork, 1991

47. A. Bodansky, M. Bodansky, The Practice of Peptide Synthesis, Springer 1984, p 19

48. J. C. Sheehan, J. Preston, P. A. Cruickshank I.Am. Chem. Soc. 87, 2492 (1965)

49. R. M. Silverstein, G. C. Bassler, T. C. Morrill Spectrometric Identification of Organic Compounds John Wiley \& Sons, 1991

50. Bodansky and Ondetti, Reptide Synthesis; John Wiley \& Sons: New York, 1966; p30

51. G. Sokrates Infrared Characteristic Group Erequencies; John Wiley \& Sons: New York, 1980

52. E. Kanutzky, F. Friedel, C. Watscheck Tetrahedron 11, 39 (1960)

53. G. Hoefle, W. Steglich, H. Vorbrueggen Angew. Chem. Int. Ed. Engl. 17, 569 (1978)

54. A. Hassner, I R. Krepski, V. Alexanian Tetrahedren 34, 2069 (1978)

55. J. E. Shaw, D. E. Kunerth J. Org. Chem. 39 (13), 1968 (1974)

56. J. E. Shaw, D. E. Kunerth, J. S. Sherry Tetr. Lett, 9, 689 (1973)

57. T. Sala, M V. Sargent J. Chem. Soc. Perkin I, 2593 (1979)

58. S. S. Wang, B. F. Gisin, D. P. Winter, R. Makofske, I. D. Kulesha, C. Tzougrake, J. Meienhofer J Org.Chem. $42(8), 1286$ (1977) 


\section{APPENDIX}

INERARED SPECTRA

PAGE

TCCPP . . . . . . . . . . . . . . . . . . . . . . 87

1-Phenylmethyl-4-(4'-pyridyl)pyridinium chloride 87

Previologen . . . . . . . . . . . . . . . . . . . 88

BromoViologen . . . . . . . . . . . . . . . . . 88

HydroxyViologen . . . . . . . . . . . . . . . . . 89

N-(Tert-butoxycarbonyl)-4-aminobutanoic acid. . . . 89

BOC-protected AminoDonor . . . . . . . . . . . . 90

AminoDonor . . . . . . . . . . . . . . . . . . . 90

AminoDonor dihydrochloride . . . . . . . . . . . . . 91 .

4-Bromobutyryl chloride . . . . . . . . . . . . . . 91

BromoDonor . . . . . . . . . . . . . . . . . . 92

NUCLEAR MAGNETIC RESONANCE SPECTRA PAGE

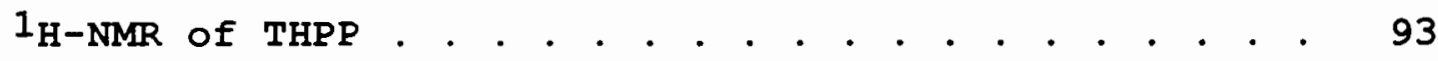

$1_{\mathrm{H}-\mathrm{NMR}}$ of Bromoviologen . . . . . . . . . . . . . . . 94

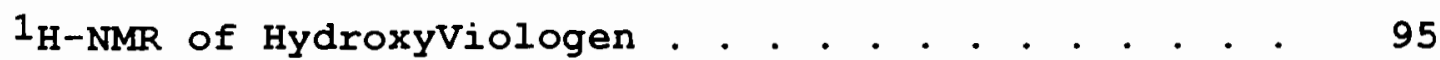

$1_{\mathrm{H}-\mathrm{NMR}}$ of BOC-AminoDonor . . . . . . . . . . . . . . . 96

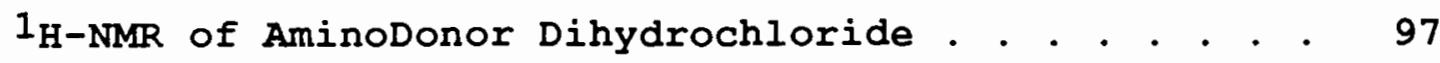

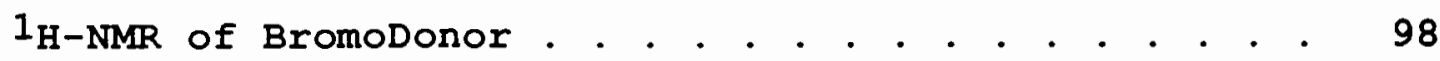

${ }^{13}$ C-NMR of Bromoviologen . . . . . . . . . . . . . . . . 99

$13 \mathrm{C}-\mathrm{NMR}$ of HydroxyViologen . . . . . . . . . . . . . 100 
FAB-MASS SPECTRA

PAGE

BOC-protected Aminodonor . . . . . . . . . . . . 101

Bromoviologen . . . . . . . . . . . . . . . . . . 102

Hydroxyviologen . . . . . . . . . . . . . . . . 103 
E-E

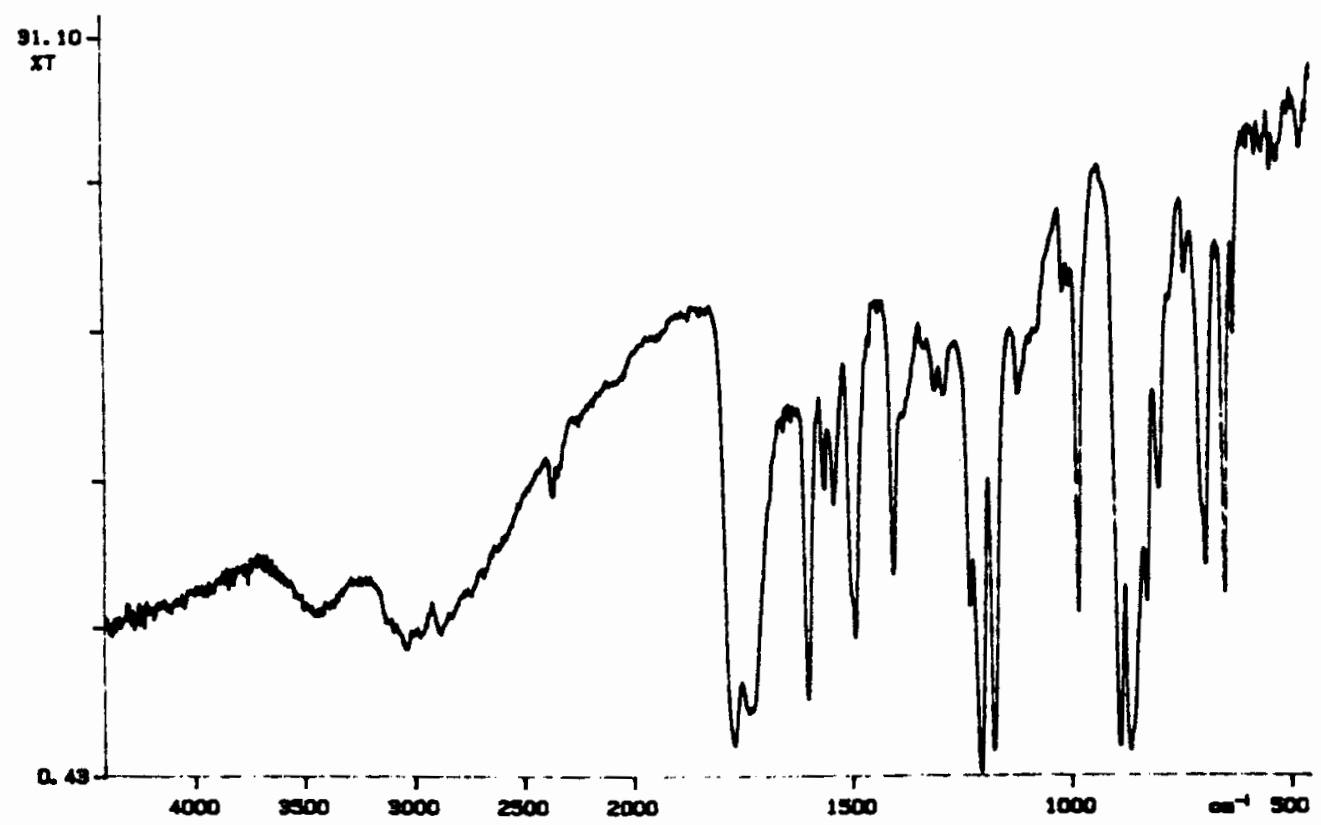

Infrared spectrum of TCCPP

E-G

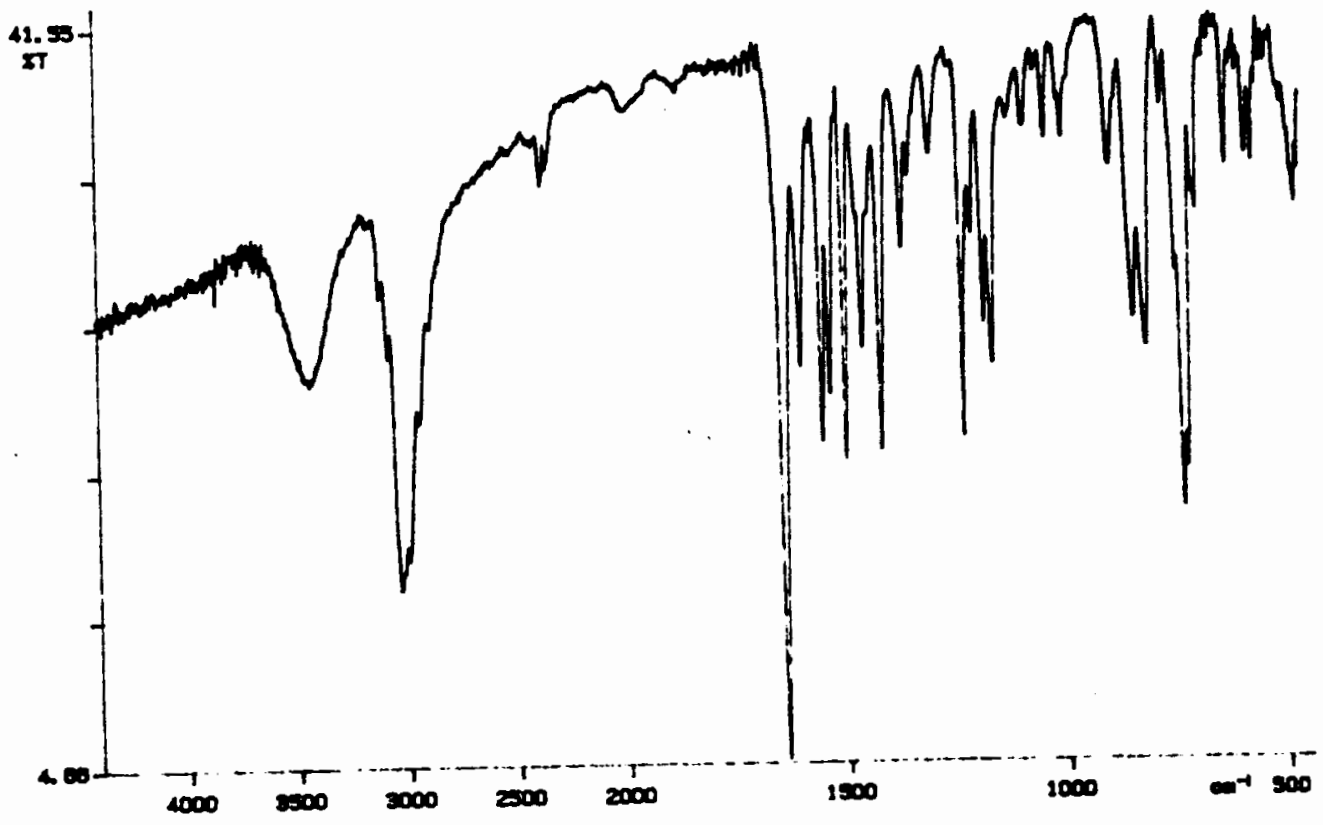

Infrared spectrum of 1-Phenylmethyl-

4-(4'-pyridyl) pyridinium chloride 
E.E

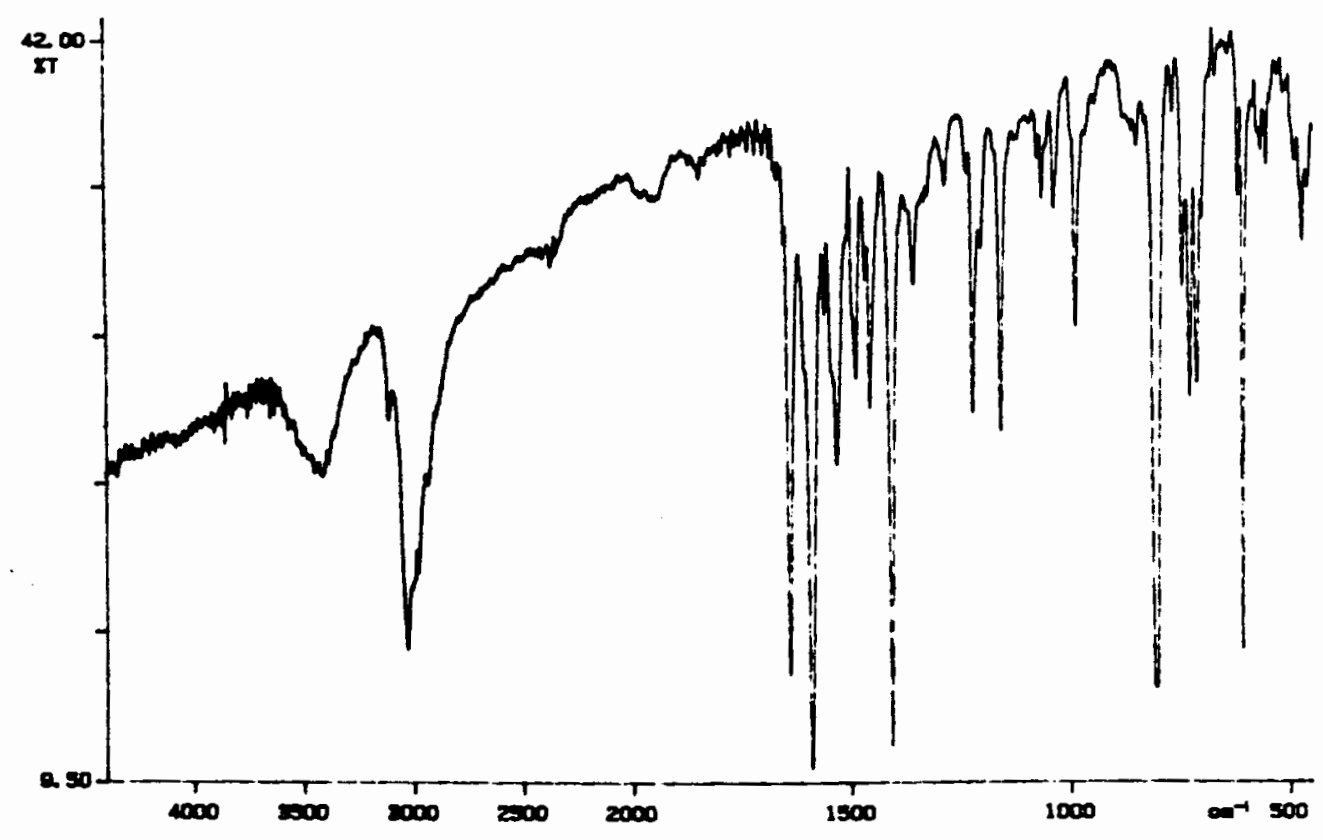

Infrared spectrum of Previologen

P.E

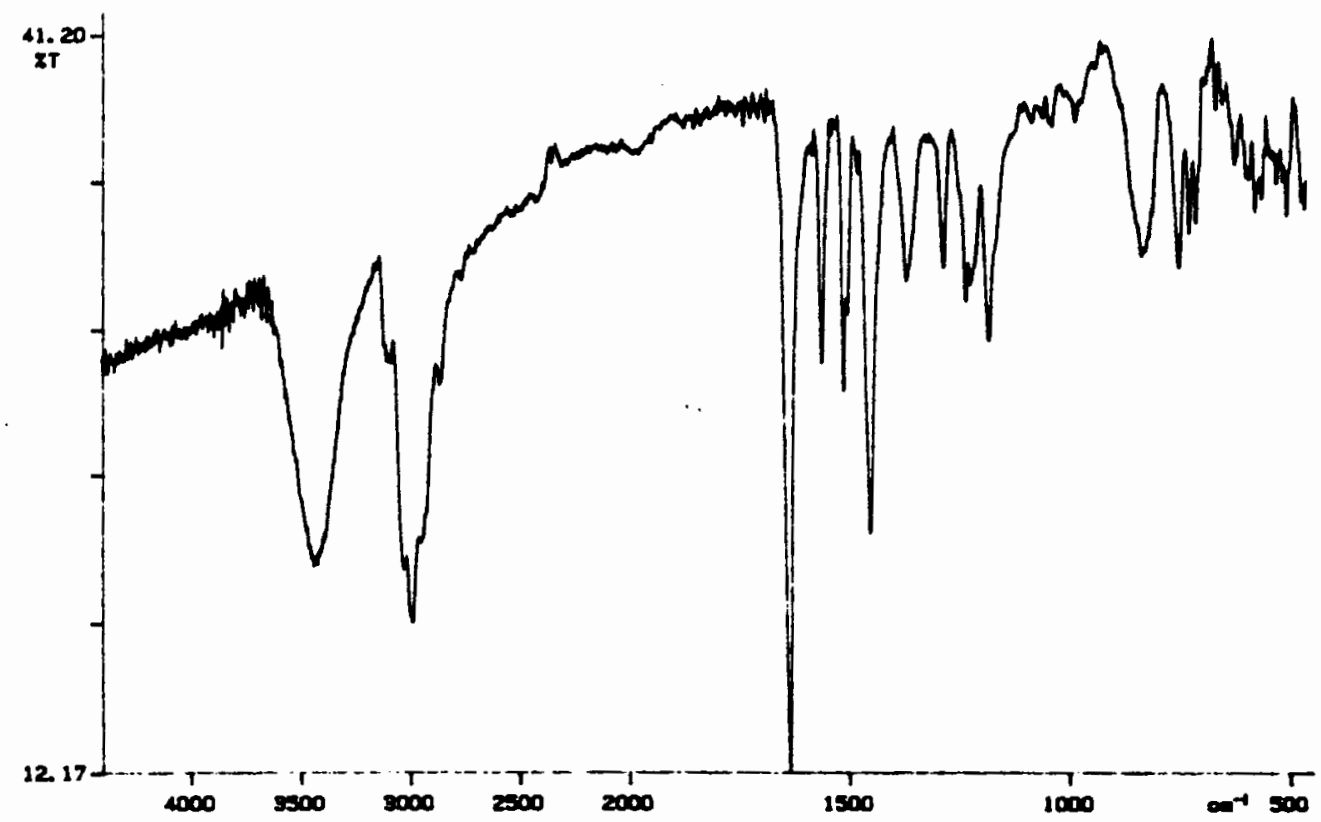

Infrared spectrum of Bromoviologen 
P-E

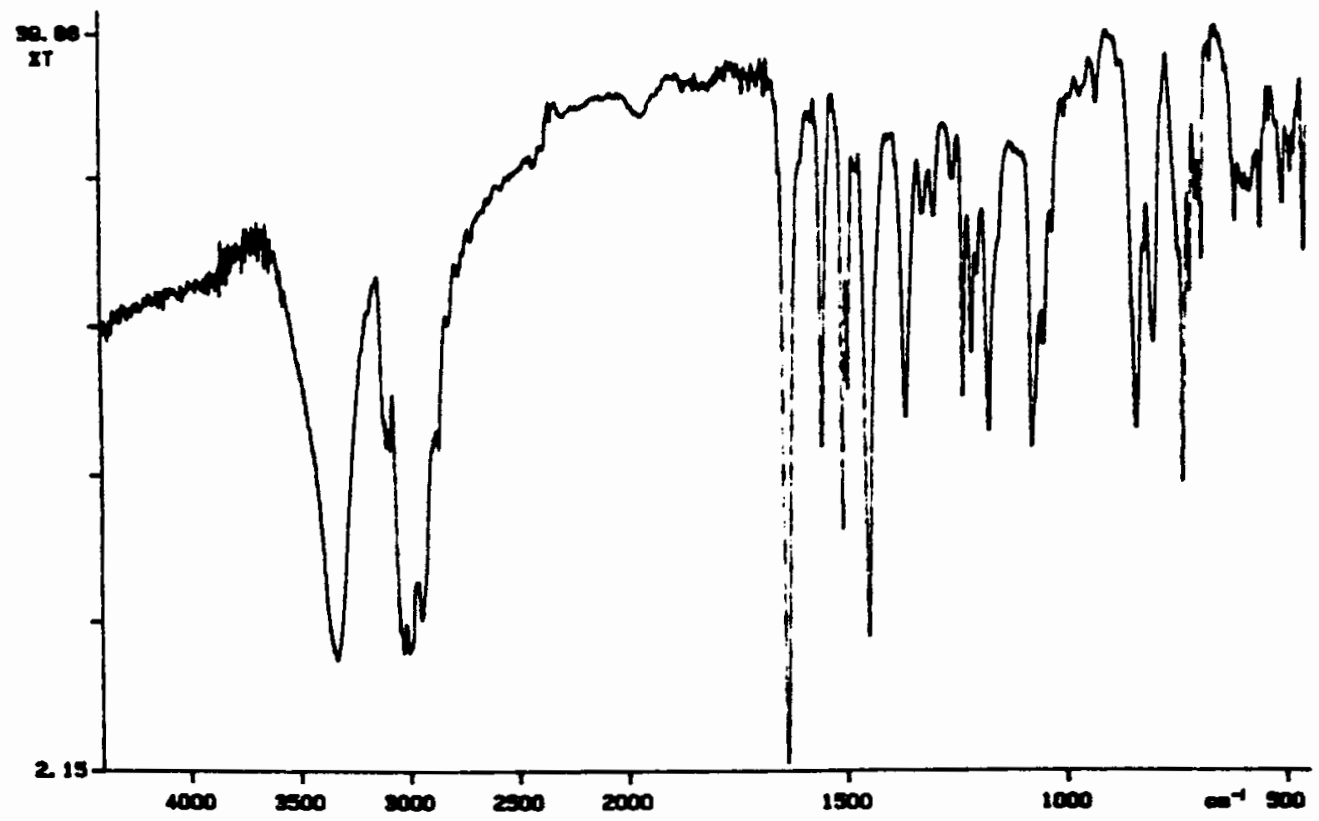

Infrared spectrum of HydroxyViologen

E-E

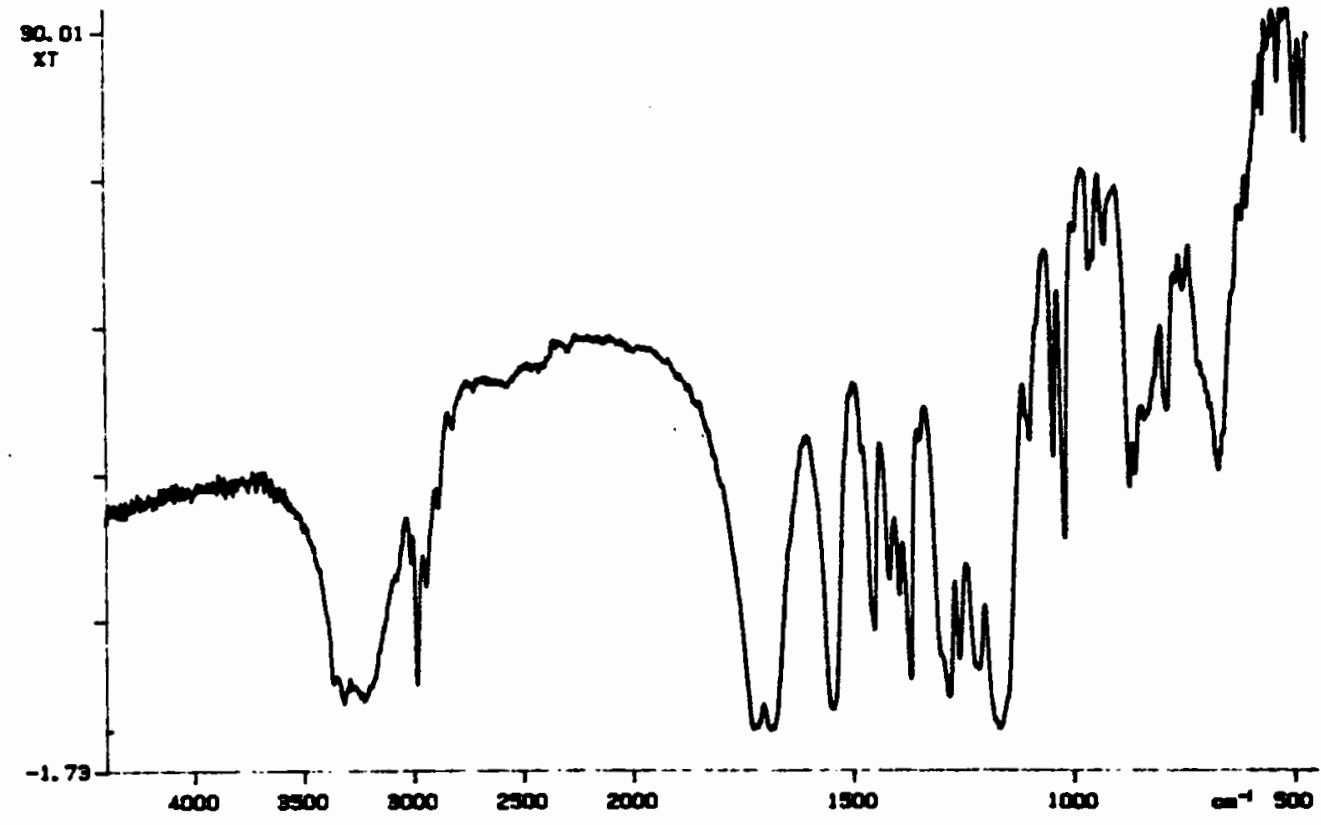

Infrared spectrum of $\mathbf{N}$-(Tert-butoxycarbonyl)-4aminobutanoic acid 
P-E

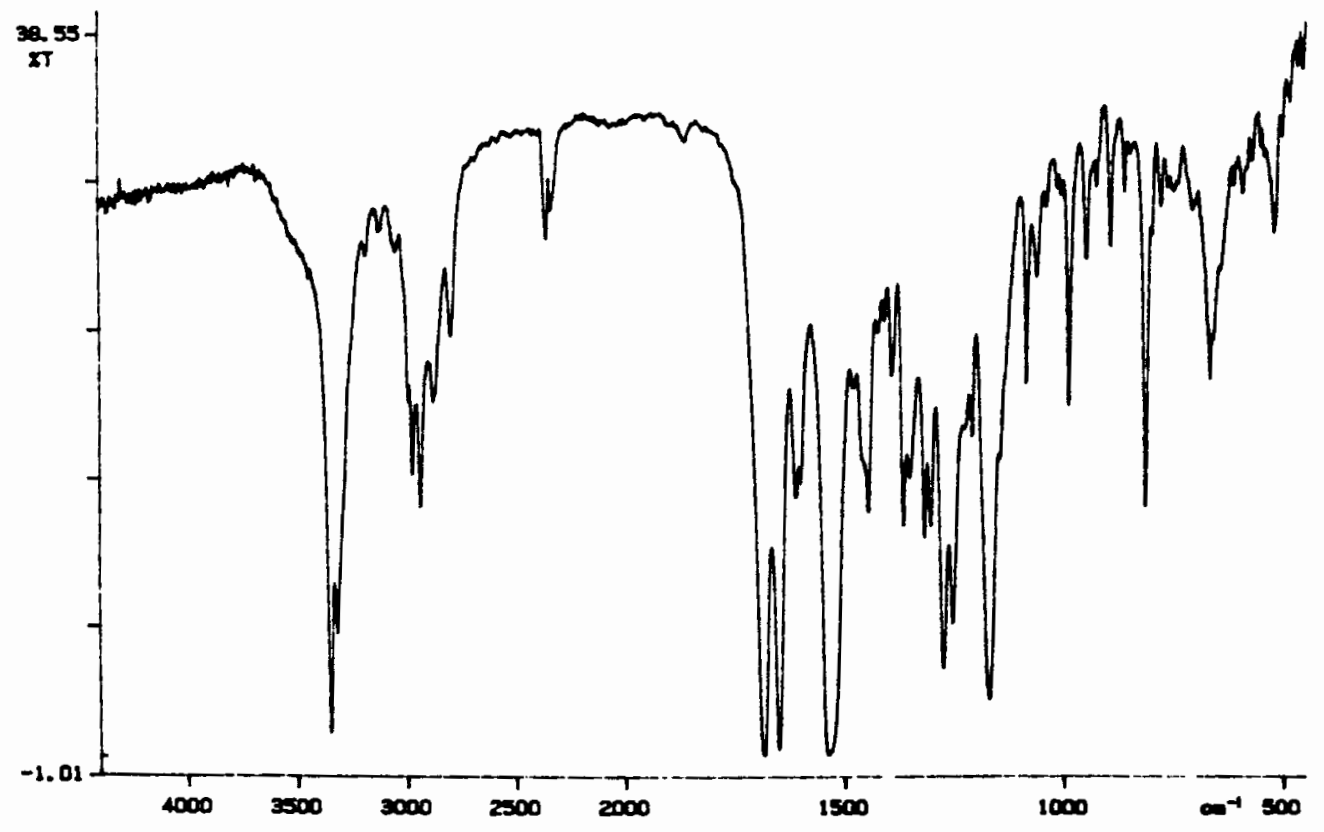

Infrared spectrum of BOC-protected AminoDonor

P-E

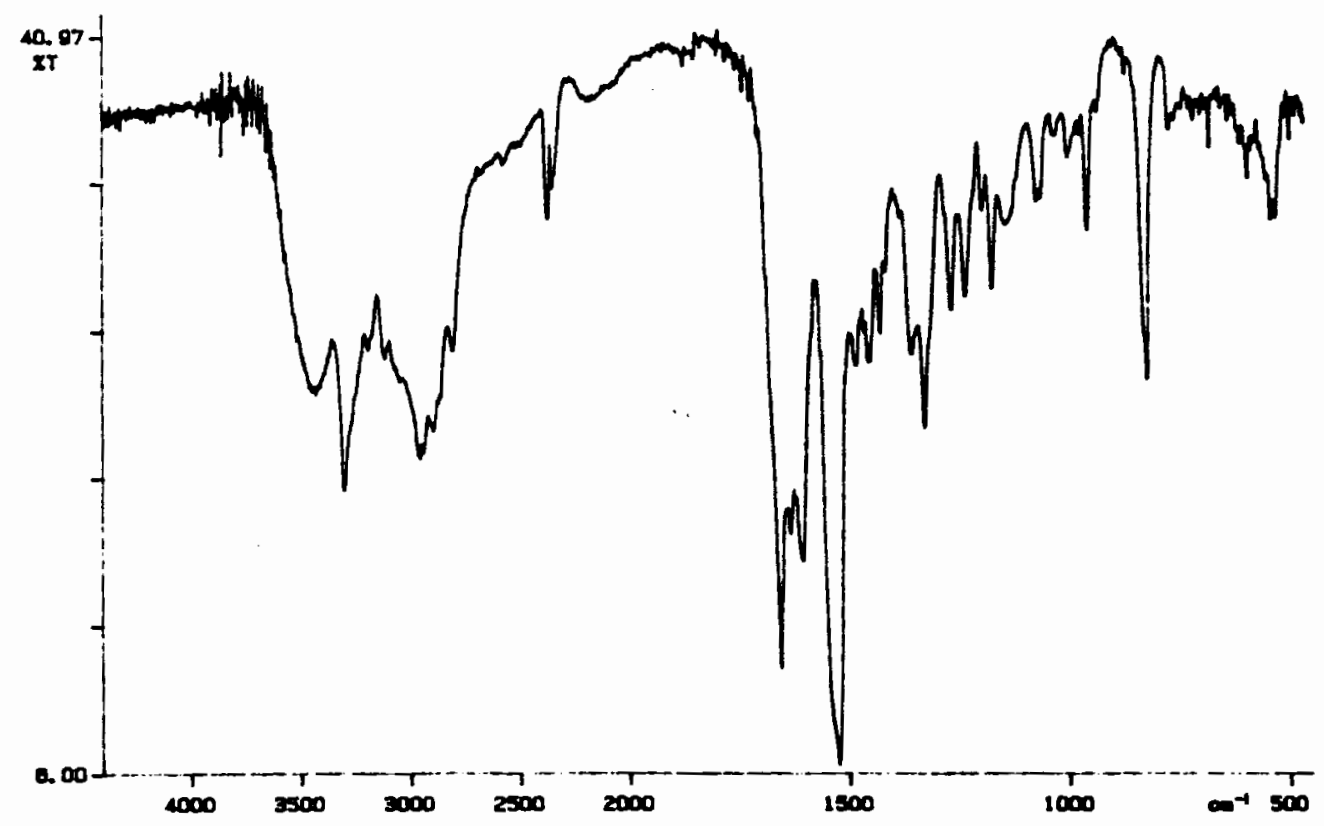

Infrared spectrum of AminoDonor 
P.E
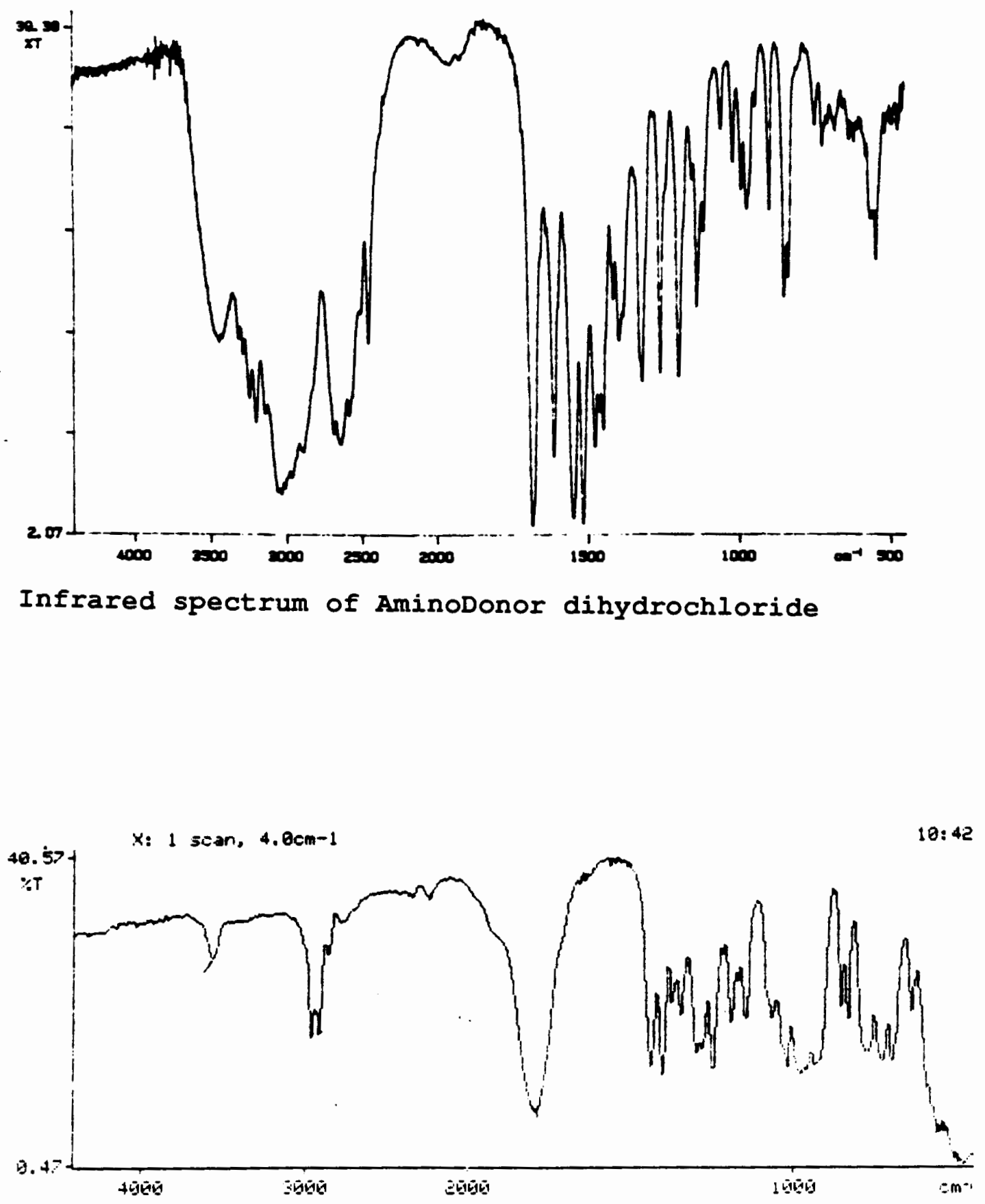

Infrared spectrum of 4-Bromobutyryl chloride 
P-E

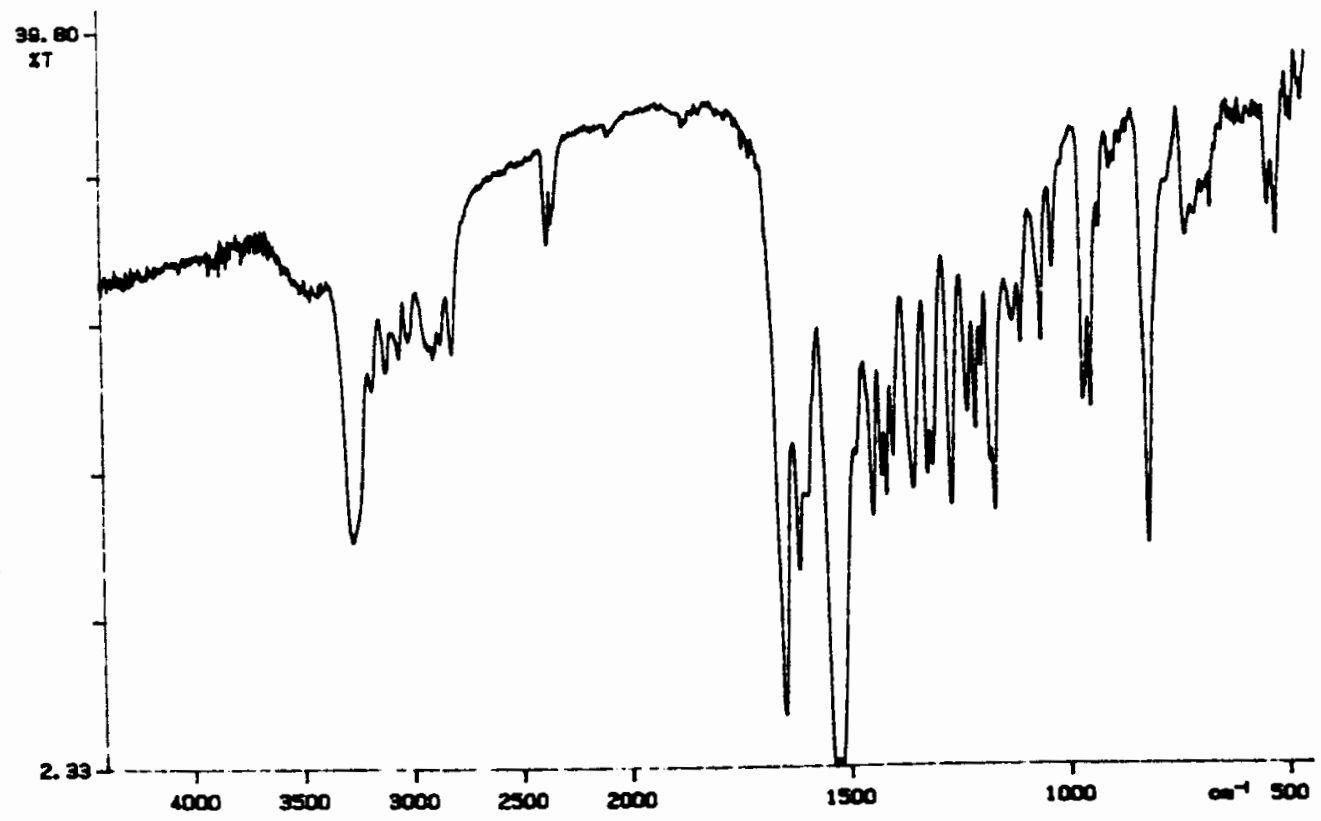

Infrared spectrum of Bromodonor 


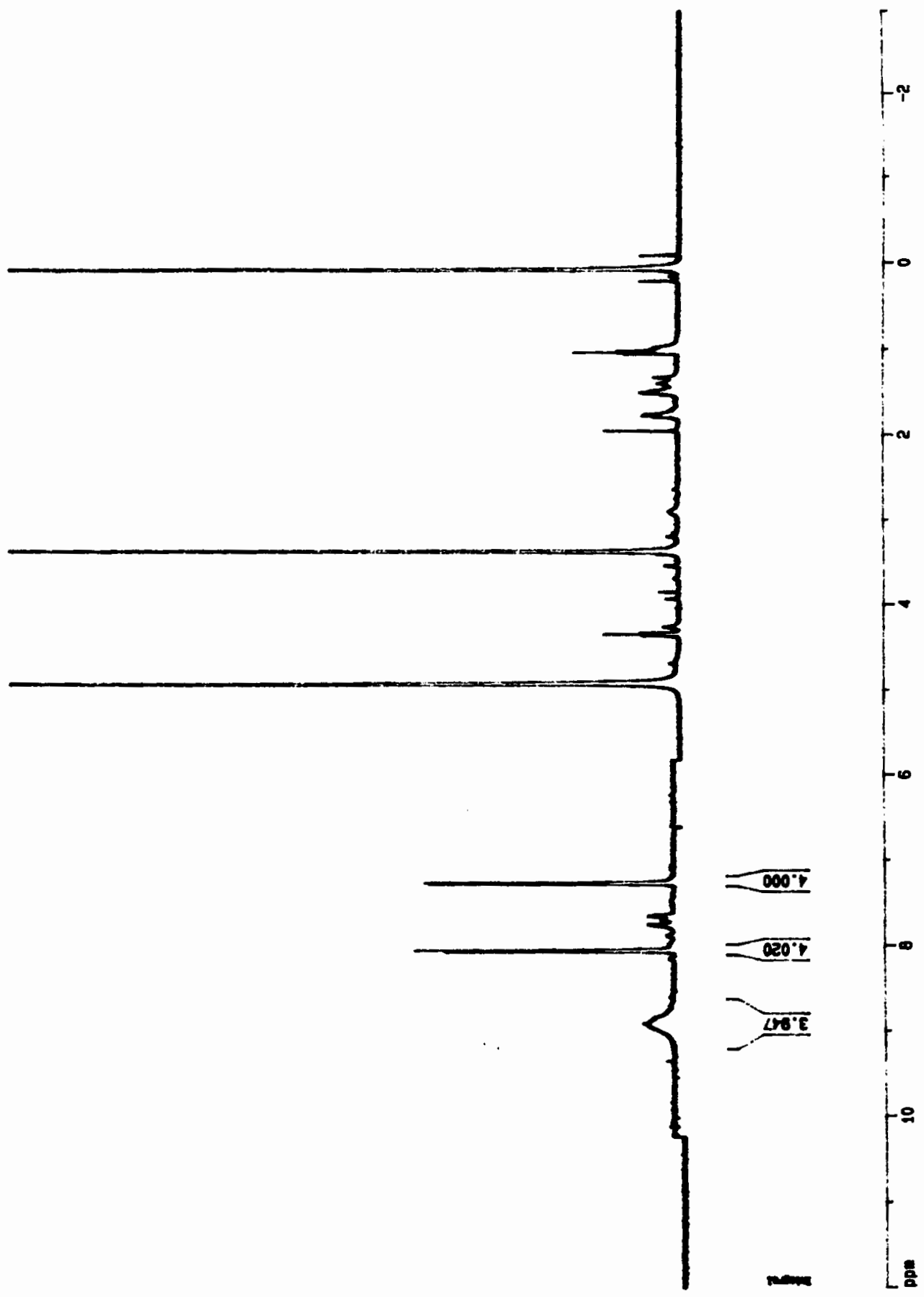


exte-

218

120.

exto-

nes.

co'

$0 \%$ -

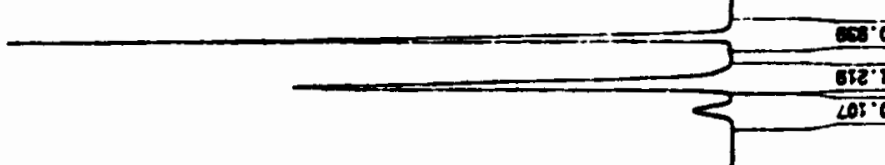

206

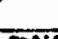

$4 x^{\circ}$

E12.

ru

00

$m<\cdot 0-$

anch

노을

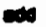

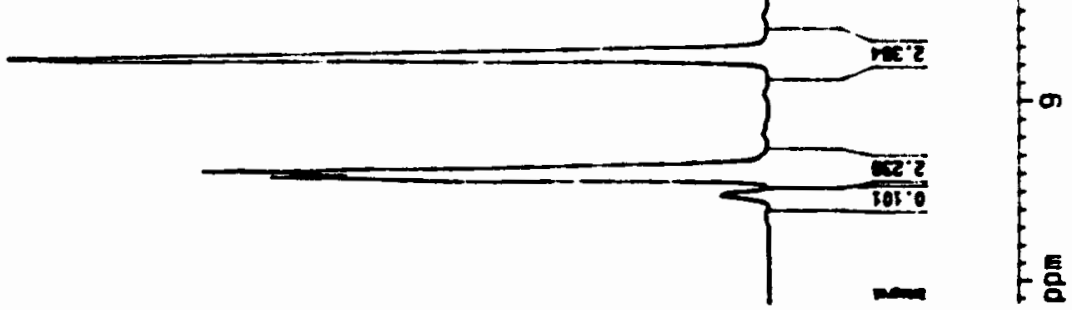

$1_{\text {H-NMR }}$ of Bromoviologen 
$r e \cdot 2-$

$662 \cdot \varepsilon-$

$\cos (E)$

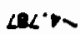

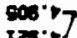

$600^{\circ} \mathrm{L}-$

6x: 12

SIL')

IE $L \cdot B$

Boe' 6

Des. 8

aLe' 61

EEE 6 -

edd

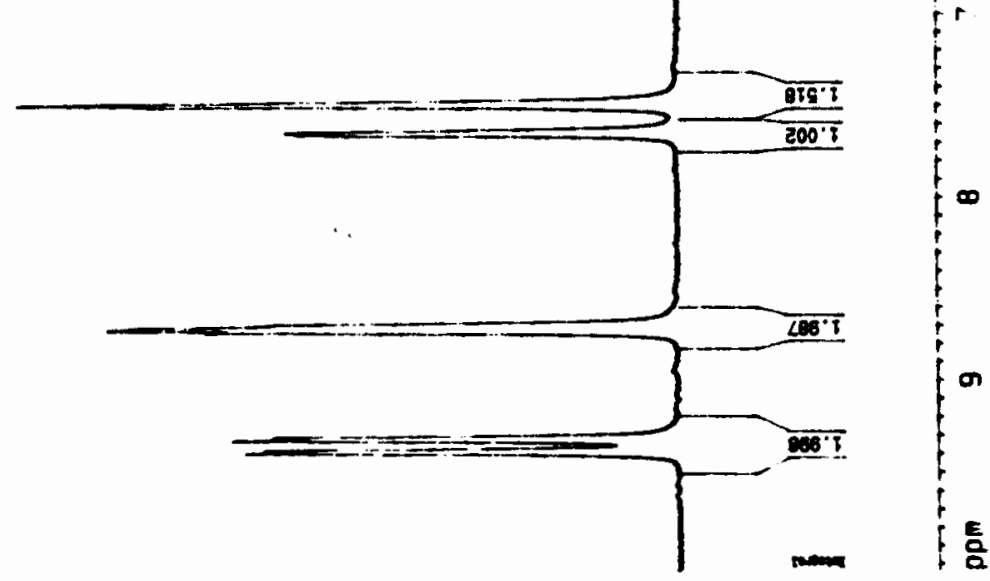

${ }^{I_{H}-N M R}$ of HydroxyViologen 
三

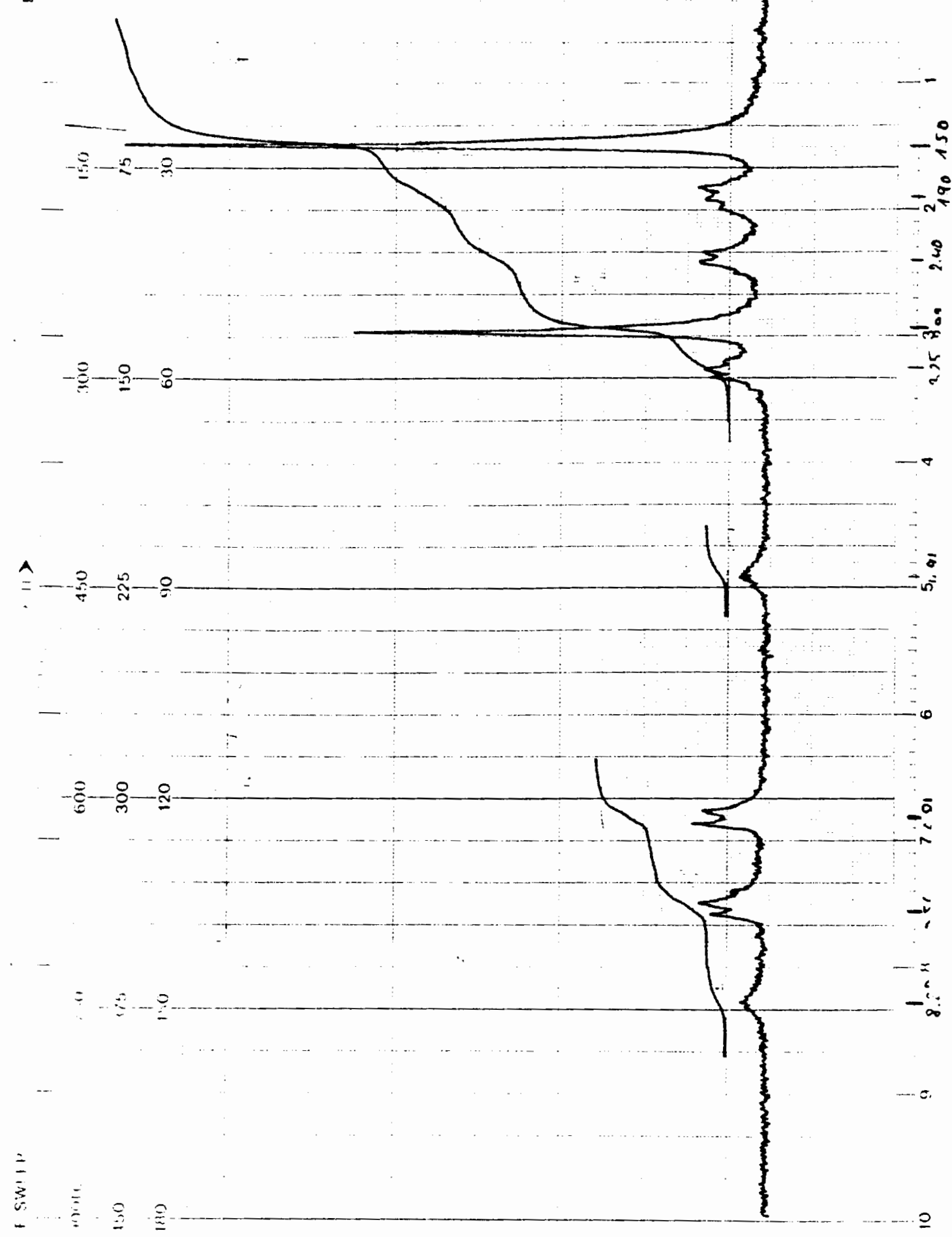

$1_{\mathrm{H}-\mathrm{NMR}}$ of BOC-AminoDonor 


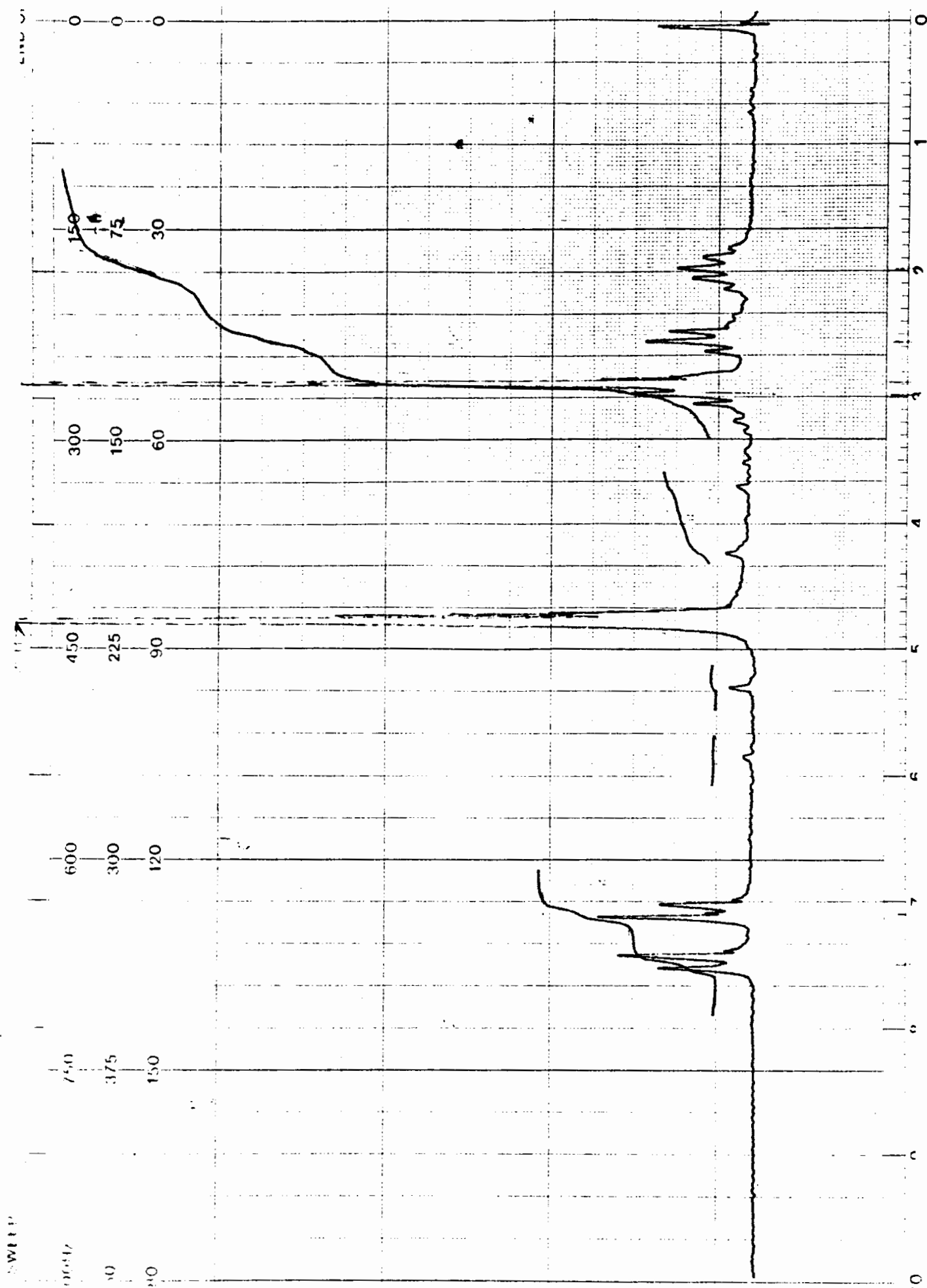

$1_{H-N M R}$ of AminoDonor dihydrochloride 


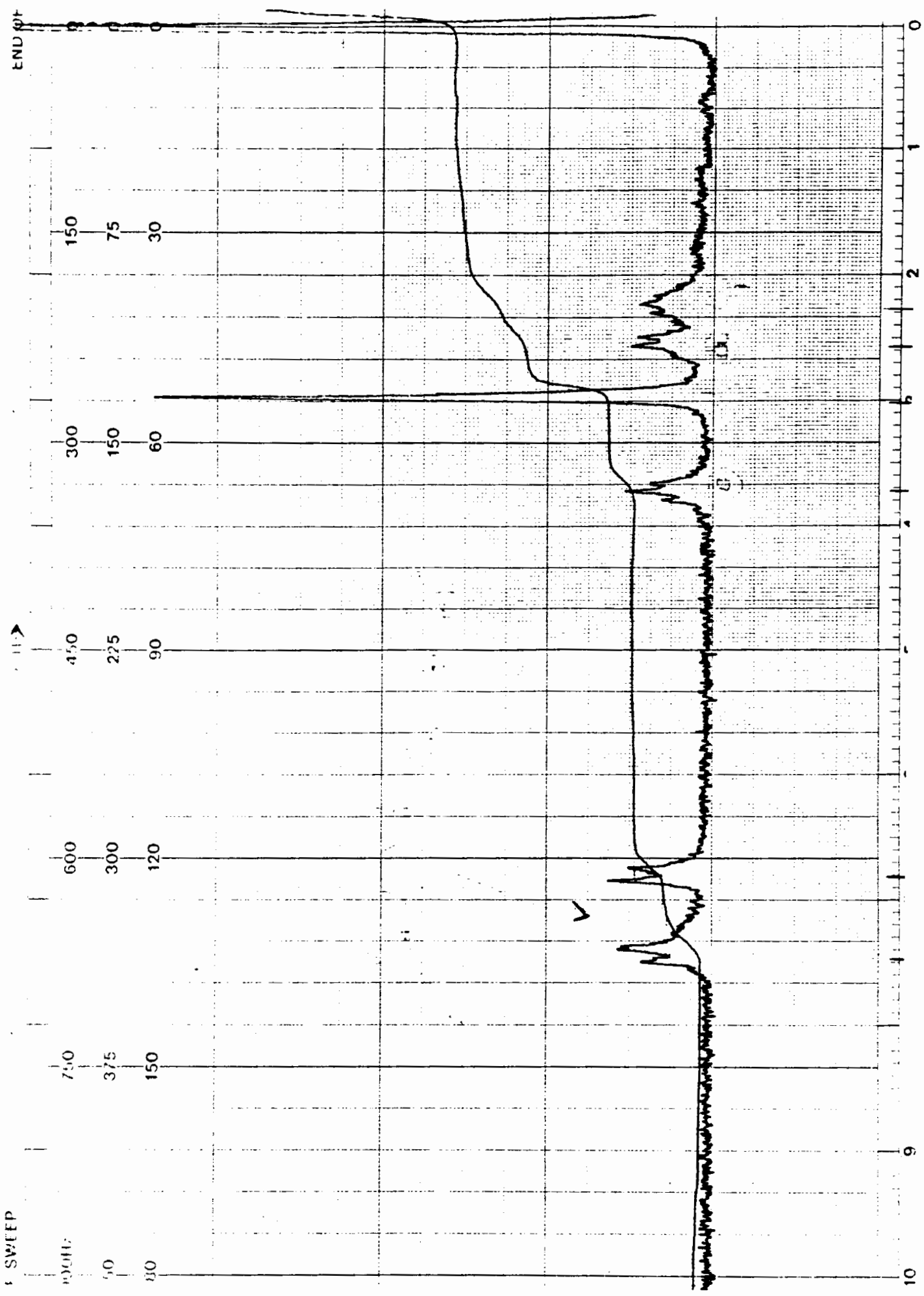

$1_{\text {H-MMR of BromoDonor }}$ 
E.e -

$4 x-$

001
0.07
0.07
2.07
5.01
40

6.

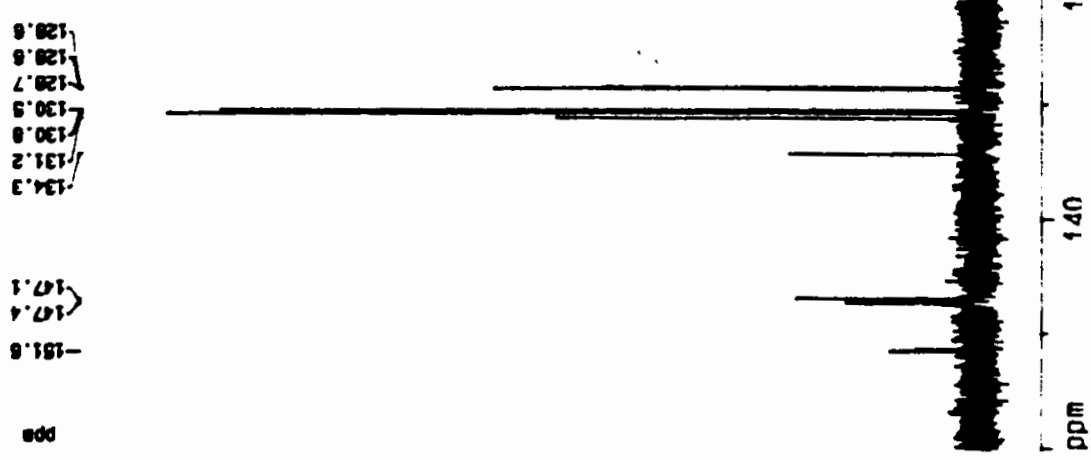

13C-NMR of Bromoviologen 
s're -

$\rightarrow \infty$

$2 \cdot 1$

0.0

0.07

s.o 1

(a)

0.65 -

$6.09-$

o.

c.ees.

g.eer.

c. 05

- oer

2. test

c'set'

0.0163

i.838

List

add 


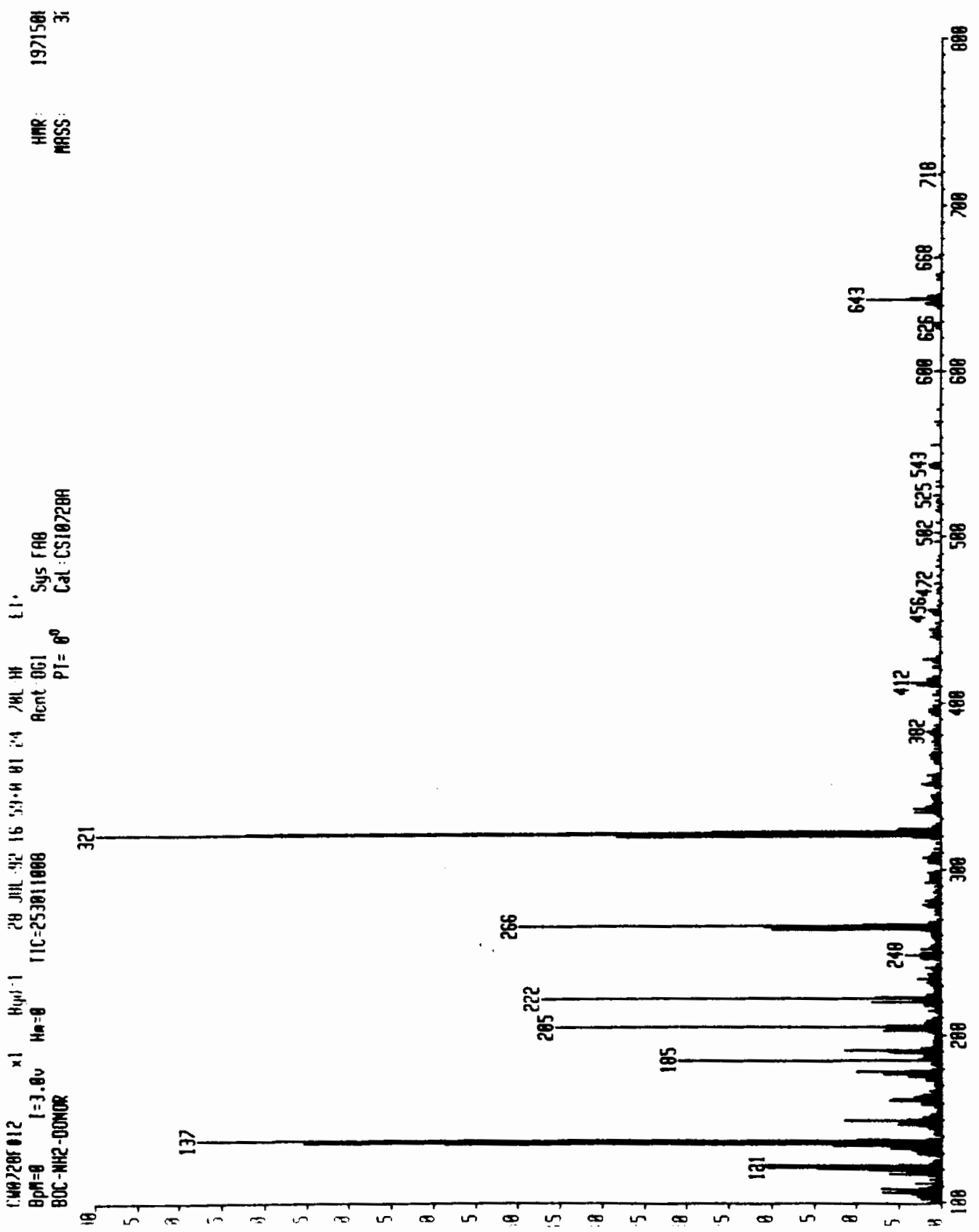

FAB-MS of spectrum of AminoDonor 
䨠

尊芦

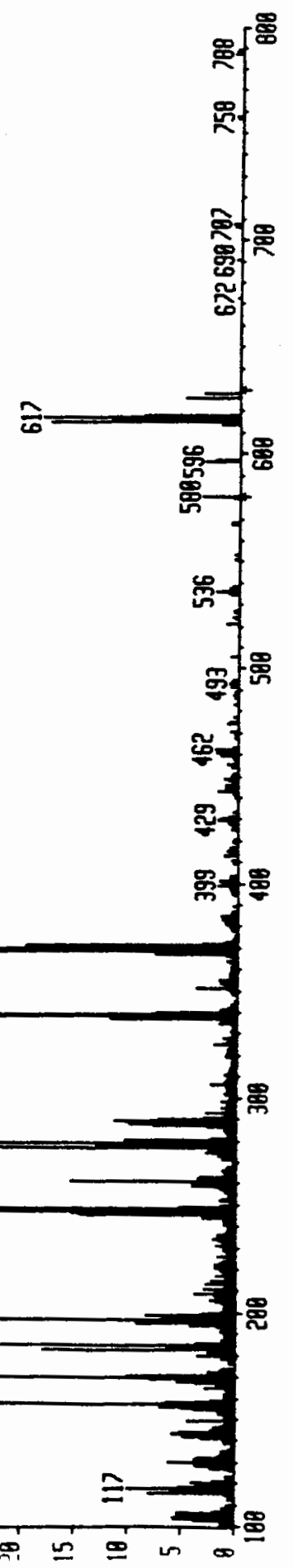

FAB-MS spectrum of Bromoviologen 


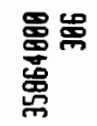

童雚

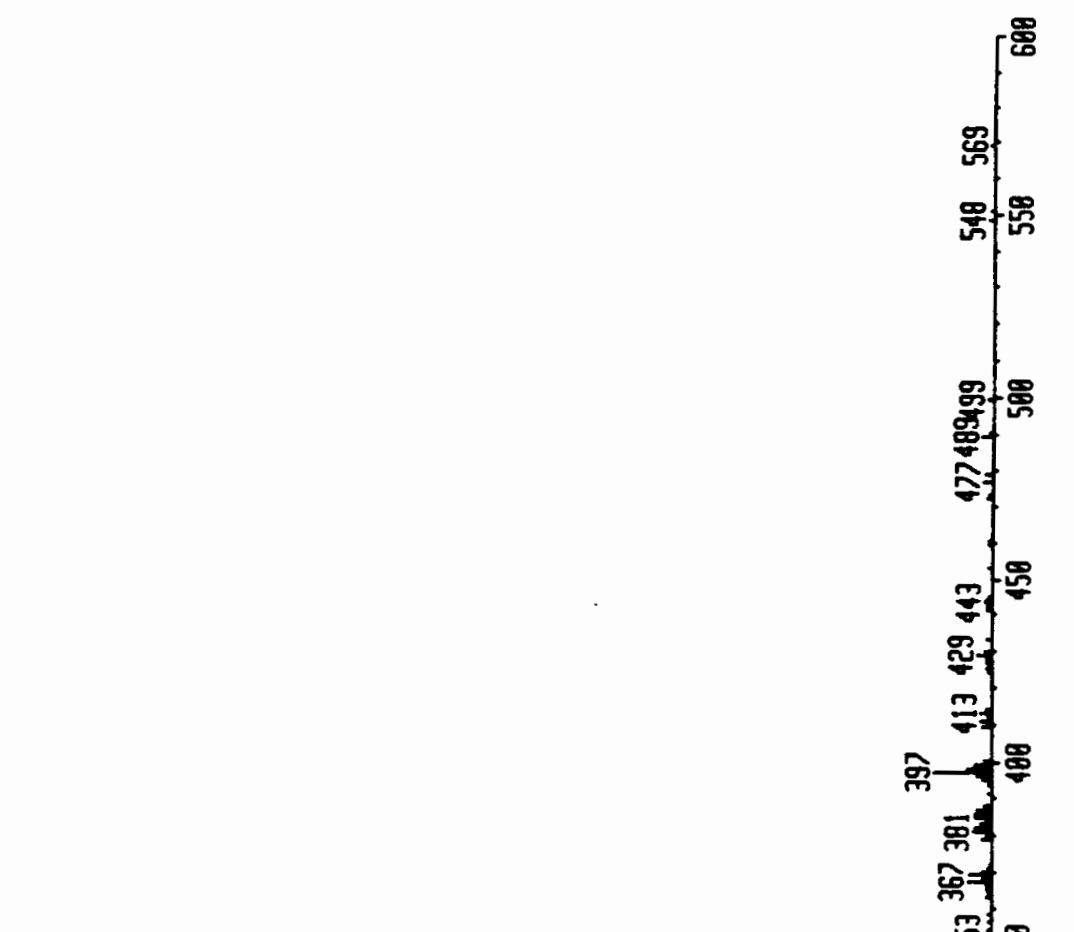

+ ज苛

覀

눟혀음

岕乒

品

a

竞

느

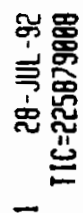

.

营

포 혼

는

兽焉

(20. 